\title{
Evaluation of Driver Visual Demand at Different Traffic Volumes on Complex Two-Dimensional Multi-Lane Highway Alignments
}

\author{
by \\ Lisa Kadoury \\ Bachelor of Science, The University of Western Ontario, Ontario, Canada, 2010
}

\author{
A thesis \\ presented to Ryerson University \\ in partial fulfillment of the \\ requirements for the degree of \\ Master of Applied Science \\ in the Program of \\ Civil Engineering
}

Toronto, Ontario, Canada, 2014

(C)Lisa Kadoury 2014 


\section{Author's Declaration}

I hereby declare that I am the sole author of this thesis. This is a true copy of the thesis, including any required final revisions, as accepted by my examiners.

I authorize Ryerson University to lend this thesis to other institutions or individuals for the purpose of scholarly research.

I further authorize Ryerson University to reproduce this thesis by photocopying or by other means, in total or in part, at the request of other institutions or individuals for the purpose of scholarly research.

I understand that my thesis may be made electronically available to the public. 


\title{
Evaluation of Driver Visual Demand at Different Traffic Volumes on Complex Two-Dimensional Multi-Lane Highway Alignments
}

\author{
Master of Applied Science 2014 \\ Lisa Kadoury \\ Civil Engineering \\ Ryerson University
}

\begin{abstract}
This research focuses on evaluating driver visual demand at different traffic volumes along with geometric design features for two-dimensional (2D) multi-lane highways consisting of horizontal and vertical alignments which is a crucial part of highway design consistency research. Three such alignments, with simple and complex curves were designed to generate desired traffic volume levels. A driving simulator was used to collect date from twenty drivers that participated in roadway alignment experiments at Ryerson University. Statistical Analysis Software (SAS) was used to analyze and process output data.Models were developed for visual demand and volume/capacity ratios, and geometric characteristics of the road, where visual demand was the only dependent variable. The research found that a relationship exists between visual demand and different traffic volumes along with geometric characteristics of the road.
\end{abstract}




\section{Acknowledgements}

First and foremost, I would like to express my appreciation and gratitude to my supervisor, Dr. Said M. Easa, for not only suggesting the idea of this thesis, but for his continuous educational and moral support throughout my studies and research work. Dr. Easa provided advice and guidance during my research that helped me progress and complete my thesis. I am also thankful to Dr. Easa for giving me the opportunity to carry out experiments using the driving simulator located at the Road Safety Research Laboratory in the Civil Engineering Department at Ryerson University.

I would also like to thank Dr. Elzohairy, Dr. Yuan and Dr. Raahemifar, for being part of my thesis defense committee, and for their continuous support throughout my studies.

I thank my colleagues and friends at the Civil Engineering Department of Ryerson University for their encouragement and help during my research. I cannot forget to mention

my family and friends' care and support that gave me the strength and drive to complete this research, especially when I was faced with difficulties. 


\section{Table of Contents}

$\begin{array}{ll}\text { Declaration } & \text { ii }\end{array}$

\begin{tabular}{ll}
\hline Abstract & iii
\end{tabular}

\begin{tabular}{|l|l}
\hline Acknowledgements & iv
\end{tabular}

\begin{tabular}{ll}
\hline List of Tables & ix
\end{tabular}

List of Figures $\quad$ xi

List of Appendices $\quad$ xiii

\begin{tabular}{lll}
\hline & Introduction & 1
\end{tabular}

1.1 Research Problem $\ldots \ldots \ldots \ldots \ldots \ldots \ldots \ldots \ldots$

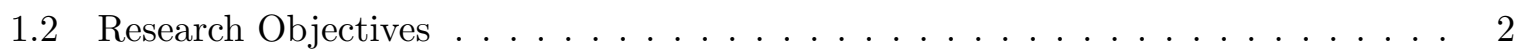

1.3 Scope and Hypothesis $\ldots \ldots \ldots \ldots \ldots \ldots$

1.4 Research Thesis Structure $\ldots \ldots \ldots \ldots \ldots$

\begin{tabular}{|lll}
\hline 2 & Literature Review & 6
\end{tabular}

$2.1 \quad$ Geometric Design Consistency $\ldots \ldots \ldots \ldots \ldots$. . . . . . . . . . . . 6

2.1 .1 Cross Section Consistency $\ldots \ldots \ldots \ldots \ldots \ldots$ 
2.1 .2 Operating Speed Consistency $\ldots \ldots \ldots \ldots \ldots \ldots \ldots \ldots$

2.1 .3 Safety Consideration $\ldots \ldots \ldots \ldots \ldots \ldots \ldots \ldots$

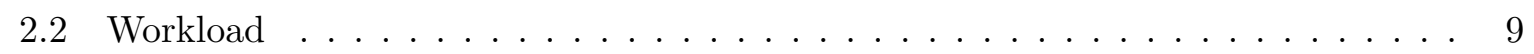

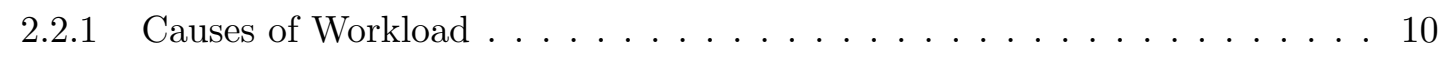

$2.2 .2 \quad$ Previous Uses of Workload \& Measurement Techniques $\ldots \ldots \ldots \ldots$

2.3 Multilane Highways $\ldots \ldots \ldots \ldots$. . . . . . . . . . . . . . . . . . 14

2.3 .1 Key Geometric Features of Multilane Highways $\ldots . \ldots \ldots \ldots$

$2.3 .2 \quad$ Design Speed Consideration $\ldots \ldots \ldots \ldots \ldots \ldots \ldots \ldots$

2.3 .3 Traffic Volume consideration $\ldots \ldots \ldots \ldots \ldots \ldots$

2.4 Probability Distributions to Model Headways . . . . . . . . . . . . . . . . . 18

2.4 .1 Vehicle Headway.$\ldots \ldots \ldots \ldots \ldots \ldots \ldots \ldots$

2.4 .2 Types of Distribution Models $\ldots \ldots \ldots \ldots \ldots$

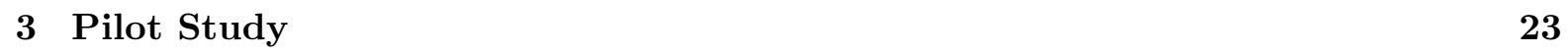

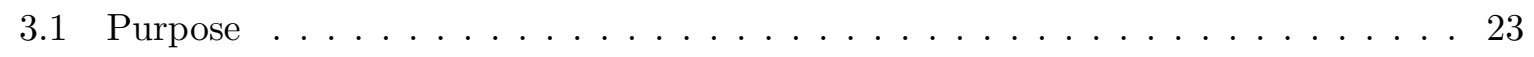

3.2 Road-Design Variables. . . . . . . . . . . . . . . . . . . . . . . . . . 24

3.3 Alignments for the Pilot Study $\ldots \ldots \ldots \ldots \ldots \ldots \ldots \ldots$

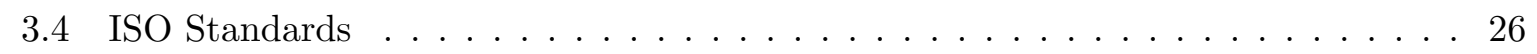

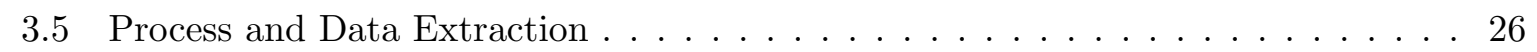

3.6 Data Analysis and Validation $\ldots \ldots \ldots \ldots \ldots$

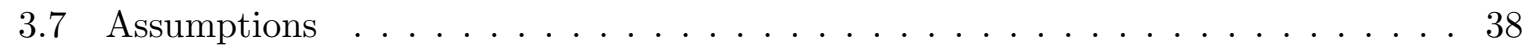

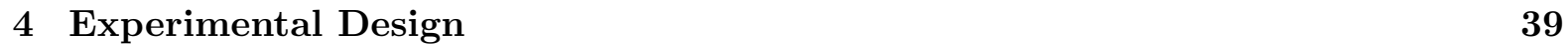

4.1 Driving Simulator $\ldots \ldots \ldots \ldots$

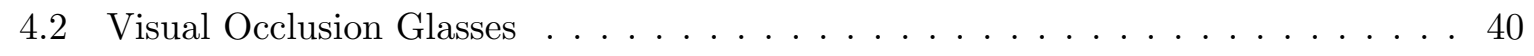




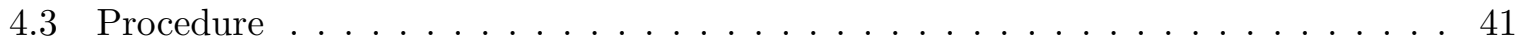

4.4 Design of Traffic Variables and Traffic Volume . . . . . . . . . . . . . . . . . . 42

4.5 Level of Service Calculation . . . . . . . . . . . . . . . . . . . 43

4.6 Determining the Number of Vehicles $\ldots \ldots \ldots \ldots$. . . . . . . . . . . . 44

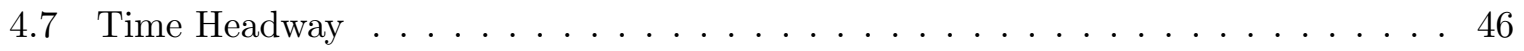

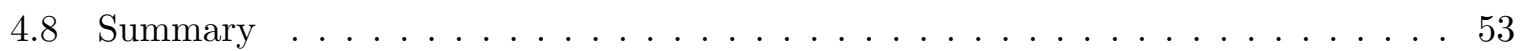

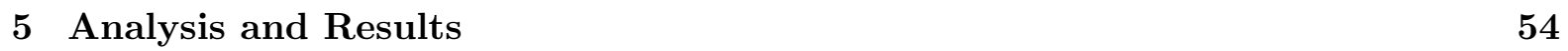

$5.1 \quad$ Analysis Procedure $\ldots \ldots \ldots \ldots \ldots \ldots \ldots \ldots \ldots$

5.2 Development of Visual Demand Models $\ldots \ldots \ldots \ldots \ldots$

$5.2 .1 \quad$ Preliminary Analysis Models $\ldots \ldots \ldots \ldots \ldots$. . . . . . . . . 56

5.2 .2 Final Models for Curves $\ldots \ldots \ldots \ldots \ldots \ldots$

5.2 .3 Final Models for Tangents $\ldots \ldots \ldots \ldots \ldots \ldots$

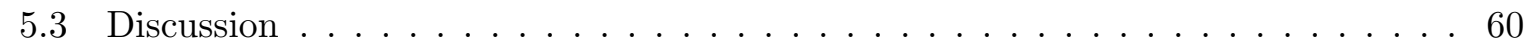

5.3 .1 Visual Demand on Curves . . . . . . . . . . . . . . . . . . . 60

5.3 .2 Visual Demand on Tangents . . . . . . . . . . . . . . . . 61

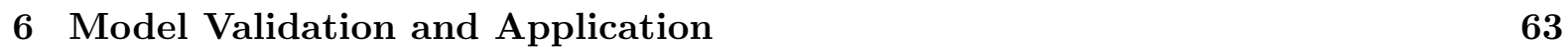

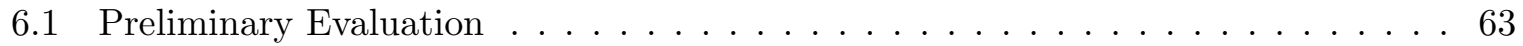

6.2 Speed Profile Design Consistency _ . . . . . . . . . . . . . . . . . . . 65

6.2 .1 Description of Test Alignments $\ldots \ldots \ldots \ldots \ldots$. . . . . . . . 67

6.2 .2 Results for Test Alignments 1 and $2 \ldots \ldots \ldots \ldots$

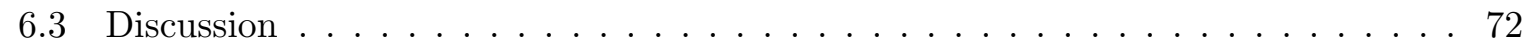

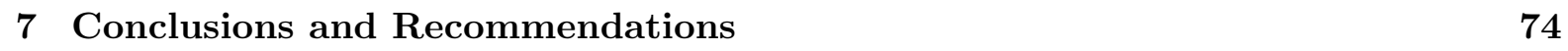

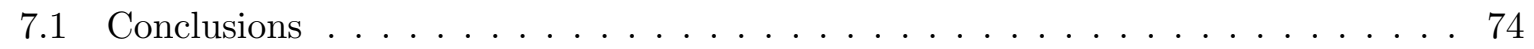




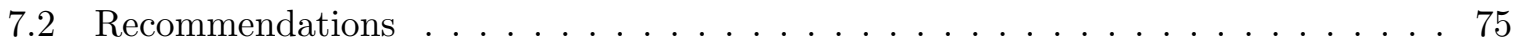

\begin{tabular}{lr}
\hline References & 129
\end{tabular} 


\section{List of Tables}

2.1 Design Parameters that Influence Driver Safety (Highway Design Manual, 2014) . 9

2.2 Causes of increased workload $\ldots \ldots \ldots \ldots \ldots \ldots \ldots \ldots \ldots$

2.3 Some design criteria for multilane highways $\ldots \ldots \ldots \ldots \ldots \ldots$

2.4 Levels of Service: A-F $\ldots \ldots \ldots \ldots \ldots \ldots$

3.1 Geometry of Horizontal Curves for Alignment 2 used in the Pilot Simulation Study $($ Design speed $=110 \mathrm{~km} / \mathrm{hr})) \ldots \ldots \ldots \ldots \ldots \ldots$

3.2 Sample Output Data for driver 1 using visual occlusion glasses $\ldots \ldots$. . . . . . 28

$3.3 \quad$ Sample Output VD values for driver 1 for low traffic volume level . . . . . . . . . 29

3.4 Analysis of Maximum Likelihood Parameter Estimates . . . . . . . . . . . . . 33

4.1 Level of Service (LOS) Classification Table (HCM, 2010) . . . . . . . . . . . . . 45

4.2 Geometry of Horizontal Curves for Alignment 1 . . . . . . . . . . . . . . . 46

4.3 Geometry of Horizontal Curves for Alignment 2 . . . . . . . . . . . . . . . . . 49

4.4 Computed headway for vehicles $\ldots \ldots \ldots \ldots \ldots \ldots$

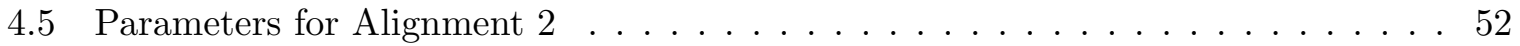

5.1 Driver 1 for no traffic volume for visual demand for the first $30 \mathrm{~m}$ of all curves. . 55

6.1 Geometric characteristics of FHWA alignment for100 km/hr (horizontal curves) . 65

6.2 Equations for estimating operating speed (2D horizontal curves only) . . . . . . 66 
6.3 Detailed geometric properties of test alignment 1 (simple 2D horizontal alignment) 69

6.4 Detailed geometric properties of test alignment 2 (complex 2D horizontal alignment) 69

6.5 Visual Demand and Operating Speed for Test Alignment 1 (low V/C ratio)) . . . 70

6.6 Visual Demand and Operating Speed for Test Alignment 1 (moderate V/C ratio) 70

6.7 Visual Demand and Operating Speed for test Alignment 1 (high V/C ratio) . . . 71

2.1 Geometry of Horizontal Curves for Alignment 1 . . . . . . . . . . . . . . 80

2.2 Geometry of Horizontal Curves for Alignment 2 $\ldots \ldots \ldots \ldots$. . . . . . 81

2.3 Geometry of Horizontal Curves for Alignment $3 \ldots \ldots$. . . . . . . . . . 81 


\section{List of Figures}

1.1 Flow Chart of Structure of Thesis . . . . . . . . . . . . . . . . . 5

2.1 Volume/Capacity Ratio Versus Operating Speed (HCM, 2010) . . . . . . . . . . . 17

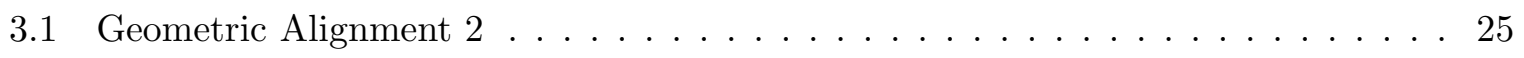

3.2 Visual Occlusion Glasses at Opaque State $\ldots \ldots \ldots \ldots$. . . . . . . . . . 27

3.3 A sample of data collected by Driver $1 \ldots \ldots \ldots \ldots$. . . . . . . . 31

3.4 SAS results for Volume/Capacity ratio and Visual Demand for the pilot study . . 32

3.5 SAS analysis for data collected for VD30 for pilot study of 10 participants . . . . 35

$3.6 \quad$ Plot visual demand versus preceding element radius (ped_pei) . . . . . . . . . . . 36

3.7 SAS output for VD30 and Volume/Capacity ratio . . . . . . . . . . . . . 37

4.1 Driving Simulator $\ldots \ldots \ldots \ldots \ldots \ldots$

4.2 Input table for 0.5 seconds using ToTaLcontrol software $\ldots \ldots \ldots$. . . . . . . . 41

4.3 Headway time distribution from experiment $\ldots \ldots \ldots \ldots \ldots$

4.4 Matlab output values for alignment $2 \operatorname{LOS} \mathrm{A} \ldots \ldots \ldots \ldots \ldots$

4.5 Normalized exponential distribution of alignment 2 LOS A . . . . . . . . . . . 52

5.1 Sensitivity of VDF, VDH and VD30 with Varying V/C Ratio (For Curve Sections) 61

5.2 Sensitivity of VDF, VDH and VD30 with Varying V/C Ratio (For Tangent Sections) 62 
$6.1 \quad$ A comparison between FHWA and research models (VDF) . . . . . . . . . . . 64

$6.2 \quad$ A comparison between FHWA and research models (VD30) . . . . . . . . . . . . 64

6.3 Test alignment 1 for consistency evaluation $\ldots \ldots \ldots \ldots \ldots \ldots$

6.4 Test alignment 2 for consistency evaluation $\ldots \ldots \ldots \ldots$. . . . . . . . 68

6.5 VD Profile vs. Speed Profile Test Alignment 1 . . . . . . . . . . . . . . 72

6.6 VD Profile vs. Speed Profile Test Alignment 2 . . . . . . . . . . . . . . . . 73

2.1 Geometric Alignment 1 . . . . . . . . . . . . . . . . . . . . . . . 82

2.2 Geometric Alignment $2 \ldots \ldots \ldots \ldots \ldots \ldots \ldots$

2.3 Geometric Alignment $3 \ldots \ldots \ldots \ldots \ldots \ldots \ldots$

2.4 Combined Geometric Alignment . . . . . . . . . . . . . . . . . . . . 85

$2.5 \quad$ Driving Simulator Display $\ldots \ldots \ldots \ldots \ldots \ldots$ 


\section{List of Appendices}

\begin{tabular}{lll}
\hline & SAS Code & 76
\end{tabular}

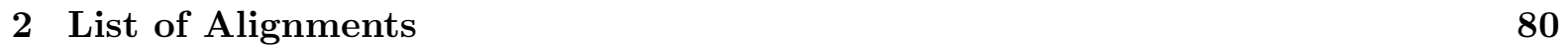

\begin{tabular}{llr}
\hline 3 & Scatter Plot Results & 87
\end{tabular}

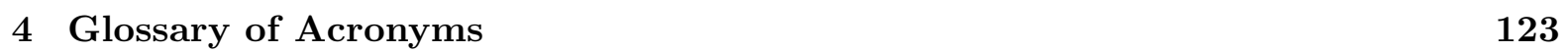




\section{Chapter 1}

\section{Introduction}

\subsection{Research Problem}

The geometric characteristics of highways such as road width, elevations, curves (horizontal and vertical), and gradients can provide optimal efficiency in traffic operations in terms of achieving desirable safety levels, without sacrificing convenience and time. Road accidents are common occurrences that are highly undesirable to road users, especially when it is a leading cause of human death, injury or trauma, and collateral damage (physical property and financial costs). Road fatalities are often caused by a driver's inexperience, intoxication, or recklessness. However, fatalities may also occur due to road design inconsistencies. Elimination of road design inconsistencies is crucial in transportation engineering. With proper research and planning, these inconsistencies can be avoided. Currently, the effect of driver workload is not considered in road design, however, its effect will be investigated in this research.

Traffic crashes and motor vehicle collisions arise when there is a collision between a driver's vehicle and another physical entity. According to the American Association of State Highway and Transportation Officials (AASHTO), highway deaths or road crashes occur every 21 minutes due to lane departure. These traffic collisions frequently result in property damages, injury, and death. Research has shown that over $80 \%$ of these collisions are due to the driver's error. This accounts for over 25,000 fatalities each year (almost over $60 \%$ of the nation's fatalities in the United States). The death toll, as well as the number of deaths relative to the total population, has declined over the last two decades. In the United States, according to the National Highway Traffic Safety Administration (NHTSA), an average of 92 individuals were killed each day in 2012. In that same year, there were 30,800 fatal crashes (NHTSA, 2013). The number of deaths decreased by $14.97 \%$ per year from 1979 to 2005, and the number of deaths 
per capita also declined by $35.46 \%$. The 2010 figures estimated a total of 5,419,000 crashes (30,296 fatal crashes), killing 32,999 people and injuring 2,239,000, while in 2011 estimated traffic fatalities were 32,479 (the lowest in 62 years since 1949). The record states that there were a total of 3,551,332 motor vehicular deaths in the US from 1899 to 2012. Canada's National Collision database by Transport Canada (NCDB) states that every year the number of serious injuries and fatalities continues to decrease, despite the increase in the number of vehicles on the roads in Canada (Transport Canada, 2013).

In 2011, fewer motor vehicular collisions occurred in Canada, which is illustrated by a downward trend in serious injuries and fatalities. This evidence clearly indicates the lowest figures collected by Transport Canada, since the early 1970's. The motor vehicle fatalities were down to 2,006 in 2011 (a significant decline of 10.3\% from 2010's 11,645). The rate of such fatalities per 100,000 of the population was 5.8 in 2011; down from 6.5 in 2010 (2011 had marked the first year that the fatality rate per 10,000 registered vehicles of 0.9 , fell below 1.0).

Greatly affected by many aspects, highway geometric characteristics are influenced by topography, environmental and design factors, speed design, and traffic related factors such as volume and capacity. Presently, detailed highway planning, such as road alignment design, is a must before moving forward with any highway or road developments. Highway planning alignment includes achieving the following objectives:

- Provide the most suitable type of road of maximum length (with the available funds)

- Anticipate a planned road system for future requirements (by constructing new roads and improving the existing ones)

- Develop a phased program for road development if the required road system cannot be constructed

- Prevent road crashes due to design inconsistencies

Driver reactions are typically estimated by simply calculating precisely how well driver's anticipations are fulfilled. The designers of highways establish countermeasures that reduce these uncertainties and unexpected road features for the drivers. Highway design consistency is gaining a wide range of attention throughout North America, where the use of consistent designs have reduced demand on drivers, thus decreasing possible road crashes. In the U.S geometric designs are based on the American Association of State Highway and Transportation Officials (AASHTO, 2004), and in Canada the Transportation Association of Canada (Easa, 2002) guidelines

\subsection{Research Objectives}

The primary objectives of this research study are the following: 
- Determine the relationship between visual demand and volume/capacity ratio for different traffic volumes through the use of the driving simulator and visual occlusion glasses.

- Determine if there exists a strong relationship, between visual demand and different geometric characteristics of the road including: radius, deflection angle, preceding curve radius, preceding curve inverse radius, type of curve, etc.

- Determine how visual demand increases or decreases depending on the type of road element (tangent/curve) and different traffic volumes.

- Determine more specific relationships between visual demand and volume/capacity ratios and geometric characteristics of the road over 30 meters, half of the total element length and the full element length.

In this research, an evaluation of visual demand (driver workload) for different traffic volumes over three different alignments (including simple and complex curves) was performed by using visual demand techniques with a driving simulator. The effects of geometric features of the road (such as curve radius, deflection angle, turning direction and other preceding element) were also considered during analysis and model development. All experiments were carried out using a driving simulator and a visual occlusion apparatus, while following AASHTO and TAC guidelines.

\subsection{Scope and Hypothesis}

This research study examines the effect of traffic volume on visual demand for multilane highways having 2D complex curves through experiments at design speed $110 \mathrm{~km} / \mathrm{h}$ forlow and moderate volume levels. The effect of traffic volumes and geometric characteristics of the road, such as design radii, turning direction, and the type of road preceding the current element are also observed.

The hypothesis of this study is that higher traffic volumes result in higher visual demand, and that the combined effect of traffic volume with other geometric design variables result in significant relationships for curves and tangents such that models may be developed.

\subsection{Research Thesis Structure:}

The structure of this thesis consists of the following chapters (Fig. 1.1):

Chapter 1 - Introduction: In this chapter, the research objectives and background, as well as the challenge and hypothesis are discussed. This chapter also includes a brief overview of 
highway design consistency, traffic volume design and driver workload as a measure of design consistency.

Chapter 2 - Literature Review: This chapter describes an in-depth and detailed study of highway design consistency, as well as other relevant measures. The literature review is divided into the following three sub-chapters: Geometric Design Consistency, Workload, and Multilane Highways.

Chapter 3 - Pilot Study: This chapter discusses the pilot study that was conducted to ensure the adequacy of the experimental design which includes the geometric characteristics and volume levels chosen for the study before conducting the large-scale investigation. The pilot study evaluated the research design and the research setting. Three highway alignments were designed for two different traffic volumes by following the AASHTO, HCM, and TAC guidelines. These highway alignments were implemented into Scenario Definition Language (SDL) of the STISIM driving simulator software. This pilot study evaluated the feasibility, time, cost, and adverse events in order to attempt to predict an appropriate sample size and improve the study design prior to performance of the full-scale research project.

Chapter 4- Experimental Design: This chapter discusses the methodology used to conduct the experiments, including the use of the visual occlusion. The geometric design of the road alignments and the driver training provided to participants is provided.

Chapter 5- Analysis and Results: In this chapter, the method used to extract and import data collected from the STISIM software to MS Excel is described. Furthermore, the method used to calculate visual demand for full, half and first 30 meters lengths of curves and tangents is described. Analysis of the data collected including visual demand as the dependent variable was conducted, while considering volume/capacity ratio as the independent variable. Finally, other independent variables describing the geometric features of the road alignments are investigated as independent variables.

Chapter 6- Model Validation and Application: This chapter discusses one of the developed models applied to estimate the design consistency of a previously defined road alignment. Driver workload and operating speed measures are explored in terms of design consistency evaluation. For two different alignments, a comparison of these measures is presented.

Chapter 7 - Conclusion and Recommendations: This chapter summarizes the results of the research study. Furthermore, conclusion, recommendations and suggestions of further research are provided. Following this chapter, appendices A, B, and C provide all relevant tables and figures. 


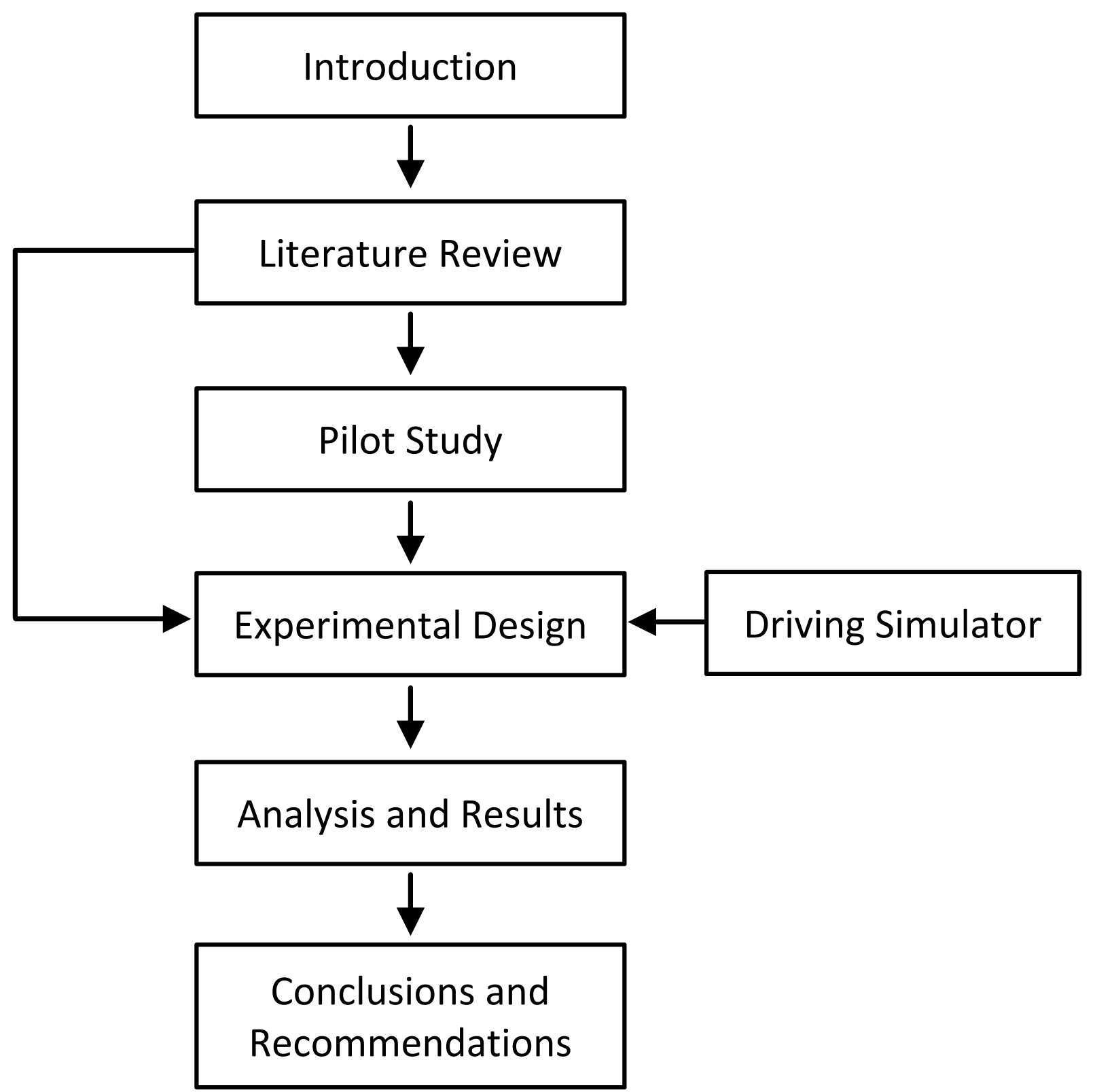

Figure 1.1: Flow Chart of Structure of Thesis 


\section{Chapter 2}

\section{Literature Review}

\subsection{Geometric Design Consistency}

Highway geometric aspects have features that relate or affect its operational quality and safety. Design consistency implies that geometry and design of roadways are not violating the expectation or the guidance and control abilities of drivers in terms of driving their vehicle safely. Consistent roadway designs are significant in preventing motorists from performing errors due to geometric features of the road. Proper highway design is key in conforming to driver's expectations rather than violating them. Consistent alignment is an important relationship between safety and consistency; inconsistencies introduce sudden changes in roadway characteristics, which can lead to improper driver reaction ( $\mathrm{Ng}$ and Sayed, 2004).

Research studies have discovered a strong relationship between design consistency and road safety. Highly inconsistent design that yields a sudden change in roadway features can lead to human errors and subsequently to collisions (Lamm et al. 1995).

Australian research found 85th percentile speeds faster than design speeds on curves with design speeds less than $90 \mathrm{~km} / \mathrm{h}$, in the late 1970's; these findings triggered revision alignment design procedures that added iterations to estimate 85th percentile speeds along an alignment, check for speed consistency, and adjust designs to limit the change in speeds between successive features. Horizontal alignment was the only consistency procedures considered in Switzerland, Germany and Australia. Arterial highways in the US, contribute only $9.3 \%$ of the total mileage of the nation's highway system but carry $48 \%$ of total travel. Approximately $44 \%$ of all fatal crashes and $47 \%$ of all injury crashes in 1992 occurred on arterial highways. An important component of the rural federal air primary highways is multilane highways. In fact, 
over 35,000 miles of arterial highways in the US are multilane, non-interstate roads in rural areas.

In this section, a revised chapter in the Transportation Association of Canada (TAC) Geometric Guide (2013) for Canadian Roads is used to discuss highway design consistency. Switzerland introduced a method for estimating speed profiles into its design policy, in the early 1970's as a means of identifying features that would require undesirably large speed reductions. Around this same time, Germany implemented a procedure for evaluation of the angular change in direction per unit of distance (i.e., curvature change rate), correlated curvature change rate with operating speeds, and limited the difference in rates (speeds) between successive roadway segments.

\subsubsection{Cross Section Consistency}

Cross section, which includes traveled way, roadway provided to users, median (usually a painted separation) and clear zone width (the distance from the edge of the traveled way to a nontraversable slope), along with other road elements, influence a driver's behaviour based on the provided consistency (Federal Highway Administration, 2012).

Driver's expectancy is key in highway design, some examples of where expectancy is violated are the following: a sudden change in cross section configurations, the number of traffic lanes increased/decreased over a relatively short section of the road, tangential exits that may cause drivers to follow the road feature inadvertently, or narrow bridges located on curves or dips, that may be difficult to spot, where the width of the preceding section is not reduced.

It is crucial to avoid such road incompatibilities between cross section and its horizontal and vertical alignments, as this could potentially cause a hazardous illusion, and ultimately provoke a driver to operate at excessive speeds (which could also result in an unexpected collision and highway death). These inconsistencies may be avoided by mitigating the impact of the unexpected features or by realigning the road, cross section, for example, should be introduced

gradually with tapers and advance signing should be used to prepare drivers of what is to come on the road ahead.

\subsubsection{Operating Speed Consistency}

Safety of a road is closely linked to variations in the speed of vehicles. Two types of speed variations exist: one where drivers increase or decrease their speed based on features of the road they encounter, such as curves, intersections, etc., and one where drivers are consciously or subconsciously traveling at significantly slower or faster speeds than the average traffic speed. For both variations, there is an increased risk of collision. 
The following two mentioned approaches were based on research conducted in the US to assess operating speed design consistency. The first method involves considering horizontal alignment only, which has proven to be effective at planning and preliminary design stages for cases where the vertical alignment could not be defined. The second approach involves both horizontal and vertical alignment, which produces more realistic predictions of operating speed as it could be used for more detailed final design stages, where vertical alignment has been defined. It has been proven that risk of collision is lowest when a driver's speed is close to the average speed of the traffic, and this risk may increase as drivers drive significantly faster or slower than the average speed. For this research, design speed will be further discussed in section 2.3.2, where the Highway Capacity Manual (HCM) will be used.

\subsubsection{Safety Consideration}

As indicated, risk of a collision increases as a driver's speed stems away from the average speed, as well as when there is notable variation in speed from one geometric design element to another. This variation in speed includes the effects of the transition from a tangent element to curve element, or from one curve element to another curve element. It has been indicated that the mean collision rate increased at a proportional rate directly with the mean speed difference caused by the transition from one geometric element to the next.

Over a period of three years, it was found that the number of collisions increased exponentially with the increase in speed reduction that was caused by the transition from one geometric element to the next (TAC 2007). It was also noted that collision rate directly increased in proportion to the exposure, which was defined as the product of curve length and the average annual traffic rate (vehicle/day). Also, it was determined that speed reduction estimates could be used as a design consistency measure.

The principle design condition is safety, whereby all designs must feature maximum capacity for safety as an objective. This is also emphasized by the Congress of the US with the passing of a Safety Act of 1966, including other acts like the Intermodal Surface Transportation Efficiency Act 1991 (ISTEA), from the Federal Highway Administration (FHWA) by endorsement of the AASHTO.

Horizontal and vertical alignment, cross section, sight distance, and traffic volume are the top priorities in terms of factors that affect traffic accidents. In order to avoid conflicts and maintain vehicle paths, visibility of the road and traffic conditions are a necessity to drivers. Motorists constantly and even after a particular degree of driving experience, subconsciously process visual information by means of observation, interpretation, as well as responsive activity. Visibility requirements are associated with the operational environment and vehicle speeds.Typically, these are fundamental factors employed in developing geometric specifications for sight distance. The majority of design features are adequately comparable to generate expectancies associated with frequent geometric, operational, and route characteristics. For 
example, due to the fact that the majority of freeway interchanges possess suitable exits; drivers ordinarily expect to exit from the right. This assists performance by permitting prompt and correct responses whenever right exits are negotiated. Nevertheless, there are many situations in which expectancies are violated. For instance, when an exit is on the left, then the right exit expectancy is incorrect, and the decision sight distance may need to be extended to compensate for the additional reaction time. Speed is related to the methodologies required to determine the specification for a particular situation.

Assumptions are made based on practical experiences or research, which are integrated in such specifications. A key assumption will relate to the condition and object that are to be seen. The object is a vehicle which approaches the passing vehicle in same lane, but in the opposite direction (such is the case for passing sight distance). Design parameters or boundaries relating to safe traffic operations and efficiency of driver performance is addressed by these safety considerations.It is clear that safety consideration addresses the design parameters related to safe traffic operation and efficient driver performance. Table 2.1 summarizes some design parameters that influence driver safety.

Table 2.1: Design Parameters that Influence Driver Safety (Highway Design Manual, 2014)

\begin{tabular}{|l|l|}
\hline Factors & Description \\
\hline \hline Stopping sight distance & $\begin{array}{l}\text { The minimal distance needed in which a vehicle moving at designed } \\
\text { speed can be stopped without a collision with a stationary object on } \\
\text { the road surface. }\end{array}$ \\
\hline Summit curves & $\begin{array}{l}\text { Vital factors are the height of the driver's eye and height of the } \\
\text { obstruction or object above road surface when considering safety in } \\
\text { terms of sight distance. }\end{array}$ \\
\hline Circular curves & $\begin{array}{l}\text { These curves are subjugated to a lateral acceleration (centrifugal } \\
\text { force) and are counterbalanced by the side friction between the } \\
\text { pavement and the vehicle's tires, and the superelevation rate. }\end{array}$ \\
\hline Superelevation & $\begin{array}{l}\text { The tilting of the road surface from outer edge towards the inner edge } \\
\text { is explained as the reduction of the toppling or skidding tendency } \\
\text { of the vehicle. The outer edges of the road pavement is raised with } \\
\text { respect to the inner edges. Maximum value of it is not allowed to } \\
\text { exceed } 1 \text { in } 15 .\end{array}$ \\
\hline
\end{tabular}

\subsection{Workload}

According to Senders (1970), performing a task or function and measuring the required effort while doing so is described as workload. Knowles (1963), on the other hand, defined workload by asking the following two questions:

1. How much attention is required? 
2. How well will the operator be able to perform additional tasks?

The definition for an inconsistent design can be stated as "a geometric feature or combination of adjacent features that have such unexpectedly high driver workload that motorists may be surprised and possibly drive in an unsafe manner (Messer, 1980). Studies performed by the Texas Transportation Institute have focused on measuring mental workload as a means to determine the adequacy of the roadway. Studying workload demands directly indicates a driver's ability to perform on the road. Quite often, drivers are multi-tasking by making decisions while absorbing visual and kinesthetic information, however, experienced drivers require much less processing skills to drive.

The relationship between the effort required to perform a given task and roadway geometrics that are present during that performance is an assumption of driver's workload. As a driver's workload rises or drops substantially, his/her respective collision rate increases. For example, if there isn't enough mental stimulus on a long stretch of road, the driver may begin to feel bored and lose focus of the road. If, on the other hand, there are too many signs, heavy fast-moving traffic, construction or advertisements, a driver may not have the ability to adequately respond to these unexpected events.

Consistent road geometry allows a driver to predict visual information and enables the focus to be on navigation instead of a decrease or increase in workload. Some of the causes of increased workload are described in Table 2.2. In comparison to other assessment techniques, the workload perspective and approach are extremely attractive, due to its ability to directly reveal the effects of geometric design on the driver. A more consistent geometric design is presented to a driver when workload turns out to be a critical factor that accounts for safe driving provisions when planning and designing a new roadway and/or auditing existing roadway structures.

\subsubsection{Causes of Workload}

Perception of the visual environment surrounding a driver is a key factor that influences a driver's performance on the road. A driver may get distracted by unexpected workload caused by his/her vehicle as well as the road. Increasing a driver's workload and distractions will negatively affect his/her safety (Verwey, Brookhuis \& Janssen, 1996). Aside from the road's design inconsistency that may increase a driver's workload, three types of safety-related distractions that could cause workload (Tijerina, 2000) are listed as follows:

1. General withdrawal of attention

2. Selective withdrawal of attention

3. Biomechanical interference 
General withdrawal is described by the driver's behaviour where he/she looks away from the road ahead. This type of visual attention withdrawal could cause an object/event detection impairment depending on the duration and frequency of the withdrawal. Another factor that could influence the driver's impairment is the direction of the glance (Lamble, Laakso, \& Summala, 1999; Summala, Nieminen, \& Punto, 1996). Generally, drivers are aware of the consequences and risks associated with general withdrawal of attention (Piechulla, Mayser, Gehrke, \& Ko nig, 2003), and therefore keep their glances from the road short usually around 1.6 s (Rockwell, 1988; Wikman, Nieminen, \& Summala, 1998).

Selective withdrawal of attention, is a result of cognitive workload, which could be associated with the use of mobile phones. This type of attention withdrawal is also connected with object/event detection impairment and can result in deteriorated object and event detection (Groeger, 2000; Haigney \& Westerman, 2001; Strayer \& Johnston, 2001). As a consequence of reduced visual interpretation and possible visual misguidance, a driver's field of view may be narrowed (Miura, 1986). Biomechanical interference usually occurs when a driver attempts to physically multitask, for example, reaching for an object and taking his/her hands off of the steering wheel. This type of distraction also effects a driver's workload as his/her body is forced to reposition itself from the ideal neutral seated position (Boer, 2001; Nakayama, Futami, Nakamura, \& Boer, 1999). Another crucial factor that affects a driver's visual demand is road geometry. For example, when a driver enters a town the landscape of his surrounding environment causes him/her to increase his/her attention to detail and subsquentially increases his/her workload. An increase in narrowness of a lane also causes a driver's workload to increase. In order to prevent collision rates, it is important to attempt to minimize workload, especially through a geometric design, which is inevitable. A driver's expectation must be overall consistent as he/she is driving. Geometric design errors may cause the driver confusion. Mental workload demand is described by the requirements of the superimposed ad hoc and priori driver workload, which mental workload capacity is described by the ability to execute the workload demand itself. Highway design may improve in safety if they are considered, as their occurrences are frequent. Table 2.2, based on TAC (2007), describes causes of increased workload.

Table 2.2: Causes of increased workload

\begin{tabular}{|l|l|}
\hline Causes of increased workload & Example \\
\hline \hline Criticality of feature being approached & An intersection or lane drop \\
\hline Limited sight distance & $\begin{array}{l}\text { A curve that could not be seen from until the } \\
\text { very last minute }\end{array}$ \\
\hline $\begin{array}{l}\text { Dissimilarity between the current and previous } \\
\text { feature }\end{array}$ & A road with an sudden stop intersection \\
\hline High number of drivers unfamiliar with road & $\begin{array}{l}\text { A major arterial road such as a highway versus } \\
\text { a local road }\end{array}$ \\
\hline $\begin{array}{l}\text { High demand of driver's attention after a period } \\
\text { of lesser demand }\end{array}$ & $\begin{array}{l}\text { A sudden sharp curve after a lengthy tangential } \\
\text { road }\end{array}$ \\
\hline
\end{tabular}

The traffic factors that may influence human workload adjustment failure are as follows: 
1. An increase in number of drivers on the road, which causes higher demands on a driver, and ultimately leading to a higher number of vehicle collisions.

2. A driver's age, as many drivers are continuing to drive as they grow older. The reason for this is due to the increased demand requirement that may not be addresses quickly enough.

3. A driver's decreased driving state, which could be influenced by driving at night, driving while fatigued, or driving while intoxicated/on drugs.

These factors cause a driver's workload to increase. Traffic volume increases the complexity associated with a driver's ability to manoeuver the roads. Also, a driver's decreased driving state affects a driver's ability to manage workload demands.

\subsubsection{Previous Uses of Workload \& Measurement Techniques}

Workload measurement techniques has been characterized by research as follows:

1. Primary Task Measurement

2. Secondary Task Measurement

3. Physiological Measurement

4. Subjective Technique

5. Visual Occlusion Method

Lee and Fisk (1993) found that driving performance was negatively affected when a road's design was not consistent; they also found that while driving improved once consistency was restored, performance disruption was still found. A study by Shafer et al. (1995) examined the relationship between vehicle collisions and highway design consistency. They found that collisions are more likely to occur when a road design calls for speed reduction from approach tangent to a horizontal line curve. They also found that the driver workload increased significantly when encountering the inverse of a radius curve. Another study by De Warrd et al. (1995) also found that speed reduction increased a driver's mental workload while driving, especially on narrow lanes. They also explored the need for further development of global workload measures for diagnostic purposes. Another study successfully developed a model for geometric design consistency evaluation based on various driver principles, such as "design attribute, sight distance, separation distance, operating speed, and driver familiarity" (Carroll, 1980).

The effect of speed and driver-adaptive strategies on their mental workload was explored by Navina and Musa (2004). They found that a driver's workload was affected not only by a 
road's complexity, but also their ability to adapt to speed changes was also significant. Baldwin and Coyne (2003) looked at the effect of traffic volume on the mental workload of a driver. They concluded that while there was a relationship between response time and accuracy when traffic was moderate or low, there was no significant difference for reaction time/accuracy as a function of detection-task modality. Blaauw (1985) examined the effects of wet roads at nighttime on curves of $200 \mathrm{~m}$ radii and tangents. The study found that conditions due to inclement weather increased the vision demand of drivers, and suggested methods of delineation to aid drivers. There have also been studies that examined the difference between curves and tangents for motorcycles. While the workload values were not found to be significant in terms of turn direction, the failure to detect oncoming vehicles resulted in different consequences for each road type (Hancock et al., 1990) Fitzpatrick et al. (1999) studied the appropriateness of using a driving simulation for the study of visual demand for drivers. They concluded that not only the results were the same for both the test track and the simulation, but also there were no significant gender or age-gender interactions within the participant. However, Tsyganov et al.(2005) found that this technique is most effective when studying the effects of a single factor, which has impacted the design of the current study. Wierwille and Eggemeir (1993) examined previously developed techniques for measuring mental workload of a driver and developed recommendations for these techniques within testing environments. Hancock and Caird (1993) tested a workload model to predict the impact of perceived distance from a goal on mental workload as well as the actions required for reducing mental workload in terms of acceptable time/distance restraints.

The use of vision occlusion within the present study has been researched thoroughly. Tsimhoni and Green (2001) found that while adding the secondary task of removing the participant's ability to see the road degraded driving ability significantly, driving performance was similar to participants who were asked to look inside their vehicle. Natasha (2003) also found that there was a relationship between a secondary task and a driver's ability to successfully navigate a safety driving scenario that involved other drivers. Van Der Horst (2004) concluded that visual occlusion techniques are effective tools for studying driver mental workload, as well as the safe use of other devices while driving. Another study by Easa and Ganguly (2004) used the visual occlusion technique to determine that visual demand is significantly increased when driver's encounter various geometric characteristics of complex road curves. Easa and He (2006) also found that with the use of vision occlusions, visual demand is significantly affected by 3D alignments, the effects of radius of horizontal curve and the K parameter of vertical curves, as well as by the age of the participant. Senders et al. (1967) studied the relation between the amount of interruption of vision and driving speed for different drivers on different roads. They found not only a positive correlation between the length of the observation period and driver speed, but also a negative relationship with the increasing complication of road design and driver speed, regardless of viewing times.

Subjective measures, including MCHMCH, SWAT, and TLX procedures require little instrumentation and are most appropriate for predicting workloads for systems or designs that have not yet been implemented. Primary-task measures are imperative while examining mental workload, however, they do not account for a driver's ability to utilize extra processing resources in low to moderate levels of workload (Wierwille and Eggemeier, 1993). Secondary-task 
measurements should be examined, as they result in inconsistencies in primary-task measurements ( Eggemeier and Wilson, 1991; Lysaght et al., 1989). Processing resources are often allocated to these secondary-tasks, such as a cell phone or the radio; for this reason they must be considered within a study's design (Wierwille and Eggemeier, 1993). Hartand and Wiskens (1990) and Wickens (1984) found that this interaction is the most apparent with there is considerable overlap in the resource demands of primary and secondary tasks.

A simple method for measuring the overall affect of workload is measuring a participant's heart rate. While this method is considered to be non-intrusive (Wilson et al., 1987), it may not be appropriate for the study of a single factor affecting driver mental workload (Hart and Wickens, 1990). Measures of brain-evoked potential techniques, while not yet firmly established, could potentially be appropriate for studies involving multi-task environments (Eggemeier and Wilson, 1991). Eye activity is another non-intrusive measurement, collected through recording aspects such as eye blink rates and blink durations. Wilson and Eggemeier (1991) concluded that this method somewhat represents the diagnostic indications of visual workload.

\subsection{Multilane Highways}

More than $56,000 \mathrm{~km}$ of the arterial highways in the US are multilane. All roads over which the US mail was carried and improved through funds provided by the Federal Aid Road Act, and as a result, there is no sufficient research on the geometric design features of rural, multilane, no freeway highways, and safety effects. It has been indicated that Federal Aid primary highways' fatality rates have been significantly high with respect to urban and rural Interstate Highways.

\subsubsection{Key Geometric Features of Multilane Highways}

From the few studies that examine safety performance of multilane rural highways in North America, Persaud (1991) investigated and developed statistical models that predicted a higher number of collisions for multilane highways than urban segments for the same level of exposure and number of lanes. In another study, Council and Stewart (1999) studied rural four-lane highways and developed models using traffic flow and shoulders widths as input variables. They discovered that larger shoulder widths were linked to a lower number of crashes. Key geometric features to consider when designing multilane highways are shown in the following Table 2.3 (HCM 2010):

- Freeflow speed (FFS) must fall between 45 to $60 \mathrm{mi} / \mathrm{h}$;

- The maximum number of lanes in one direction is two or three;

- The lane width is a minimum of $10 \mathrm{ft}$, but could sometimes exceed more than $12 \mathrm{ft}$; 
Table 2.3: Some design criteria for multilane highways

\begin{tabular}{|l|l|}
\hline Design Criteria & Description \\
\hline \hline Shoulder Width & $\begin{array}{l}\text { In most cases, left shoulders should be } 6 \text { feet }(1.8 \mathrm{~m}) \text { wide. This allows } \\
\text { for the use of } 1 \mathrm{~V}: 6 \mathrm{H} \text { slopes in the median. However, if the 20-year level of } \\
\text { service approaches Level C, then consider a } 8 \mathrm{ft}(2.4 \mathrm{~m}) \text { wide left shoulder, } \\
\text { and decrease the median slopes to } 1 \mathrm{~V}: 5 \mathrm{H} .\end{array}$ \\
\hline Clear Zone & $\begin{array}{l}\text { The clear zone will vary according to design speed, traffic volumes, side } \\
\text { slopes, and horizontal curvature. }\end{array}$ \\
\hline Ditch Width & $\begin{array}{l}\text { The clear zone will vary according to design speed, traffic volumes, side } \\
\text { slopes, and horizontal curvature. }\end{array}$ \\
\hline Back Slope & $\begin{array}{l}\text { Where the height of cut exceeds } 10 \mathrm{ft}(3 \mathrm{~m}), \text { consider using a 1V:2H back } \\
\text { slope beyond the clear zone. Also, for heights greater than } 30 \mathrm{ft}(9 \mathrm{~m}), \\
\text { consider the use of benching. }\end{array}$ \\
\hline Fill Slope & $\begin{array}{l}\text { For fill heights greater than } 30 \mathrm{ft}(9 \mathrm{~m}), \text { use a } 1 \mathrm{~V}: 2 \mathrm{H} \text { uniform slope with a } \\
\text { roadside barrier. Also, for heights greater than } 30 \mathrm{ft}(9 \mathrm{~m}), \text { consider the } \\
\text { use of benching. }\end{array}$ \\
\hline
\end{tabular}

- Right-side lateral clearance: aft to more than $6 \mathrm{ft}$;

- The terrain could be level, rolling, or mountainous

\subsubsection{Design Speed Consideration}

The importance of controlling geometric design elements of roadways will warrant the accountability of overall highway requirements. The visual field and peripheral vision is reduced and restricted, which consequently limits time availability for the driver in terms of perception and reaction.

Building highways with high design standards will compensate for these limitations by simplifying guidance and control, through appropriate informational aid, by positioning the information within clear view, through elimination of the need for peripheral vision, by subsequently simplifying decision-making requirements, including spacing them further away from each other to decrease the thinking demands. Different classes of road are designated with different speed standards. Assessment of geometric design consistency using operating speed is the most widespread used strategy. The speed in which $85 \%$ of the vehicles can be found travelling, is used as a determinant of the speed limits for traffic regulation. The vehicular speed of drivers directly affects two of the highway system performance measurements (mobility and safety). Lower travel times are provided by higher speeds, and are a measurement of good mobility, but the relation between safety and speed is not clear cut. The difficulties in separating speed, from other characterizations, including the type of highway facility; reduces high speed to a general agreement (the risk of injuries and fatalities increases with speed).

In 1938, design speed was redefined by the American Association of State Highway 
Officials (AASHO) as the maximum approximately uniform speed which would possibly be adopted by the faster group of drivers, but not, necessarily, by the small percentage of reckless ones. In 1954, design speed was once again redefined as the maximum safe speeds that can be maintained over a specified section of highway when conditions are so favorable that the design features of the highway govern. It has been recognized that operating at a speed greater than design speed does not necessarily imply unsafety. Designated design speed is referred to as the minimum highway design value for horizontal curve radius and sight distance. Highway design requires designated design speed in order to define features of the road. Speed limits are defined based on safety, however, drivers have their own safety perception, and consequently adjust their speed accordingly. This causes their speed measures to vary from one another. Design speed is directly influenced by the following: radius of horizontal curves, superelevation, gradient, road width, clearance requirements, and sight distance. On the other hand terrain and topography affect design speed standards. Research has proven that the higher the increase or decrease in speed, from a tangent to a curve, the higher the chances of crashing on a curve. This is caused by the decreased likelihood of drivers to reduce their speed.

\subsubsection{Traffic Volume consideration}

The maximum number of vehicles, passenger per unit time, that may be accommodated given reasonable expectation occurrence is also known as the capacity. Level of service is affected by the volume to capacity ratio. Volume to capacity of pavements, bridges and roadways is crucial in determining their structural and geometric design. Traffic volume considerations aid in designing intersections and minimum turning paths.

\section{Levels of Service}

Since it has been decided that only low and moderate volume levels will be studied, their adequacy for the study is investigated.

1. Speed and travel time

2. Traffic interruptions/restrictions

3. Freedom to travel with desired speed

4. Driver comfort and convenience

5. Operating cost

The HCM uses travel speed and volume by capacity ratio (v/c ratio) to distinguish different volume levels. This $\mathrm{v} / \mathrm{c}$ ratio ranges between 0 and 1 . Siix levels of service are defined from A to $\mathrm{F}$ as shown in Figure 2.1 (HCM 2010) and Table 2.4 (NPTEL, 2006). 


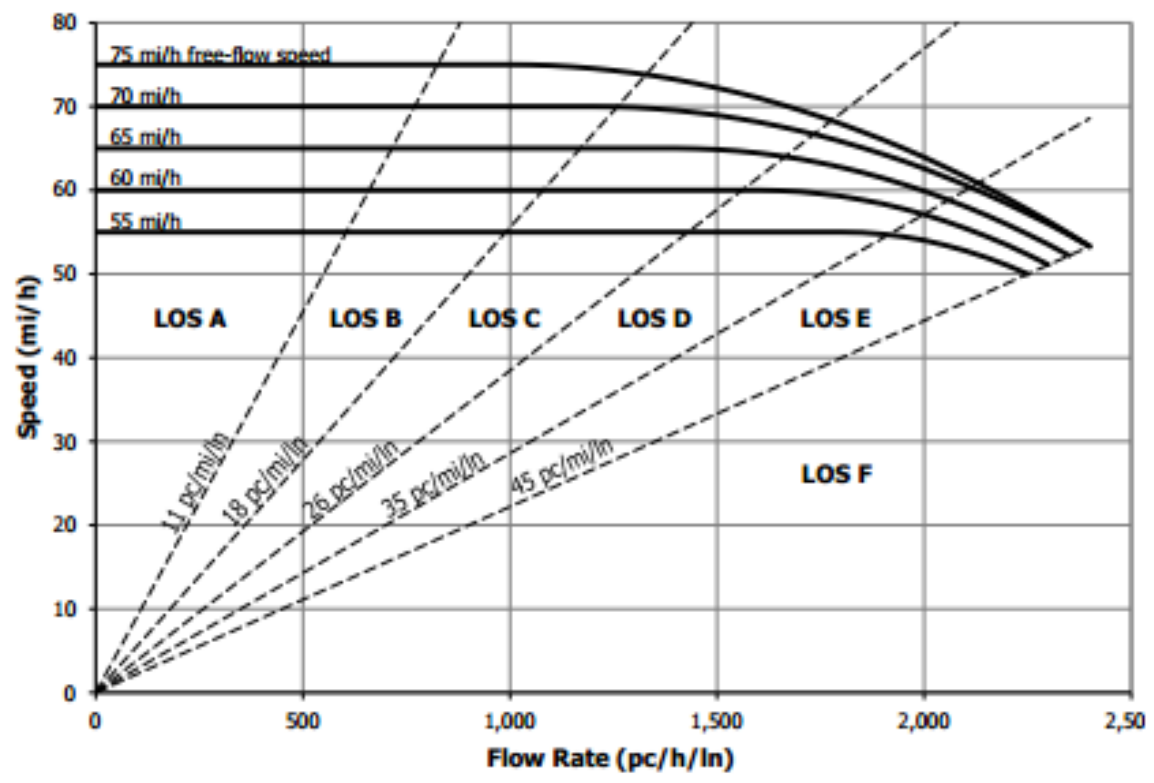

Figure 2.1: Volume/Capacity Ratio Versus Operating Speed (HCM, 2010)

For the experiments, low and moderate volume levels will be studied. Low volume is the upper limit of level service A and moderate volume is the upper limit of level service C. Level of service $\mathrm{A}$ is a zone of free flow, while level of service $\mathrm{C}$ is a zone affected by restrictions. It is important to note that level of service A is described by the following:

- Volume is lower

- Traffic will experience free flow

- Drivers have the complete freedom to choose their desired speed

- Even at maximum density, the average spacing value between vehicles is $167 \mathrm{~m}$

On the other hand, the level of service $\mathrm{C}$ is described by the following:

- Presence of other vehicles begins to restrict the manoeuvrability within the traffic stream

- Average speed remain at or near the free flow speed

- Driver vigilance is required at this level

- Minimum average spacing between vehicles is in the range of $67 \mathrm{~m}$

- Queues may be expected to form behind any significant blockage 
Table 2.4: Levels of Service: A-F

\begin{tabular}{|c|c|}
\hline Service & Description \\
\hline $\mathbf{A}=$ Zone of free flow & $\begin{array}{l}\text { - Volume is lower } \\
\text { - Traffic will experience free flow } \\
\text { - Drivers have the complete freedom to choose their desired speed } \\
\text { - Even at maximum density, the average spacing value between vehicles is } 167 \mathrm{~m}\end{array}$ \\
\hline $\mathbf{B}=$ zone of reasonable flow & $\begin{array}{l}\text { - Free flow speeds are still maintained } \\
\text {-Drivers' freedom to choose their desired speed is only slightly restricted } \\
\text {-The lowest average spacing between vehicles is about } 100 \mathrm{~m}\end{array}$ \\
\hline $\mathbf{C}=$ zone with restrictions & $\begin{array}{l}\text { - Presence of other vehicles begins to restrict the manoeuvrability within the traffic } \\
\text { stream } \\
\text {-Average speed remain at or near the free flow speed } \\
\text { - Driver vigilance is required at this level } \\
\text {-Minimum average spacing between vehicles is in the range of } 67 \mathrm{~m} \\
\text { - Queues may be expected to form behind any significant blockage }\end{array}$ \\
\hline $\mathbf{D}=$ zone with restrictions & $\begin{array}{l}\text { - A verage speeds begin to decline with increasing flows } \\
\text { - Freedom to maneuver within the traffic stream is noticeably restricted } \\
\text { - Density deteriorates more quickly with flow } \\
\text { - Spacing is about } 50 \mathrm{~m} \\
\text { - As traffic stream has little space to absorb disruptions, minor incidents can lead } \\
\text { to queuing of vehicles }\end{array}$ \\
\hline $\mathbf{E}=$ zone operating at capacity & $\begin{array}{l}\text { - Operation at capacity } \\
\text { - Stream reaches its maximum density limit } \\
\text { - No usable gaps in the stream } \\
\text { - Slight disruptions will cause breakdown, with queues forming rapidly behind the } \\
\text { disruption } \\
\text { - Manoeuvring within the traffic stream becomes extremely difficult }\end{array}$ \\
\hline $\mathbf{F}=$ zone of forced flow & $\begin{array}{l}\text { - Zone with conditions in a queue that has formed behind a breakdown or disruption } \\
\text { - Vehicles will be shuffling through the queue } \\
\text { - There may be periods when they move quickly, and others when they are stopped } \\
\text { completely } \\
\text { - Point of breakdown } \\
\text { - Region of forced flow at low speed }\end{array}$ \\
\hline
\end{tabular}

By looking at Figure 2.1, it can be noted that there is a significant operating speed gap between level of service A and level of service C. This gap will ensure that there will be significant variances between the two volume levels for the experiments. The combination of the alignments and the volume levels will give a total of six different cases, from which conclusions may be drawn once data is collected.

\subsection{Probability Distributions to Model Headways}

\subsubsection{Vehicle Headway}

Vehicle headway is the measure of time space between two vehicles. It can be obtained by measuring the time elapsed between the arrival of the leading vehicle and the following vehicle at a designated test point. Some of the key aspects of vehicle headway are the following: 
- The average of vehicle headways is the reciprocal of flow rate

- Vehicle headways represents microscopic measures of flows passing a point

- Minimum acceptable mean headway determines the roadway capacity

There are two main categories for headway models:

1. Single statistical distribution

2. Mixed models of two or more distributions

Single Statistical Distribution includes:

1. Exponential distribution

2. Normal distribution

3. Gamma distribution

4. Lognormal distribution

Mixed Distribution Models include:

1. Cowan M3

2. Cowan M4 and generalized queuing model

3. Double displaced negative exponential distribution

Note that single distribution models will be the focus of this research.

\subsubsection{Types of Distribution Models}

In normal distribution models, no appropriate theory supports the assumption that vehicle arrival patterns obey the law of proportionate effect. This assumption is easily violated in complex traffic conditions.

Lognormal headway distribution model is used under car-following situations. A vehicle maintains a safe distance while following its leading vehicle closely at variable speeds.

Gamma distribution model is widely used due to its flexibility and compatibility. It is a family of curves and it may evolve into its two child-distributions: $\mathrm{P}$ and Exponential distributions when one of the two parameters is fixed with specific values. 


\section{Distribution Models}

As mentioned previously, no appropriate theory supports the assumption that vehicle arrival patterns obey the law of proportionate effect, therefore, normal distributions will not be considered for this study.

Lognormal headways, as mentioned, are used under car-following situations, where a vehicle remains at a safe distance from the leading vehicle - following the vehicle closely at different speeds. The change of headway is described in Eq. 2.1.

$$
V_{i}-V_{i-1}=V_{i-1} \times \lambda_{i}
$$

where $V_{i}$ is the headway at the ith interval and $\lambda_{i}$ is the ratio of headway change $V_{i}-V_{i-1}$ and $V_{i}$. The following equation is then obtained in Eq. 2.2.

$$
\ln V_{n}=\ln V_{1}+\sum_{i=1}^{n} \lambda_{i}
$$

From the Central Limit Theorem, $\sum_{i=1}^{n} \lambda_{i}$ is normally distributed and $V_{n}$ is lognormally distributed. However, since the experiments consist of low and moderate traffic levels, this distribution cannot be used and will not be discussed. There is no appropriate theory that supports that vehicle arrival obeys the law of proportionate effect (Zhang et al., 2006).

Gamma distribution model, on the other hand, is widely used for its flexibility and compatibility. A mixed headway distribution model, Double Displaced Negative Exponential Distribution (DDNED), is presented in Eq. 2.3.

$$
f(x)= \begin{cases}\phi \times \gamma_{i} \times \exp \left(-\gamma_{1} \times(t-d)\right)+(1-\varphi) \times \gamma_{2} \times \exp \left(-\gamma_{2} \times(t-d)\right), & t \geq d \\ 0, & t<d\end{cases}
$$

where $f(t)$ is the probability density function, $\phi$ is a weighing factor constrained by $0<\phi \leq 1$ and $\gamma_{1}$ and $\gamma_{2}$ are constants associated with the flow status, and $d$ is a displaced parameter. Since the data required to apply this distribution is unavailable, it cannot be used to generate headways for the experiments.

In another case, two headway distributions on traffic status are discussed: one being the log-normal distribution model - which is more suitable for traffic that is in free flow status, and 
the other being log-logistic distribution model - which is more suitable in fitting headway data when the traffic is in congestion status (Shengchao et. al, 2008). The log-normal distribution is shown in Eq. 2.4:

$$
f(h)=\frac{1}{\sqrt{2 \pi} \sigma h} \exp -\left(\frac{(\ln h-\mu)^{2}}{2 \sigma^{2}}\right)
$$

In this distribution, variable $h$ represents the possible value of headway data, $\mu$ is the location parameter, and $\sigma$ is the scale parameter. The log-logistic distribution model, on the other hand, is depicted in eq. 2.5

$$
f(h)=\frac{\exp \left(\frac{\ln h-\mu}{\sigma}\right)}{\sigma\left(1+\exp \left(\frac{\ln h-\mu}{\sigma}\right)\right)^{2}}
$$

Because the mean or standard deviation of the experiments are not available, these two models cannot be used.

Other models were found, such as Markov's model for headway/spacing (Chen and Zhang, 2009) and modelling highway-traffic distributions using superstatistics (El-Arish, 2008), however, the conditions needed to use these distributions are not applicable. With superstatistics, there needs to be a free flow zone, which is applicable to only part of the experiments. In the other case, Markov's model cannot be applied because it is a car-following model. In the experiments, levels of service $\mathrm{A}$ and $\mathrm{C}$ are studied, $\mathrm{A}$ being a free flow zone and $\mathrm{C}$ being a zone with some minor restrictions.

In another case, Traffic Performance on Major Arterials (TPMA) model is used. In ordinary traffic simulation models, the average time headway between arriving vehicles is calculated as the inverse of the traffic flow. The following exponential time headway distribution using TPMA model is shown in Eq. 2.6 (Olstam, 2005):

$$
f(x)=0.1 \times p_{1}^{2} \times \ln \left(\frac{1+e^{\left(x-p_{2}\right)}}{1+e^{-10 p_{2}}}\right) \times \frac{\left(1+e^{-10 p_{2}}\right)^{0.1 p_{1}}}{\left(1+e^{10\left(x-p_{2}\right)}\right)^{0.1 p_{1}+1}} \times e^{10\left(x-p_{2}\right)}
$$

Where $x$ represents time headway, and $p_{1}$ and $p_{2}$ are parameters that depend on demand volume $Q$ according to the following equation 2.7 for right lane and 2.8 for left lane:

$$
\left[\begin{array}{l}
p_{1} \\
p_{1}
\end{array}\right]=\left[\begin{array}{c}
-7.991 \cdot 10^{-3}+7.737 \cdot 10^{-4} Q-3.099 \cdot 10^{-7} Q^{2}+1.089 \cdot 10^{-10} Q^{3} \\
-2.807 \cdot 10^{-1}+6.485 \cdot 10^{-3} Q-9.794 \cdot 10^{-6} Q^{2}+3.479 \cdot 10^{-9} Q^{3}
\end{array}\right]
$$




$$
\left[\begin{array}{l}
p_{1} \\
p_{1}
\end{array}\right]=\left[\begin{array}{c}
-7.628 \cdot 10^{-3}+9.527 \cdot 10^{-4} Q-1.500 \cdot 10^{-7} Q^{2}+3.991 \cdot 10^{-11} Q^{3} \\
3.890-5.273 \cdot 10^{-3} Q-2.885 \cdot 10^{-6} Q^{2}+5.432 \cdot 10^{-10} Q^{3}
\end{array}\right]
$$

For demand volume greater than 1800veh/h, the following equation 2.9 must be used to adjust the demand flow:

$$
f_{\text {stretch }}(x)=\frac{f\left(\frac{x}{\operatorname{corr}(Q)}\right)}{\operatorname{corr}(Q)}
$$

However, in order to use the mentioned time headway distribution functions, a model for estimating how the traffic flow splits is needed. The following equation 2.10 will be used:

$$
Q_{\text {right }}=k \times\left(1-e^{-l \cdot Q}\right)
$$

Where $k$ and $l$ (constants) are calculated from equations 2.11 and 2.12 .

$$
\begin{gathered}
k=2600 \times(1-0.34 \times \alpha-0.90 \times \beta) \\
l=\frac{3.1+4 \times(\alpha+\beta)}{10000}
\end{gathered}
$$

The parameter $\alpha$ represents the proportion of trucks and buses, and the parameter $\beta$ represents the proportion of trucks with trailer. The left lane is calculated by subtracting the total lane flow from the right lane flow. This model could be used for the purpose of the experiments since all of the initial conditions are available: demand flow and proportion of trucks and buses. $k$ and $l$ are constants that determine traffic flow, and the values alpha and beta represent the fraction of buses and trucks, respectively. When generating numbers for a graph, a value of 0 was substituted for both $\alpha$ and $\beta$. Therefore, traffic flow is not adjusted, even with the absence of trucks and buses. 


\section{Chapter 3}

\section{Pilot Study}

\section{$3.1 \quad$ Purpose}

A pilot study was conducted to ensure that the experimental design is adequate for the research purpose before proceeding with the regression analysis on Statistical Analysis Software (SAS); this adequacy includes the appropriateness of the geometric characteristics of the alignments and the volume levels chosen. This small-scale study was also carried out to evaluate feasibility, time, cost, adverse events, and effect size (statistical variability) to attempt and predict an appropriate sample size and improve the study design prior to performance of the full-scale research project. The steps taken for the pilot study were as follows:

1. Calculated appropriate design speeds, demand volume, and volume/capacity ratios for low and moderate volume levels using the Highway Capacity Manual.

2. Developed scenarios according to calculated geometric design characteristics and traffic volume using the driving simulator software language (Scenario Definition Language $(\mathrm{SDL}))$.

3. Operated the visual occlusion spectacles using ToTaLcontrol 2 software simultaneously with the driving simulator's STISIM software.

4. Ran all three alignment scenarios for a total of 5 participants on the driving simulator and collected data (visual demand, running time, and longitudinal distance traveled by the driver).

5. Extracted the output data onto an Excel file and calculated the visual demand values for each design element of the highway alignments.

6. Developed models on SAS to analyze the effect of volumes on visual demand. 


\subsection{Road-Design Variables}

The purpose of the pilot study was to determine the existence of a strong relationship between a driver's visual demand and different traffic volumes. The road element's design radii for left and right turning directions, as well as different deflection angles at design speed of $110 \mathrm{~km} / \mathrm{h}$, were taken into consideration along with the different traffic volumes. Each participant drove the alignments for two different traffic volumes.

\subsection{Alignments for the Pilot Study}

A total of three highway alignments were designed (following the AASHTO and TAC design standards) and implemented into the driving simulator's STISIM software. These highway alignments were combined into one highway alignment. Two different traffic volumes were then applied to the same highway alignment (levels of service A and C) to create two different scenarios: low traffic volume and moderate traffic volume. Table 3.2 and Figure 3.1 demonstrate the different curve and tangent combinations including compound curves, reverse curves, and simple curves.

Table 3.1: Geometry of Horizontal Curves for Alignment 2 used in the Pilot Simulation Study (Design speed=110 km/hr))

\begin{tabular}{|c|c|c|c|c|c|c|c|c|}
\hline Element & $\begin{array}{c}\text { Element } \\
\text { Length }\end{array}$ & $\begin{array}{c}\text { Turning } \\
\text { Direction } \\
\text { of Curve }\end{array}$ & $\begin{array}{c}\text { Radius of } \\
\text { Curve(m) }\end{array}$ & $\begin{array}{c}1 / \\
\text { Radius }\end{array}$ & $\begin{array}{c}\text { PC } \\
(\mathrm{m})\end{array}$ & $\begin{array}{c}\text { PT } \\
(\mathrm{m})\end{array}$ & $\begin{array}{c}\text { Deflection } \\
\text { angle }\end{array}$ & $\begin{array}{c}\text { Lane } \\
\text { width }\end{array}$ \\
\hline \hline Tangent & 200 & & & & & & & 3.7 \\
\hline Curve (1) & 320.7 & $\mathrm{~L}$ & 525 & 0.00227 & 200 & 468.89 & 35 & 3.7 \\
\hline Curve (2) & 737.7 & $\mathrm{R}$ & 650 & 0. & 200 & 468.89 & 35 & 3.7 \\
\hline Tangent & 400 & & & & & & & 3.7 \\
\hline Curve (3) & 353.57 & $\mathrm{R}$ & 525 & 0.00222 & 1606.59 & 1960.16 & 45 & 3.7 \\
\hline Curve (4) & 654.76 & $\mathrm{~L}$ & 750 & 0.00133 & 1960.16 & 2614.92 & 50 & 3.7 \\
\hline Tangent & 450 & & & & & & & 3.7 \\
\hline Curve (5) & 576.19 & $\mathrm{R}$ & 1100 & 0.00091 & $3064 . .92$ & 3641.11 & 30 & 3.7 \\
\hline Curve (6) & 550 & $\mathrm{R}$ & 900 & 0.00111 & 3641.11 & 4191.11 & 35 & 3.7 \\
\hline Tangent & 300 & & & & & & & 3.7 \\
\hline
\end{tabular}

${ }^{*} \mathrm{PC}=$ Point of curvature; $\mathrm{PT}=$ Point of tangency

Each of the three alignments consisted of seven horizontal curves. The first alignment has a set of seven simple curves with one preceding and one following tangent (the radii and turning directions are varied to examine the effects of the turning direction). The second alignment has a set of two reverse curves and one compound curve with one preceding and one following tangent. The third alignment has a set of two compound curves and one reverse curve 


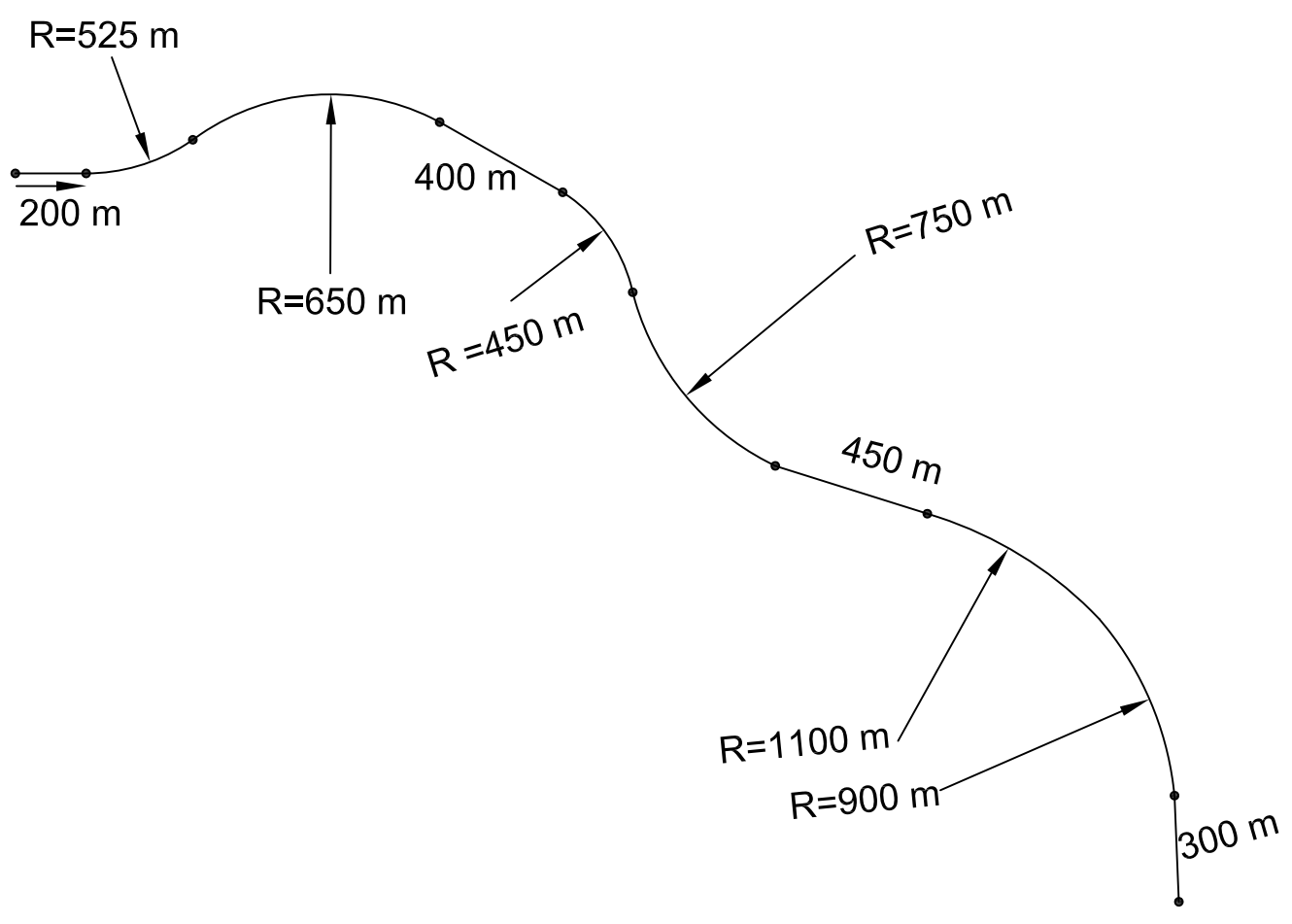

Figure 3.1: Geometric Alignment 2

with one preceding and one following tangent. A compound curve occurs when the turning direction of the preceding curve element is the same as that of the current curve element. A reverse curve occurs when the turning direction of the preceding curve element is opposite to that of the current curve element. In other words, a compound curve is a set of two or more circular curves between two main tangents, whereas, a reverse curve is an instant change in direction. The tables describing the geometric features of each alignment are found in Appendix 2 .

The geometric characteristics of alignment elements were calculated by ensuring that each curve was kept at more than the minimum radius required for the design speed (by following the TAC and AASHTO standards). The length of curve was calculated by using the following equation 3.1 .

$$
\text { Length }=\frac{\pi \times R \times \theta}{180}
$$

where Length $=$ length of curve; $R=$ radius of curve; $\theta=$ deflection angle in degrees. 


\subsection{ISO Standards}

The visual occlusion procedure, as described in ISO 16673 (2007), includes a set of requirements when calculating visual demand via the occlusion method. The requirements are as follows:

- A minimum of 10 participants should be used in any occlusion study;

- Participants should undergo training in tasks and the occlusion method;

- Up to five practice trials should be undertaken prior to actual trials;

- Participants should complete 5 trials on each task with full vision (static trials) and 5 trials whilst under occlusion conditions

- Tasks acceptable for occlusion studies should have static task times of greater than 5 seconds;

- The order of occlusion and static trials should be counterbalanced to avoid learning effects

In the research study, a total of 10 subjects participated in the pilot study and underwent proper training in tasks and the occlusion method. Participants were asked to perform at least one practice trial for each scenario prior to actual trials. Because of time and cost constraints, subjects were asked to complete one trial on each task under occlusion conditions, and static trials were not considered.

\subsection{Process and Data Extraction}

A total of five subjects drove the simulation alignments for the pilot study. In this way, the outcomes could be estimated without having invested the time and cost required to conduct the entire full experiment. The participants were trained to use the driving simulator and visual occlusion glasses thoroughly. Training included allowing the subjects to practice driving the alignments without the visual occlusion glasses, and then asking them to practice while wearing the glasses.

Initially, there was a total of four alignments and three volume levels (A, C, and E) to be tested, including an alignment consisting of a combination of six complex curves (reverse and compound curves). The total time required for a participant to complete the experiment was calculated to exceed an hour, which is not feasible considering the fact that participants may begin to feel nausea or fatigue if participating for more than 40 minutes. Therefore, for health and safety purposes, it was necessary to cut down the experiment to three alignments and two volume levels. The duration of time needed to complete high volume level was found to be not feasible. low and moderate volume Levels were therefore kept, and alignments one through three were also chosen. It was expected that a total of 20 drivers would participate in 
this study due to time and cost. Each participant was paid a total of $\$ 20$ to participate in a 30-40 minute experiment.

The visual occlusion glasses (see Figure 3.2) at normal state are opaque, and when triggered by the pedal (found where the clutch would normally be) they opened for one half of a second. The drivers were advised to press the pedal when they felt the need to obtain a clear view of the roadway when driving the simulator. The visual occlusion glasses were connected to a laptop that recorded the time elapsed between each pulse. The data recorded by ToTaLcontrol 2 software was then saved and used to calculate visual demand for each driver. Table 3.2 shows a sample of one of the driver's recording of visual demand with elapsed time. The table, which was converted into an Excel file, shows a sample of one of the driver's recording of visual demand with elapsed time.

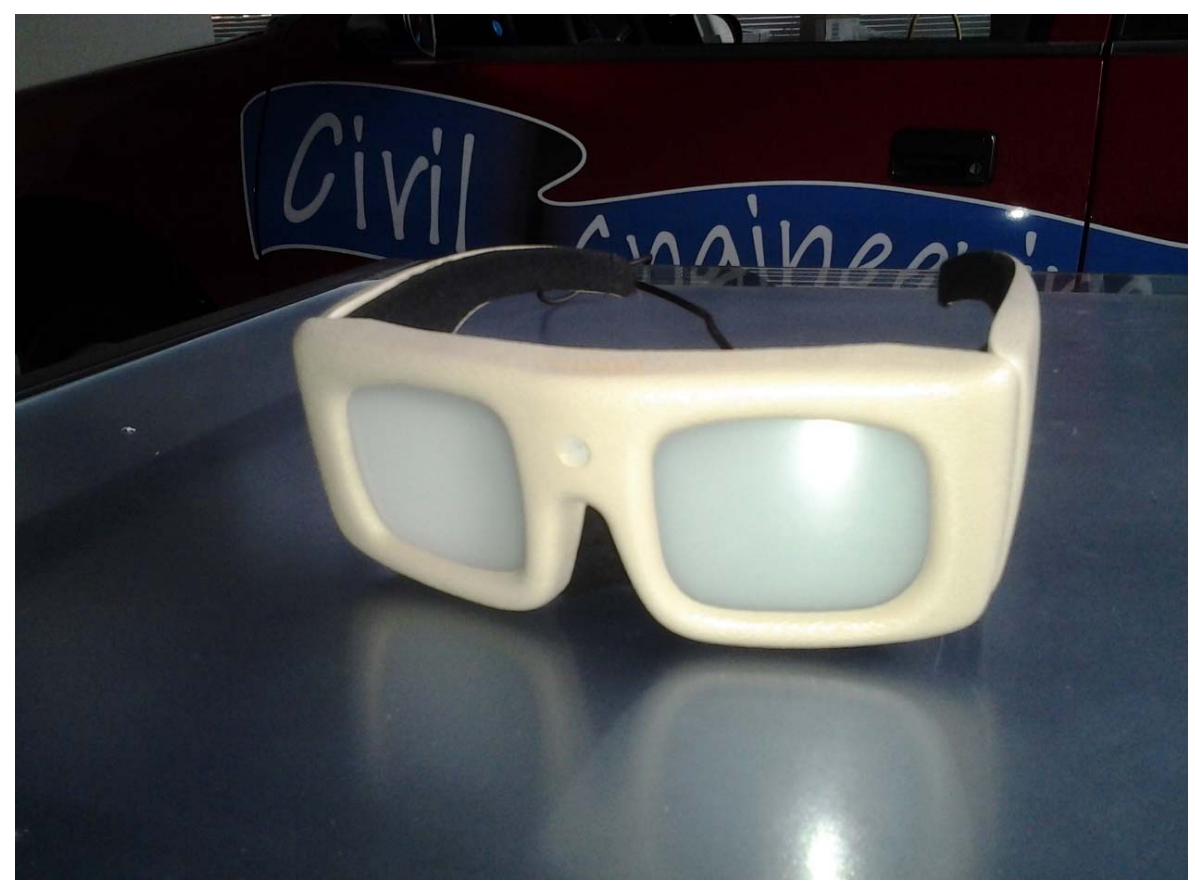

Figure 3.2: Visual Occlusion Glasses at Opaque State

In Table 3.2, the first column represents the computer system's time and the second column represents the elapsed time between each pulse. Visual demand was then calculated in Table 3.3 .

The following data was extracted from ToTaLcontrol 2 software, and converted into Excel files. As previously mentioned, ToTaLcontrol 2 software was set up in such a way that when the driver presses the pedal (previously installed) on the left, the lens of glass would change from opaque to clear for 0.5 seconds before returning to its original opaque state. The data collected from ToTaLcontrol 2 software includes starting time as well timestamps for every 
Table 3.2: Sample Output Data for driver 1 using visual occlusion glasses

\begin{tabular}{|c|c|}
\hline System time & Elapsed time $(\mathrm{s})$ \\
\hline \hline $00: 34.4$ & 0.988664 \\
$00: 38.6$ & 5.170893 \\
$00: 41.2$ & 7.781833 \\
$00: 44.1$ & 10.683856 \\
$00: 47.3$ & 13.853122 \\
$00: 50.8$ & 17.400384 \\
$00: 53.9$ & 20.477598 \\
$00: 57.3$ & 23.86542 \\
$01: 00.8$ & 27.392247 \\
$01: 02.2$ & 28.75241 \\
$01: 03.1$ & 29.681282 \\
$01: 03.9$ & 30.518115 \\
$01: 04.9$ & 31.424924 \\
$01: 05.7$ & 32.259395 \\
$01: 06.5$ & 33.019505 \\
$01: 07.2$ & 33.776752 \\
$01: 07.7$ & 34.277763 \\
$01: 08.5$ & 35.060516 \\
$01: 09.0$ & 35.561524 \\
$01: 09.7$ & 36.294957 \\
$01: 10.7$ & 37.260402 \\
$01: 11.7$ & 38.304748 \\
$01: 12.2$ & 38.805754 \\
$01: 13.6$ & 39.627616 \\
$01: 13.6$ & 40.128625 \\
\hline
\end{tabular}

time that the driver would press the pedal, which would trigger the visual occlusion glasses to open. The data obtained from the driving simulator as well from ToTaLcontrol was converted to text files, and then imported onto Excel. From Excel, the data was separated and organized by using the delimited option. Since the beginning of the run, the data such as driver's longitudinal distance was expressed cumulatively. The data was then broken down into time elapsed between each pulse. This data was then organized next to longitudinal distance when the driver has traveled. From there, the data was highlighted such that the point of curvature, as well as the point of tangency were separated. In this way, the visual demand for each segment was calculated by using the following equation 3.2 .

$$
\text { Visual Demand }=\frac{0.5}{\left(T_{\text {currenttime }}-T_{\text {Lastime }}\right)}
$$

where $0.5=$ Time interval when lenses are in open state (clear) in seconds, $T_{\text {currenttime }}=$ Time recorded at current request to open lenses in seconds, and $T_{\text {Lasttime }}=$ Time recorded at previous request to open lenses in seconds. 
Table 3.3: Sample Output VD values for driver 1 for low traffic volume level

\begin{tabular}{|c|c|c|}
\hline System time & Elapsed time (s) & VD \\
\hline \hline $30: 29.0$ & 1.377076 & 0.363088 \\
\hline $30: 31.7$ & 4.117976 & 0.182422 \\
\hline $30: 34.4$ & 6.842766 & 0.1835 \\
\hline $30: 34.9$ & 7.34377 & 0.997996 \\
\hline $30: 35.4$ & 7.844776 & 0.997992 \\
\hline $30: 37.2$ & 9.601568 & 0.28461 \\
\hline $30: 40.3$ & 12.43678 & 0.176354 \\
\hline $30: 42.7$ & 15.08116 & 0.18908 \\
\hline $30: 45.3$ & 17.666745 & 0.19338 \\
\hline $30: 47.3$ & 0.19719025 & 0.243631 \\
\hline $30: 50.0$ & 22.355576 & 0.189642 \\
\hline $30: 52.1$ & 24.520619 & 0.230942 \\
\hline $30: 54.8$ & 27.223734 & 0.184942 \\
\hline $30: 56.7$ & 29.110569 & 0.264994 \\
\hline $30: 58.5$ & 30.855801 & 0.286495 \\
\hline $31: 00.5$ & 32.930381 & 0.241013 \\
\hline $31: 02.0$ & 34.352199 & 0.351662 \\
\hline $31: 03.0$ & 35.399115 & 0.477593 \\
\hline $31: 04.4$ & 36.831704 & 0.349018 \\
\hline $31: 05.9$ & 38.313345 & 0.337464 \\
\hline $31: 07.2$ & 39.603745 & 0.387477 \\
\hline $31: 08.5$ & 40.859997 & 0.398009 \\
\hline $31: 09.7$ & 42.079449 & 0.41002 \\
\hline $31: 11.6$ & 44.046619 & 0.254172 \\
\hline
\end{tabular}


This process was repeated for all participants' collected data. Table 3.3 displays a sample of the data collected for Driver 1. In the first column the system time is indicated, and in the second column the elapsed time is indicated for each pulse of the visual occlusion glasses where they opened for 0.5 seconds. The third column contains the calculated visual demand, by using the equation 3.2 . Then, the average visual demand values were calculated using equation 3.2 (this is the average visual demand calculated for all curves and all tangents, separately). The elapsed time from the driving simulator data was matched with the time elapsed from the visual occlusion glasses such that the elapsed distance for each curve or tangent could be indicated in Figure 3.3. The yellow highlight indicates the beginning of a curve, whereas the blue highlight indicates the beginning of a tangent. The radius, as well as $1 /$ Radius were also matched according to the elapsed distance.

The first five columns of Figure ?? (sample data for driver 1) was extracted from the STISIM software, and was inputted into an Excel file:

The radius and $1 / \mathrm{R}$ values were taken from the geometric characteristics in Table3.3. They matched with the cumulative distance described in the dat file from the STISIM software. STISIM software collected the following data:

- Elapsed time since beginning of run ( $\mathrm{sec}$ )

- Driver's longitudinal acceleration $(\mathrm{m} / \mathrm{s})$

- Driver's longitudinal velocity $(\mathrm{m} / \mathrm{s})$

- Total longitudinal distance that the driver has traveled since beginning of run (m)

- Driver's longitudinal velocity $(\mathrm{km} / \mathrm{h})$

\subsection{Data Analysis and Validation}

Once the pilot study was completed and visual demand was calculated for each respective element (curve or tangent), regression analysis using SAS software was carried out to check for a good model fit. In this case, the pilot study analysis results using SAS proved to be not suitable. Using SAS, an analysis was performed in order to develop a model between visual demand for the first 30 meters of curves and volume/capacity (V/C) ratio. Generalized regression, using $\log$ as a link function, was used in order to achieve the results. By observing the results, the relationship between $\mathrm{V} / \mathrm{C}$ ratio and Visual Demand (VD) of the first 30 meters of the curve can be described. The following data analysis table (see Figure 3.4) was extracted from SAS for $\mathrm{V} / \mathrm{C}$ ratio and $\mathrm{VD}$, and the following model (Eq 3.3 ) was obtained:

$$
\log (\mathrm{VD} 30)=-1.6031-0.0132 \times V / C_{\text {ratio }}
$$

It can be concluded that the intercept of the model would be significant, however, the 


\begin{tabular}{|c|c|c|c|c|c|c|c|}
\hline System time & Elapsed time (s) & VD & AVG VD & Radius & 1/Radius & Elapsed Distance & Curve \\
\hline 2:30:29 PM & 1.377076 & 0.363088 & & & & & \\
\hline 2:30:32 PM & 4.117976 & 0.182422 & & & & & \\
\hline 2:30:34 PM & 6.842766 & 0.1835 & & & & & \\
\hline 2:30:35 PM & 7.34377 & 0.997996 & & & & & \\
\hline 2:30:35 PM & 7.844776 & 0.997992 & & & & & \\
\hline 2:30:37 PM & 9.601568 & 0.28461 & & & & & \\
\hline 2:30:40 PM & 12.43678 & 0.176354 & & & & & \\
\hline 2:30:43 PM & 15.08116 & 0.18908 & & & & & \\
\hline 2:30:45 PM & 17.666745 & 0.19338 & & & & & \\
\hline 2:30:47 PM & 19.719025 & 0.243631 & & & & & \\
\hline 2:30:50 PM & 22.355576 & 0.189642 & & & & & \\
\hline 2:30:52 PM & 24.520619 & 0.230942 & & & & & \\
\hline 2:30:55 PM & 27.223734 & 0.184972 & & & & & \\
\hline 2:30:57 PM & 29.110569 & 0.264994 & & & & & \\
\hline 2:30:58 PM & 30.855801 & 0.286495 & 0.233446 & 525 & 0.001904762 & 400 & 1 begins \\
\hline 2:31:01 PM & 32.930381 & 0.241013 & & & & & \\
\hline 2:31:02 PM & 34.352199 & 0.351662 & & & & & \\
\hline 2:31:03 PM & 35.399115 & 0.477593 & & & & & \\
\hline 2:31:04 PM & 36.831704 & 0.349018 & & & & & \\
\hline 2:31:06 PM & 38.313345 & 0.337464 & & & & & \\
\hline 2:31:07 PM & 39.603745 & 0.387477 & & & & & \\
\hline 2:31:08 PM & 40.859997 & 0.398009 & & & & & \\
\hline 2:31:10 PM & 42.079449 & 0.41002 & & & & & \\
\hline 2:31:12 PM & 44.046619 & 0.254172 & & & & & \\
\hline 2:31:14 PM & 46.094449 & 0.244161 & & & & & \\
\hline 2:31:16 PM & 48.298478 & 0.226857 & & & & & \\
\hline 2:31:17 PM & 49.864655 & 0.319249 & & & & & \\
\hline 2:31:20 PM & 51.970611 & 0.237422 & 0.325701 & & & 949.78 & 1 ends \\
\hline $2: 31: 22$ PM & 53.92721 & 0.255545 & & & & & \\
\hline 2:31:23 PM & 55.584802 & 0.301642 & & & & & \\
\hline 2:31:25 PM & 57.534678 & 0.256427 & & & & & \\
\hline 2:31:27 PM & 59.028493 & 0.334713 & & & & & \\
\hline 2:31:29 PM & 61.236174 & 0.226482 & & & & & \\
\hline 2:31:30 PM & 62.804265 & 0.318859 & & & & & \\
\hline 2:31:31 PM & 63.305276 & 0.997982 & & & & & \\
\hline 2:31:31 PM & 63.832399 & 0.948545 & & & & & \\
\hline 2:31:33 PM & 65.649007 & 0.275238 & & & & & \\
\hline 2:31:36 PM & 68.070071 & 0.206521 & & & & & \\
\hline 2:31:38 PM & 70.209872 & 0.233667 & & & & & \\
\hline 2:31:39 PM & 71.425127 & 0.411436 & & & & & \\
\hline 2:31:41 PM & 73.650508 & 0.224681 & 0.38398 & 750 & 0.001333333 & 1449.78 & 2 begins \\
\hline 2:31:44 PM & 76.592987 & 0.169925 & & & & & \\
\hline 2:31:46 PM & 78.399908 & 0.276714 & & & & & \\
\hline 2:31:48 PM & 80.215002 & 0.275468 & & & & & \\
\hline 2:31:49 PM & 81.56233 & 0.371105 & & & & & \\
\hline 2:31:51 PM & 83.349551 & 0.279764 & & & & & \\
\hline 2:31:53 PM & 84.917244 & 0.31894 & & & & & \\
\hline 2:31:54 PM & 86.743135 & 0.273839 & & & & & \\
\hline 2:31:56 PM & 88.395436 & 0.302608 & & & & & \\
\hline 2:31:59 PM & 91.168605 & 0.180299 & & & & & \\
\hline 2:32:01 PM & 93.094715 & 0.259591 & & & & & \\
\hline 2:32:03 PM & 95.1376 & 0.244752 & & & & & \\
\hline 2:32:03 PM & 95.638607 & 0.99799 & & & & & \\
\hline 2:32:05 PM & 97.568702 & 0.259055 & & & & & \\
\hline 2:32:07 PM & 99.08671 & 0.329379 & & & & & \\
\hline 2:32:08 PM & 100.552834 & 0.341035 & & & & & \\
\hline 2:32:11 PM & 102.487402 & 0.258456 & 0.321182 & & & 2104.54 & 2 ends \\
\hline 2:32:12 PM & 104.30157 & 0.275608 & & & & & \\
\hline 2:32:15 PM & 106.458337 & 0.231828 & & & & & \\
\hline
\end{tabular}

Figure 3.3: A sample of data collected by Driver 1 


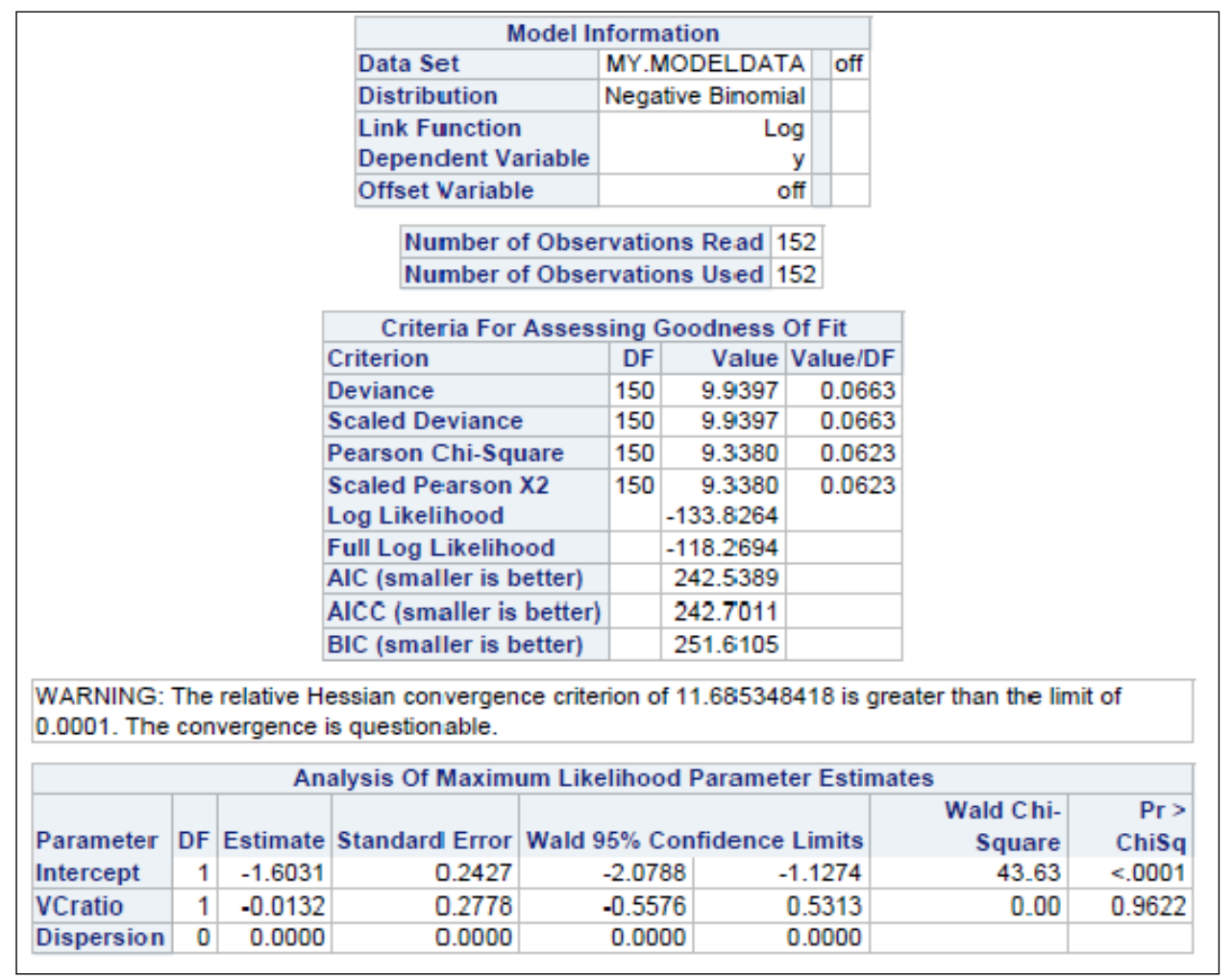

Figure 3.4: SAS results for Volume/Capacity ratio and Visual Demand for the pilot study 
$\mathrm{V} / \mathrm{C}$ ratio is not. The same type of analysis was carried out on SAS with the geometric features of the road. In an attempt to fit a simple linear regression model, the objective is to develop a model that shows evidence of a relationship such as the model (Eq. 3.4):

$$
\begin{array}{r}
\log (\mathrm{VD} 30)=\beta_{0}+\beta_{1} \times L+\beta_{2} \times R+\beta_{3} \times C C+\beta_{4} \times R C+\beta_{5} \times T+\beta_{6} \times \text { Radius+ } \\
\beta_{7} \times I N V R+\beta_{8} \times \text { DefAngl }+\beta 9 \times \operatorname{PrcCrvRad}+\beta_{1} 0 \times R P E I N V+\beta_{1} 1 \times V / C_{\text {ratio }}
\end{array}
$$

Table 3.4: Analysis of Maximum Likelihood Parameter Estimates

\begin{tabular}{|c|c|c|c|c|c|c|c|c|}
\hline & & & & & \multicolumn{2}{|c|}{ Wald 95\% } & Wald & \\
Parameter & & DF & Estimate & Standard Error & \multicolumn{2}{|c|}{ Confidence Limits } & $\mathrm{P}$ & $P_{r}>$ Chi Sq \\
\hline \hline Intercept & & 1 & -1.3175 & 0.7072 & -2.7036 & 0.0686 & 3.47 & 0.0625 \\
Turn & $\mathrm{L}$ & 1 & -0.0486 & 0.0648 & -0.1756 & 0.0783 & 0.56 & 0.4527 \\
Turn & $\mathrm{R}$ & 0 & 0.0000 & 0.0000 & 0.0000 & 0.0000 & & \\
PrcElmnt & $\mathrm{CC}$ & 1 & -0.5647 & 1.6626 & -3.8235 & 2.6940 & 0.12 & 0.7341 \\
PrcElmnt & $\mathrm{RC}$ & 1 & -0.4440 & 1.6514 & -3.6806 & 2.7926 & 0.07 & 0.7880 \\
PrcElmnt & $\mathrm{T}$ & 0 & 0.0000 & 0.0000 & 0.0000 & 0.0000 & & \\
Radius & & 1 & 0.0005 & 0.0004 & -0.0003 & 0.0012 & 1.43 & 0.2322 \\
INVR & & 1 & 293.6595 & 251.8835 & -200.023 & 787.3420 & 1.36 & 0.2437 \\
DefAngl & & 1 & -0.0009 & 0.0022 & -0.0053 & 0.0035 & 0.17 & 0.6826 \\
PrcCrvRad & & 1 & 0.0002 & 0.0010 & -0.0017 & 0.0021 & 0.05 & 0.8263 \\
PEINV & & 1 & 242.9359 & 591.2442 & -915.881 & 1401.753 & 0.17 & 0.6812 \\
VC ratio & & 1 & -0.0270 & 0.1449 & -0.3109 & 0.2569 & 0.03 & 0.8519 \\
\hline
\end{tabular}

In an attempts to fit a simple linear regression model, (Equation. 3.5 was developed:

$$
\begin{array}{r}
\log (\mathrm{VD} 30)=\beta_{0}+\beta_{1} \times L+\beta_{2} \times R+\beta_{3} \times C C+\beta_{4} \times R C+\beta_{5} \times T+\beta_{6} \times \text { Radius }+ \\
\beta_{7} \times I N V R+\beta_{8} \times \text { DefAngl }+\beta 9 \times \operatorname{PrcCrvRad}+\beta_{1} 0 \times R P E I N V+\beta_{1} 1 \times V / C_{\text {ratio }}
\end{array}
$$

where Turn $L=$ Left turn, Turn $R=$ Right turn, Radius = Radius, $I N V R=$ Inverse radius, Def $A n g l=$ Deflection angle, PrcCrvRad= Preceding curve radius, $P E I N V=$ Preceding Inverse radius $V C_{\text {ratio }}=$ Volume/Capacity ratio, PrcElmntCC= Preceding element is a compound curve, PrcElmntRC= Preceding element is a reverse curve, PrcElmntT= Preceding element is a tangent

All variables have significance levels greater than 5\% (P). Therefore, based on the data, the regression model cannot be built. A regression model with interaction terms was developed. The analysis was performed between the following different interaction terms: Turn,

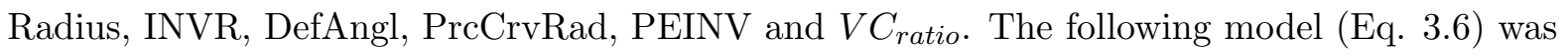


developed:

$$
\log (\mathrm{VD} 30)=\beta_{0}+\beta_{1} \times L \times V / C_{\text {ratio }}+\beta_{2} \times R \times V / C_{\text {ratio }}
$$

After SAS analysis, no significant relationship was found. These conclusions could be made about the pilot study analysis: The regression analysis performed on SAS indicated that the relationship between Visual demand for the first 30 meters, half of the element length and the full element length for both curves and tangents was not significant enough to develop the models proposed. The reasons for this could be the following:

1. There could be outliers in the data set that may offset the regression analysis. The outliers, once removed, may produce a stronger relationship between visual demand and $\mathrm{V} / \mathrm{C}$ ratio.

2. The vehicles that were modeled in the scenarios did not all drive at the same speed, causing braking, which consequently could have affected the collected data for visual demand.

3. The scenarios should be tested without traffic volume in order to compare visual demand with and without traffic volume. The combination of both traffic volume and geometric characteristics of the road could bias the visual demand results as both aspects could affect it.

4. The sample size of participants is too low to make conclusions.

In order to test the adequacy of the sample size for the pilot study, the experiments were carried out for another five participants. Similar results were obtained where no significant results were obtained. A script file, found in Appendix 1, was then created to remove outliers from the data. An Excel file titled "SASvVD30 LOS ACv30m curve LOS AC (2)" was implemented into SAS user library called "VD30curves". By running the coded script in Appendix 1, it was obvious that there were extreme values for visual demand. The extreme values were therefore replaced with the mean of 0.5572 . Then, linear regression was conducted by running the following script:

proc reg data= VD30curvesnew;

model vdf = left pedel peinv vc_ratio;

run;

The overall variability in the dependent variable visual demand is 1.1367 . The variability explained by the 4 independent variables is 0.02789 , which means only $2.45 \%$ of visual demand has been explained by the model. This suggests that there exists a very weak correlation between visual demand and the 4 independent variables. The same analysis for the interaction terms is run by using the following script 2.2 in Appendix 3. Running the program, SAS produces the following results. 


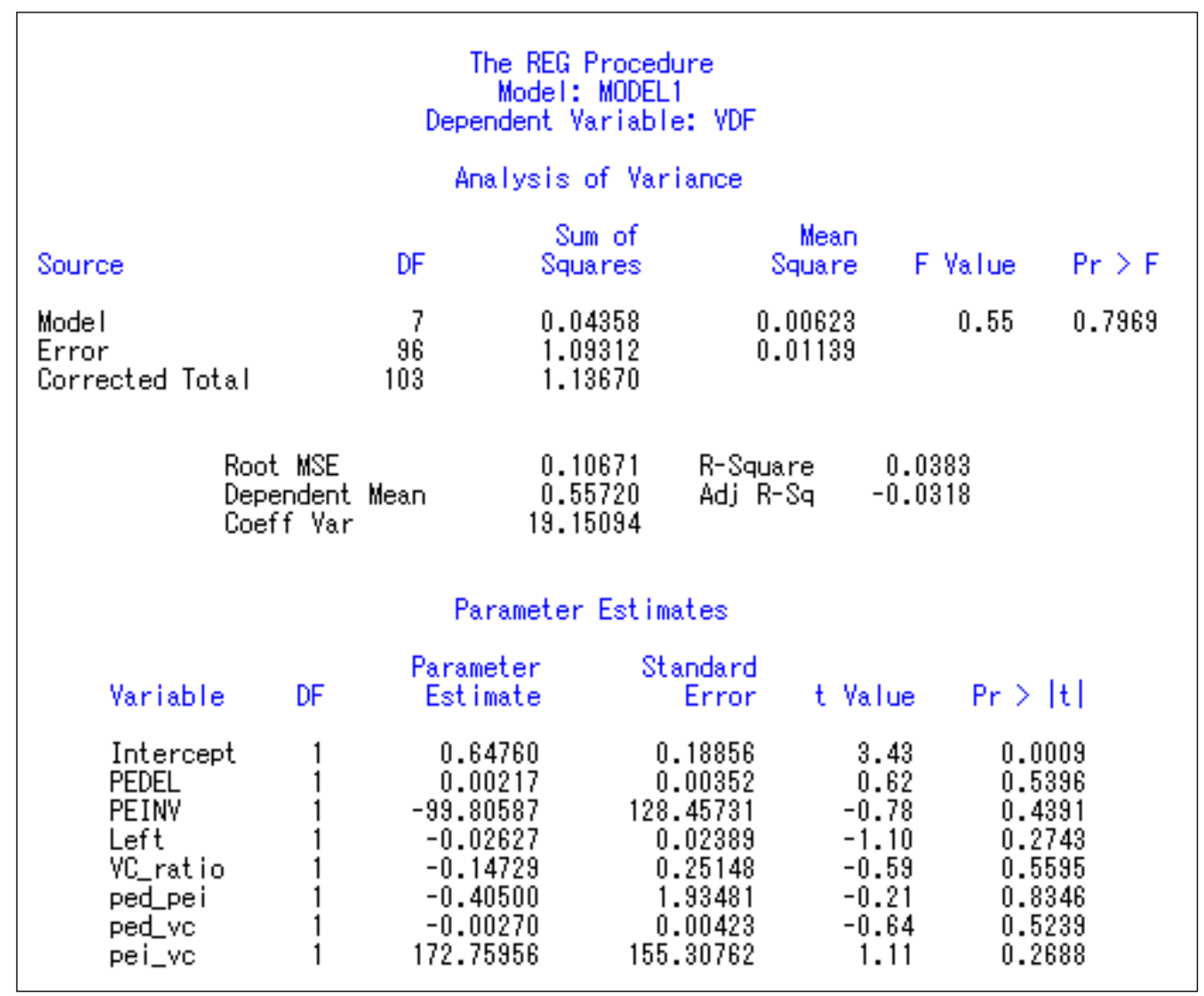

Figure 3.5: SAS analysis for data collected for VD30 for pilot study of 10 participants

From Figure 3.5, the R-squared value is only 3.83\%. This suggests that there is a very weak correlation between visual demand and the seven independent variables. Hence, from this data, it can be concluded that visual demand does not have a relationship with other variables. In order to reconfirm the conclusion, a scatter plot of visual demand against one of the variables (preceding element radius $=$ ped_pei) was plotted as seen in Figure 3.6 ; other variables had lower variability:

Observing Figure 3.6, a plot of visual demand versus a geometric characteristic of the road, it can be concluded that no pattern can be found. Since no relationship was found from excluding outliers and by increasing the number of participants, data was recollected for the same participants, however, the participants were asked to run the experiments for the same scenario, but this time without any traffic volume. A small sample size of five participant's data 


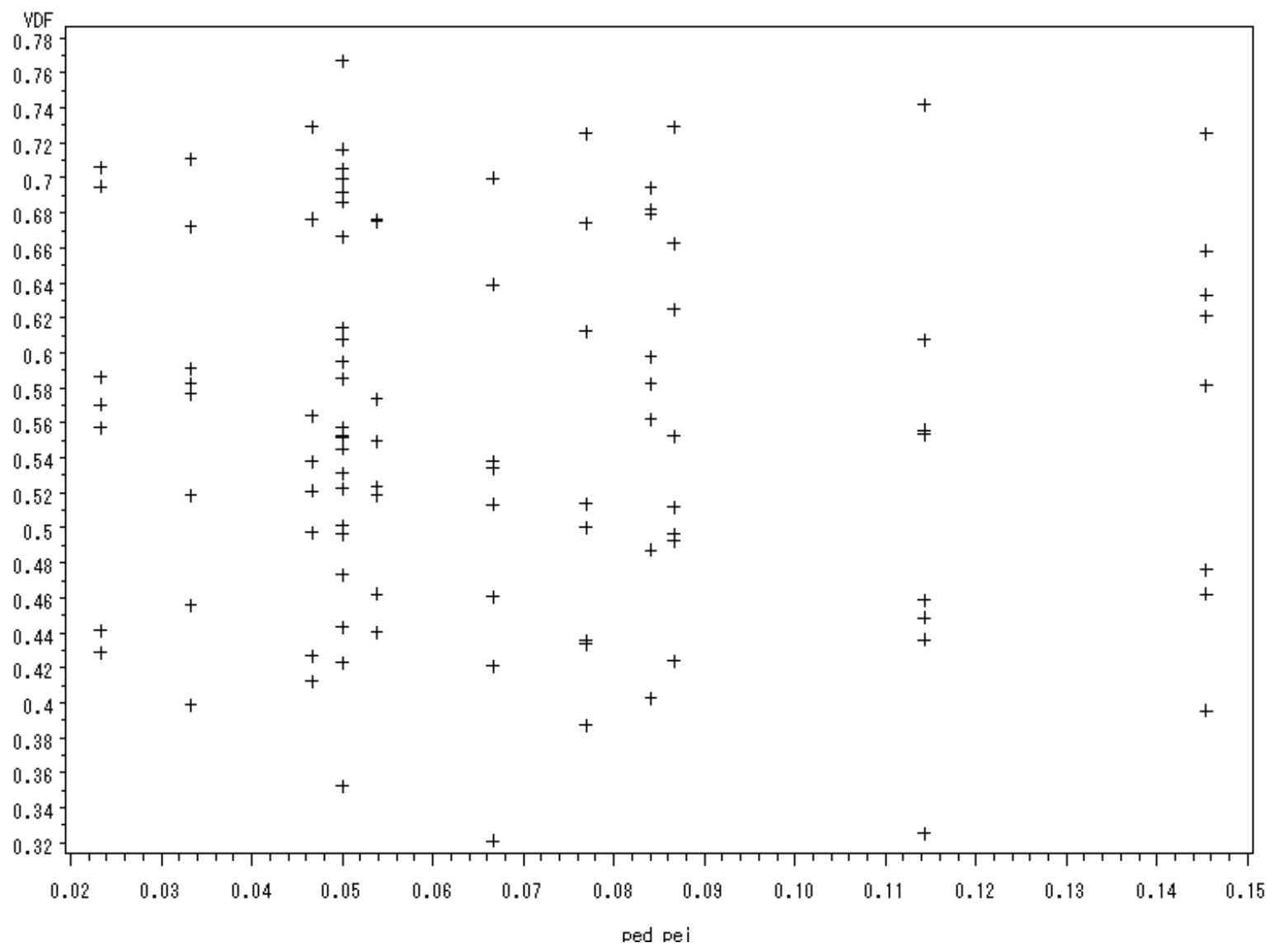

Figure 3.6: Plot visual demand versus preceding element radius (ped_pei)

was collected and analyzed. The same procedure was repeated, without taking into consideration the outliers. The results proved to be promising, therefore, further data was collected, and the same participants from previous data collection were contacted and asked to run the new scenario.

The following output file was obtained from SAS for V/C ratio for curves (Fig. 3.7). Observing the $\mathrm{p}$-values for the intercept and $\mathrm{V} / \mathrm{C}$ ratio variable, it can be noted that they are well below 5\%. This indicated a strong relationship between $\mathrm{V} / \mathrm{C}$ ratio and Visual Demand. The same procedure was performed for the remaining elements lengths (VDH and VDF). 


\section{Fitting Model between curve VD30 and V/C ratio}

\section{The GENMOD Procedure}

\begin{tabular}{|l|r|l|}
\hline \multicolumn{3}{|c|}{ Model Information } \\
\hline Data Set & ROAD.CURVE_VD30 & \\
\hline Distribution & Normal & \\
\hline Link Function & Log & \\
\hline Dependent Variable & VD30 & VD30 \\
\hline
\end{tabular}

\begin{tabular}{|l|l|}
\hline Number of Observations Read & 684 \\
\hline
\end{tabular}

\begin{tabular}{|l|l|}
\hline Number of Observations Used & 684 \\
\hline
\end{tabular}

\begin{tabular}{|l|r|r|r|}
\hline \multicolumn{4}{|c|}{ Criteria For Assessing Goodness Of Fit } \\
\hline Criterion & DF & Value & Value/DF \\
\hline Deviance & 682 & 24.8798 & 0.0365 \\
\hline Scaled Deviance & 682 & 684.0001 & 1.0029 \\
\hline Pearson Chi-Square & 682 & 24.8798 & 0.0365 \\
\hline Scaled Pearson X2 & 682 & 684.0001 & 1.0029 \\
\hline Log Likelihood & & 162.8004 & \\
\hline Full Log Likelihood & & 162.8004 & \\
\hline AIC (smaller is better) & & -319.6008 & \\
\hline AICC (smaller is better) & & -319.5655 & \\
\hline BIC (smaller is better) & & -306.0169 & \\
\hline
\end{tabular}

Algorithm converged.

\begin{tabular}{|l|r|r|r|r|r|r|r|}
\hline & & Analysis Of Maximum Likelihood Parameter Estimates \\
\hline Parameter & DF & Estimate & $\begin{array}{r}\text { Standard } \\
\text { Error }\end{array}$ & $\begin{array}{r}\text { Wald 95\% } \\
\text { Confidence } \\
\text { Limits }\end{array}$ & $\begin{array}{r}\text { Wald } \\
\text { Chi-Square }\end{array}$ & Pr > ChiSq \\
\hline Intercept & 1 & -1.0680 & 0.0322 & -1.1310 & -1.0050 & 1103.47 & $<.0001$ \\
\hline VC_ratio & 1 & 0.1842 & 0.0704 & 0.0463 & 0.3222 & 6.85 & 0.0089 \\
\hline Scale & 1 & 0.1907 & 0.0052 & 0.1809 & 0.2011 & & \\
\hline
\end{tabular}

Figure 3.7: SAS output for VD30 and Volume/Capacity ratio 


\subsection{Assumptions}

The experiments were initially conducted for low and moderate volume levels, however, after collecting data from the driving simulator along with data from TotaLcontrol 2 software for visual demand, it was noted that no relationship was found. Five additional participants were asked to participate in the study, and their data was added onto to the original data collected, and SAS statistical analysis was once again performed. Once again, no relationship was found between $\mathrm{V} / \mathrm{C}$ ratio and visual demand. Outliers from the data were then replaced using a script file on SAS. Finally, a relationship was discovered when a "no volume" scenario was introduced. Data was collected from all three volume levels, and SAS analysis was run.

Since no relationship was found from excluding outliers and by increasing the number of participants, data was recollected for the same participants, however, the participants were asked to run the experiments for the same scenario, but this time without any traffic volume. A small sample size of five participant's data was collected and analyzed. The same procedure as previously discribed was followed, without taking into consideration the outliers. The results proved to be promising, therefore, further data was collected, and the same participants from previous data collection were contacted and asked to run the new scenario.A relationship was discovered when a "no volume" scenario was introduced. Data was collected from all three levels of traffic volume (no volume, low volume, and moderate volume). 


\section{Chapter 4}

\section{Experimental Design}

\subsection{Driving Simulator}

The driving simulator used to conduct experiments for this research is located in the Road Safety Laboratory of the Civil Engineering Department at Ryerson University, Toronto. The driving simulator consists of the following parts:

- Pontiac car integrated with the computer simulator software

- STISIM driving simulator computer software

- Four computers: three of which control the computer graphics, and one that controls the program software

- Control box for the visual occlusion spectacles

- Laptop computer with ToTaLcontrol 2 software installed (records open/closed state of the glasses over time)

- Splitter that simultaneously signals the spectacles and the horn input of the simulator

- A visual occlusion pedal to the left of the brake pedal (where a clutch would normally be seen)

- Three projectors displaying a view of the road on a white screen (controlled by simulator and dynamics computers)

The driving simulator used for this research study is the STISIM Model 300 developed by Systems Technology Inc. (ST Inc.). The simulator used for experiments allows the driver to control his or her speed and steering. The scenarios that the participants drive have been 
designed through simple text commands. The three projectors projecting the roadway from afar allow the driver to get a realistic driving experience, hence allowing valid collection of data. Figures 4.1 displays a photo taken during one of the experiments, where the participant is wearing the visual occlusion glasses.

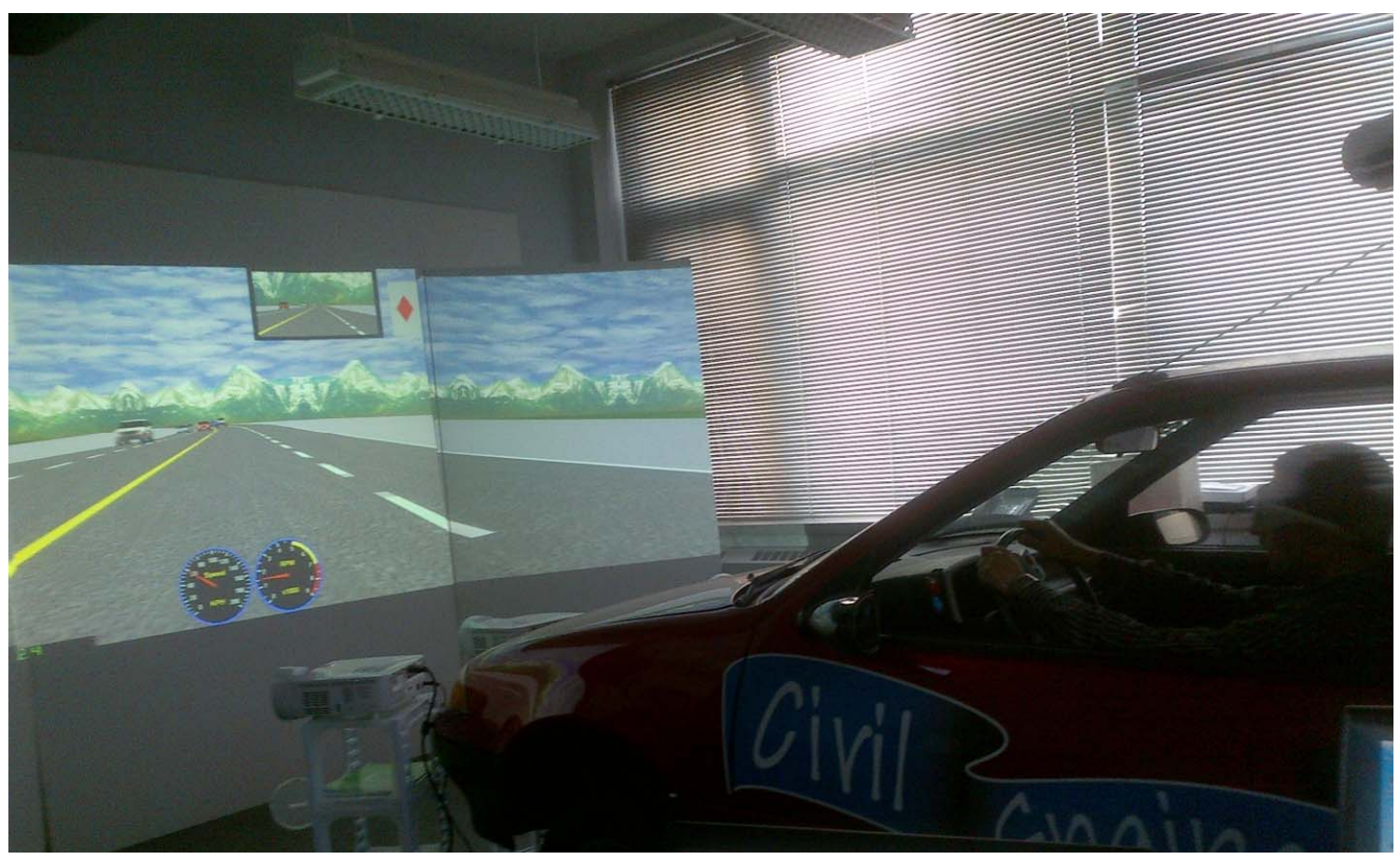

Figure 4.1: Driving Simulator

\subsection{Visual Occlusion Glasses}

The visual occlusion glasses used in this study for acquiring data about visual demand while driving are operated with a software called ToTaLcontrol 2 software, developed by Translucent Technologies at the University of Toronto. The open/closed state of the glasses may be controlled by a predetermined cycle or through the pulse of the pedal that was previously installed in the vehicle. For this research, however, the software was programmed in such a way to allow a glimpse of 0.5 seconds of the road when a pulse is signaled (through the driver's request) with a minimum "pause" of 0.1 second between each pulse in the case that the driver requests a consecutive glimpse. Figure 4.2 displays the Input table used for the experiments. The visual occlusion spectacles apparatus includes the following components: 
- a pair of glasses that may change from opaque to clear view

- a control box with an on/off switch

- a laptop with ToTaLcontrol 2 software installed that records data received from the spectacles

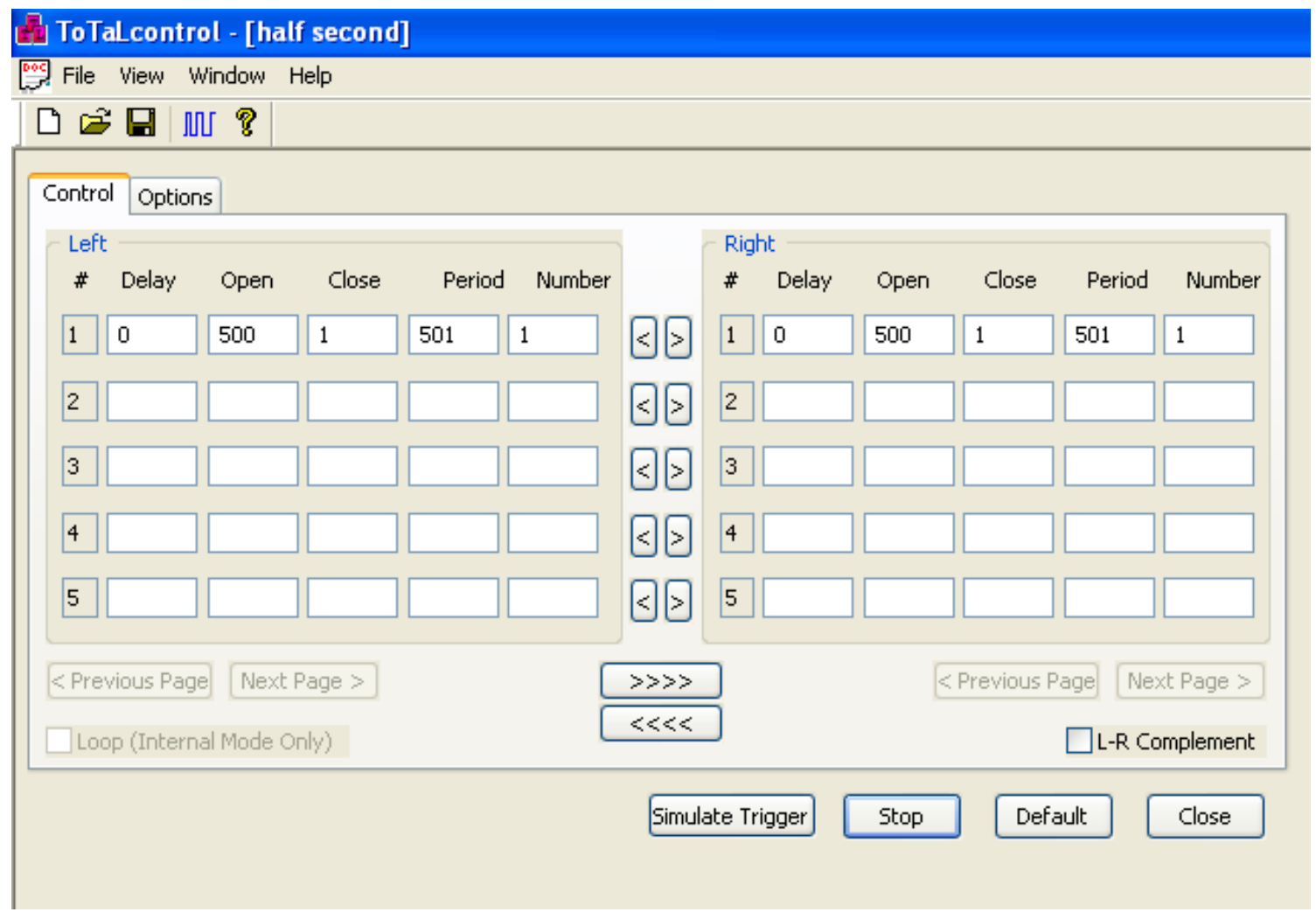

Figure 4.2: Input table for 0.5 seconds using ToTaLcontrol software

As mentioned, the software gives two options of signal input for the user, namely the External Sync and the Internal Sync. For this research, External Sync was used in order to allow the participants to control the number of times they required a view of the road, hence calculating visual demand.

\subsection{Procedure}

For this research, experiments were designed for multilane highways, where three road alignments were designed by the AASHTO and TAC standards for a design speed of $110 \mathrm{~km} / \mathrm{h}$. The three alignments comprised of simple and complex curves. The geometric details of all three alignments 
may be found in Appendix A. The following describes the composition of each alignment, where each curve was preceded with and followed by a tangent :

- The first alignment was composed of seven simple curves

- The second alignment comprised of two reverse curves and one compound curve.

- The third alignment entailed two compound curves and one reverse curve

The length of each element (curve or tangent) was fixed in such a way that drivers would have sufficient time to react to each element as they encounter them. The geometric features of the road were then transferred onto SDL on STISIM software, where event files were created for each alignment. These alignments were at first defined in separate files, but due to time restrictions for experiments and different traffic volumes added onto the scenarios, the alignments were compressed into one file. This means that alignments 1,2 , and 3 were combined into one lengthy alignment. Once the alignments were combined, they were tested to determine their precision and accuracy with respect to the length of the elements and the radii/turning direction of the curves. The following procedure/considerations were taken during the experiments:

1. The roadway included a multi-lane highway, where the geometric characteristics of the road included tangents and curves only (traffic intersections, road signs, and traffic lights were not considered).

2. In the case that a participant ran off the road or drove in the opposite lane, the simulation run was halted and the driver was asked to start the experiment again.

3. A total of twenty subjects drove the alignments. Each participant had a valid G license and at least three years of experience driving on the highway.

4. The subjects were given instructions in terms of the use of the driving simulator. The drivers were shown where the pedal controlling the visual occlusion glasses was located and was instructed to press the pedal only when the view of the road was needed.

5. Drivers were given as much time as required to train using the driving simulator. This includes a run test without the visual occlusion glasses, followed by a run test with the visual occlusion glasses. Only until the drivers felt comfortable enough to begin the experiments were they asked to begin.

6. Drivers were advised to terminate their participation when they experience nausea or fatigue from driving the scenarios.

\subsection{Design of Traffic Variables and Traffic Volume}

According to the Ministry of Transportation's Geometric Design Manual, the maximum rate of superelevation depends on the following factors: 
- climate conditions

- terrain

- type of development (rural or urban))

- maintenance

As a general policy, the maximum superelevation rate for all roadways is $0.06 \mathrm{~m} / \mathrm{m}$. The maximum superelevation rate for urban freeway interchange ramps is $0.08 \mathrm{~m} / \mathrm{m}$ in the case where high maintenance is necessary (and little ice or snow accumulation is expected). A maximum superelevation rate of $0.06 \mathrm{~m} / \mathrm{m}$ will be used since that is the norm for all roadways and the experiment will not include interchange ramps. Therefore, for the design speed of 110 $\mathrm{km} / \mathrm{h}$, there will be a minimum radius of $525 \mathrm{~m}$ for all of the alignments. Point of curvature (PC) represents the start distance of a curve, whereas Point of Tangency (PT) represents the end distance of a curve. The following Eq. 4.1 was used to calculate the length of each curve.

$$
\text { Length of curve }=\frac{\theta \pi}{180} \times R
$$

where $\theta=$ Deflection angle and $R=$ Radius of curve. The point of curvature is only the beginning of the curve, and the point of tangency is the end of the curve. The table in Appendix A displays all results from calculations.

\subsection{Level of Service Calculation}

In order to determine the traffic volume requirements for the levels of service in this research, the Highway Capacity Manural (HCM 2010) was used as a design guide. The following steps were followed:

Step 1: Determine the level of service needed and base conditions:

$\mathrm{LOS}=\mathrm{A}$

Methodology:

1. Input:

- Geometric data

- Free-Flow Speed FFS or Base Free-Flow Speed BFFS

- Volume

2. Adjustment on volume: PHF, \# lanes, driver population, HV

3. Compute flow rate

4. Determine speed 
5. Determine LOS

6. Geometric data:

- Lane width $=12 \mathrm{ft}$

- Clearance at roadside: $4 \mathrm{ft}$

- Number of lanes $=2$

- PHF: $1900 \mathrm{veh} / \mathrm{h}$

- Assuming traffic composition: 0\% trucks and 0\% RVS

- No access points

- Level terrain

- FFS: $55 \mathrm{mi} / \mathrm{h}$

The table 4.1 was taken from the HCM (2010) in order to obtain an estimation of traffic volume for levels of service A and $\mathrm{C}$ for the research study. Table 4.1 describes Level of Service (LOS) classification.

Step 2: From the volume level, it can be determined that the speed and volume were based on the initial conditions:

- Demand flow rate=density $\times$ speed

- Speed=Demand flow rate/Density

- Demand flow rate $=\mathrm{V} / \mathrm{PHF} \times \mathrm{N} \times \mathrm{fHV} \times \mathrm{fP}$

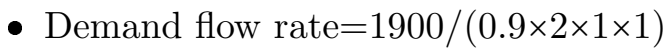

- Demand flow rate $=1900 / 1.8$

- Demand flow rate $=1056 \mathrm{pc} / \mathrm{h}$

- Speed $=1056 /(8.5 \times 2)=62.12 \mathrm{mi} / \mathrm{h}$

- Demand volume $=$ Demand flow $\operatorname{rate} \times\left(\mathrm{PHF} \times \mathrm{N} \times \mathrm{fHV} \times f_{p}\right)$

- Demand volume $=(8.5 \times 55) \times(0.9 \times 2 \times 1 \times 1)$

- Demand volume=841.5 veh $/ \mathrm{h}$

Note: Heavy vehicles such as trucks, buses, and RVs were not considered in this study due to the driving simulator's restrictive programming features.

\subsection{Determining the Number of Vehicles}

In order to determine the traffic volume requirements for the levels of service in this research, the Highway Capacity Manual (HCM, 2010) was used as a design guide. For each volume level (using level of service chart), the total number of vehicles is calculated by following the steps below:

\section{Methodology:}


Table 4.1: Level of Service (LOS) Classification Table (HCM, 2010)

\begin{tabular}{|c|c|c|}
\hline LOS & ATS (mi/h) & Density (pc/mi/ln) \\
\hline \hline A & All & $>0-11$ \\
\hline B & All & $>11-18$ \\
\hline C & All & $>18-26$ \\
\hline D & All & $>26-35$ \\
\hline E & 60 & $35-40$ \\
& 55 & $>35-41$ \\
& 50 & $>35-43$ \\
& 50 & $>35-43$ \\
& 45 & $>35-45$ \\
\hline \multirow{2}{*}{ Demand exceeds } & 60 & $>40$ \\
Capacity & 55 & $>41$ \\
& 50 & $>43$ \\
& 45 & $>45$ \\
\hline
\end{tabular}

1. Input:

- Speed for specified LOS

- Demand volume for specified LOS

- Length of specified alignment

2. Determine total time required to complete the alignment

3. Determine the number of vehicles required by multiplying demand volume by the total time required to complete the alignment

The following speeds and demand volumes were previously calculated for level of services A, C and E. Level of Service (LOS) A:

- Speed $=62.12 \mathrm{mi} / \mathrm{h}$

- Demand volume=841.5 veh $/ \mathrm{h}$

Note: Once the number of vehicles are determined per volume level for each alignment, the vehicles can be evenly spread out to the total length.

Table 4.2 describes the geometric design characteristics for alignment 1, which is comprised of seven simple curves. The total length of the alignment was calculated to be 9608.07 $\mathrm{m}$. The steps as previously described where followed to calculate low volume level:

1. Input:

- Speed $=62.12 \mathrm{mi} / \mathrm{h}$ or speed $=99 \mathrm{~km} / \mathrm{h}$

- Demand volume $=841.5 \mathrm{veh} / \mathrm{h}$

- Total length $=9608.07 \mathrm{~m}$ or $9.608 .07 \mathrm{~km}$ 
2. The total time required to complete the alignment given the speed is determined by multiplying the length of alignment by the speed.

3. Total time $=$ speed $\times$ length $=99 \mathrm{~km} / \mathrm{h} \times 4.54292 \mathrm{~km}=0.045423204 \mathrm{~h}$

4. The number of vehicles required is determined by multiplying demand volume by the total time required to complete the alignment

Number of vehicles $=$ total time $\times$ demand volume $=0.045423204 \mathrm{~h} \times 841.5 \mathrm{veh} / \mathrm{h}=38.22362628$ veh

Table 4.2: Geometry of Horizontal Curves for Alignment 1

\begin{tabular}{|c|c|c|c|c|c|c|c|c|}
\hline Element & $\begin{array}{c}\text { Element } \\
\text { Length }\end{array}$ & $\begin{array}{c}\text { Turning } \\
\text { Direction } \\
\text { of Curve }\end{array}$ & $\begin{array}{c}\text { Radius of } \\
\text { Curve(m) }\end{array}$ & $\begin{array}{c}1 / \\
\text { Radius }\end{array}$ & $\begin{array}{c}\text { PC } \\
(\mathrm{m})\end{array}$ & $\begin{array}{c}\text { PT } \\
(\mathrm{m})\end{array}$ & $\begin{array}{c}\text { Deflection } \\
\text { angle }\end{array}$ & $\begin{array}{c}\text { Lane } \\
\text { width }\end{array}$ \\
\hline \hline Tangent & 400 & & & & & & & 3.7 \\
\hline Curve (1) & 549.78 & $\mathrm{R}$ & 525 & 0.001905 & 400 & 949.78 & 60 & 3.7 \\
\hline Tangent & 500 & & & & & & & 3.7 \\
\hline Curve (2) & 654.76 & $\mathrm{~L}$ & 750 & 0.001333 & 1449.78 & 2104.54 & 50 & 3.7 \\
\hline Tangent & 300 & & & & & & & 3.7 \\
\hline Curve (3) & 1475.4 & $\mathrm{~L}$ & 1300 & 0.000769 & 2404.54 & 3879.94 & 65 & 3.7 \\
\hline Tangent & 700 & & & & & & & 3.7 \\
\hline Curve (4) & 873.02 & $\mathrm{R}$ & 1000 & 0.001 & 4579.94 & 5452.96 & 50 & 3.7 \\
\hline Tangent & 400 & & & & & & & 3.7 \\
\hline Curve (5) & 420.19 & $\mathrm{R}$ & 535 & 0.001869 & 5852.96 & 6273.15 & 45 & 3.7 \\
\hline Tangent & 750 & & & & & & & 3.7 \\
\hline Curve (6) & 768.25 & $\mathrm{R}$ & 550 & 0.001818 & 7023.15 & 7791.4 & 80 & 3.7 \\
\hline Tangent & 500 & & & & & & & 3.7 \\
\hline Curve (7) & 916.67 & $\mathrm{~L}$ & 1500 & 0.000667 & 8291.4 & 9208.07 & 35 & 3.7 \\
\hline Tangent & 400 & & & & & & & 3.7 \\
\hline
\end{tabular}

${ }^{*} \mathrm{PC}=$ Point of curvature; $\mathrm{PT}=$ Point of tangency

Therefore, the approximate total number of vehicles needed for thelow volume level is 38 vehicles. However, this calculation does not consider the headway distribution, which will be discussed in the next section.

\subsection{Time Headway}

As previously discussed in Chapter 2, Traffic Performance on Major Arterials (TPMA) model is suitable for this research and will be therefore used. In conventional traffic simulation models, theaverage time headway between arriving vehicles is calculated as the inverse of the traffic flow. The following exponential time headway distribution using TPMA model is shown in (Eq. 4.2) 
(Olstam, 2005):

$$
f(x)=0.1 \times p_{1}^{2} \times \ln \left(\frac{1+e^{\left(x-p_{2}\right)}}{1+e^{-10 p_{2}}}\right) \times \frac{\left(1+e^{-10 p_{2}}\right)^{0.1 p_{1}}}{\left(1+e^{10\left(x-p_{2}\right)}\right)^{0.1 p_{1}+1}} \times e^{10\left(x-p_{2}\right)}
$$

where $x$ represents time headway, and $p_{1}$ and $p_{2}$ are parameters that depend on demand volume $Q$ according to the following equations for right lane (Eq. 4.3) and left lane (Eq. 4.4):

$$
\begin{aligned}
& {\left[\begin{array}{l}
p_{1} \\
p_{1}
\end{array}\right]=\left[\begin{array}{c}
-7.991 \cdot 10^{-3}+7.737 \cdot 10^{-4} Q-3.099 \cdot 10^{-7} Q^{2}+1.089 \cdot 10^{-10} Q^{3} \\
-2.807 \cdot 10^{-1}+6.485 \cdot 10^{-3} Q-9.794 \cdot 10^{-6} Q^{2}+3.479 \cdot 10^{-9} Q^{3}
\end{array}\right]} \\
& {\left[\begin{array}{l}
p_{1} \\
p_{1}
\end{array}\right]=\left[\begin{array}{c}
-7.628 \cdot 10^{-3}+9.527 \cdot 10^{-4} Q-1.500 \cdot 10^{-7} Q^{2}+3.991 \cdot 10^{-11} Q^{3} \\
3.890-5.273 \cdot 10^{-3} Q-2.885 \cdot 10^{-6} Q^{2}+5.432 \cdot 10^{-10} Q^{3}
\end{array}\right]}
\end{aligned}
$$

For demand volume greater than 1800veh/h, the following equation must be used to adjust the demand flow:

$$
f_{\text {stretch }}(x)=\frac{f\left(\frac{x}{\operatorname{corr}(Q)}\right)}{\operatorname{corr}(Q)}
$$

However, to use the time headway distribution functions mentioned, a model for estimating how the traffic flow splits is needed. The following equation 4.6 will be used:

$$
Q_{\text {right }}=k \times\left(1-e^{-l \cdot Q}\right)
$$

where $k$ and $l$ (constants) are calculated from equations 4.7 and 4.8 .

$$
\begin{gathered}
k=2600 \times(1-0.34 \times \alpha-0.90 \times \beta) \\
l=\frac{3.1+4 \times(\alpha+\beta)}{10000}
\end{gathered}
$$


The parameter $\alpha$ represents the proportion of trucks and buses, and the parameter $\beta$ represents the proportion of trucks with trailer. The left lane is calculated by subtracting the total lane flow from the right lane flow. This model could be used for the experiments since all of the initial conditions were met: demand flow and proportion of trucks and buses. $k$ and $l$ are constants that determine traffic flow, and the values alpha and beta represent the fraction of buses and trucks, respectively. When generating numbers for the graph, a value of 0 was substituted for both alpha and beta. In this way,Therefore, traffic flow is not adjusted, even with the absence of trucks and buses. For example, using equation 4.9 .

$$
k=2400(1-0.03655(\alpha)-0.9675(\beta))
$$

By substituting $\alpha$ and $\beta$ with $0, \mathrm{k}=2400 \times(1)=2400$. Equations 4.8 and 4.9 for $k$ and $l$ are actually quite similar equations to the equations used in the Highway Capacity Manual (that were used to determine traffic volumes for the experiments). When applying this distribution, Figure 4.3 was obtained from a previous study (Olstam, 2005):

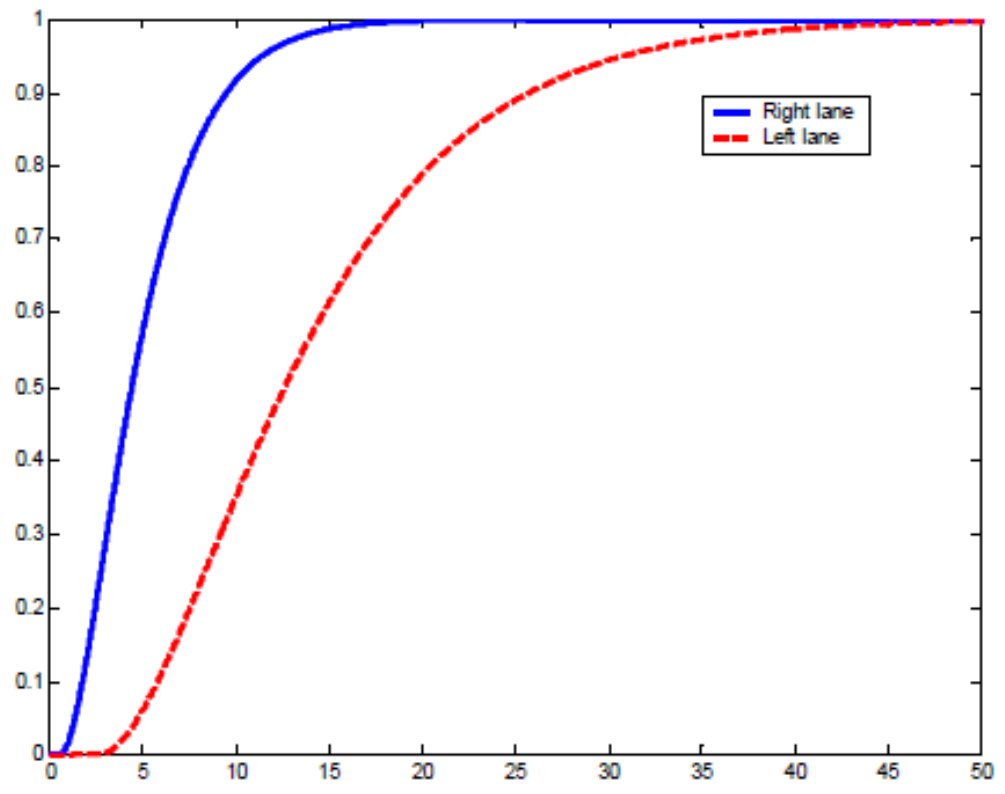

Figure 4.3: Headway time distribution from experiment

The following is an example of data calculated for a specific volume level for alignment 2 of the experiments:

- Length of alignment $=4542.92 \mathrm{~m}$

- Speed = $62.12 \mathrm{mi} / \mathrm{h}$ 
- Demand volume $=841.5 \mathrm{veh} / \mathrm{h}$

- Number of vehicles $=38$ vehicles

The data shown in table 4.3 was used to generate low traffic volume Level on alignment 2 based on the following-defined geometric characteristics:

Table 4.3: Geometry of Horizontal Curves for Alignment 2

\begin{tabular}{|c|c|c|c|c|c|c|c|c|}
\hline Element & $\begin{array}{c}\text { Element } \\
\text { Length }\end{array}$ & $\begin{array}{c}\text { Turning } \\
\text { Direction } \\
\text { of Curve }\end{array}$ & $\begin{array}{c}\text { Radius of } \\
\text { Curve(m) }\end{array}$ & $\begin{array}{c}1 / \\
\text { Radius }\end{array}$ & $\begin{array}{c}\text { PC } \\
(\mathrm{m})\end{array}$ & $\begin{array}{c}\text { PT } \\
(\mathrm{m})\end{array}$ & $\begin{array}{c}\text { Deflection } \\
\text { angle }\end{array}$ & $\begin{array}{c}\text { Lane } \\
\text { width }\end{array}$ \\
\hline \hline Tangent & 200 & & & & & & & 3.7 \\
\hline Curve (1) & 320.7 & $\mathrm{~L}$ & 525 & 0.00227 & 200 & 468.89 & 35 & 3.7 \\
\hline Curve (2) & 737.7 & $\mathrm{R}$ & 650 & 0.00154 & 468.89 & 1206.59 & 65 & 3.7 \\
\hline Tangent & 400 & & & & & & & 3.7 \\
\hline Curve (3) & 353.57 & $\mathrm{R}$ & 525 & 0.00222 & 1606.59 & 1960.16 & 45 & 3.7 \\
\hline Curve (4) & 654.76 & $\mathrm{~L}$ & 750 & 0.00133 & 1960.16 & 2614.92 & 50 & 3.7 \\
\hline Tangent & 450 & & & & & & & 3.7 \\
\hline Curve (5) & 576.19 & $\mathrm{R}$ & 1100 & 0.00091 & $3064 . .92$ & 3641.11 & 30 & 3.7 \\
\hline Curve (6) & 550 & $\mathrm{R}$ & 900 & 0.00111 & 3641.11 & 4191.11 & 35 & 3.7 \\
\hline Tangent & 300 & & & & & & & 3.7 \\
\hline
\end{tabular}

*PC $=$ Point of curvature; $\mathrm{PT}=$ Point of tangency

In order to generate the time-headway values, the number of vehicles needed, and each vehicle's respective speed, a MATLAB code previously scripted was used to calculate the number of cars needed as well as their headway distribution (refer to Appendix 1 for entire MATLAB code). The following code in MATLAB will be discussed:

[time,lane,kind, $\mathrm{v}]=\operatorname{generate}\left(\mathrm{Q}\right.$, fraction, $\mathrm{v}_{-}$limit, Maxtime $)$

where the values to the left of the equation sign represent the input values, whereas the values to the right represent the output values and are described as the following:

\section{Input values:}

- $\mathrm{Q}=$ demand volume

- Fraction= fraction of buses and trucks

- V_limit =speed

- Maxtime=the duration of the simulation

These input values are required data that must be provided in order to run the code and obtain the following output variables:

\section{Output values:}


- Time=headway time

- Lane=left or right lane

- Kind=car or truck (for this research, only cars are considered)

- $\mathrm{V}=$ speed for each respective vehicle

Table 4.4: Computed headway for vehicles

\begin{tabular}{|c|c|c|c|c|}
\hline Headway (s) & Speed & Distance & Spacing & Absolute Spacing \\
\hline \hline 3.09 & 105.6673 & 90.69778 & 90.69778 & 90.69778288 \\
12.11 & 116.5195 & 391.9588 & 301.261 & 301.2610122 \\
12.55 & 99.3815 & 346.4549 & -45.5039 & 45.50385649 \\
14.01 & 99.61078 & 387.652 & 41.19702 & 41.19702305 \\
17.28 & 105.9399 & 508.5113 & 120.8593 & 120.8593479 \\
21.62 & 108.2031 & 649.82 & 141.3087 & 141.3087159 \\
22.89 & 113.9293 & 724.4007 & 74.58069 & 74.58069475 \\
29.98 & 96.8449 & 806.5028 & 82.10207 & 82.10206711 \\
30.91 & 94.7139 & 813.2241 & 6.721281 & 6.72128099 \\
33.89 & 97.80072 & 920.6851 & 107.4611 & 107.4610533 \\
35.24 & 86.04746 & 842.309 & -78.3761 & 78.3760816 \\
40.06 & 101.1102 & 1125.132 & 282.823 & 282.8230392 \\
46.22 & 103.988 & 1335.091 & 209.9585 & 209.9584725 \\
49.21 & 99.41816 & 1358.991 & 23.90044 & 23.90044369 \\
51.57 & 97.01811 & 1389.784 & 30.7934 & 30.79339718 \\
56.1 & 115.8361 & 1805.112 & 415.3274 & 415.3274152 \\
57.25 & 99.5296 & 1582.797 & -222.315 & 222.31474 \\
69.99 & 103.1622 & 2005.645 & 422.8477 & 422.8477467 \\
76.31 & 121.9916 & 2585.884 & 580.239 & 580.2389761 \\
78.22 & 107.4991 & 2335.716 & -250.168 & 250.1677972 \\
82.7 & 107.838 & 2477.279 & 141.5626 & 141.5625629 \\
87.18 & 119.1074 & 2884.384 & 407.1053 & 407.1052913 \\
87.58 & 91.5222 & 2226.532 & -657.852 & 657.8522016 \\
94.84 & 95.09564 & 2505.242 & 278.7101 & 278.7101095 \\
101.46 & 100.6099 & 2835.521 & 330.2792 & 330.2792461 \\
107.05 & 102.0085 & 3033.337 & 197.8156 & 197.8155746 \\
107.98 & 99.42951 & 2982.333 & -51.0038 & 51.00378086 \\
114.13 & 130.6089 & 4140.666 & 1158.333 & 1158.332797 \\
119.96 & 131.8622 & 4393.943 & 253.2774 & 253.2773532 \\
120.81 & 121.6338 & 4081.826 & -312.117 & 312.1168617 \\
123.91 & 113.1185 & 3893.477 & -188.349 & 188.3489544 \\
130.28 & 109.0107 & 3944.976 & 51.49929 & 51.49928861 \\
138.21 & 125.0479 & 4800.797 & 855.8205 & 855.8205434 \\
154.92 & 92.73493 & 3990.693 & -810.104 & 810.1039255 \\
156.78 & 91.23554 & 3973.308 & -17.3853 & 17.38529171 \\
158.37 & 91.84731 & 4040.516 & 67.20865 & 67.20865114 \\
160.75 & 127.9736 & 5714.379 & 1673.862 & 1673.862106 \\
162.35 & 99.76847 & 4499.281 & -1215.1 & 1215.097527 \\
165.24 & 90.54969 & 4156.231 & -343.05 & 343.0503468 \\
\hline & & & & \\
\hline
\end{tabular}

Table 4.4 was generated via the MATLAB. The first column in Table 4.3 represents data extracted for headways for all 38 vehicles by using the exponential distribution function 
previously discussed (TPMA) in the MATLAB code. The second column represents the speed corresponding to each vehicle, respectively. The third column is time-headway converted into distance-headway by using the equation: speed = distance/time. Note that this distance is actually the cumulative distance. The fourth column represents the spacing distance between each vehicle (this is calculated by subtracting the headway distance between each vehicle in the corresponding lane). Lastly, the final column represents the absolute spacing distance since there were some negative values for spacing distance. These values are appropriate since the average spacing distance was found to be $321 \mathrm{~m}$. The average spacing distance must be at least $167 \mathrm{~m}$ (minimum spacing value at maximum density). From this MATLAB code, values for number of vehicles and traffic flow are obtained and confirmed with the values obtained using the Highway capacity Manual (HCM). Zooming into the command window, the obtained data values in Figure 4.4 of the MATLAB code output values are shown. These obtained values are extremely comparable to the data obtained from the following calculations:

- Length $=4542.92 \mathrm{~m}$

- Speed $=62.12 \mathrm{mi} / \mathrm{h}=100.0132 \mathrm{~km} / \mathrm{h}$

- Demand volume $=841.5 \mathrm{veh} / \mathrm{h}$

- Number of vehicles $=38$ vehicles

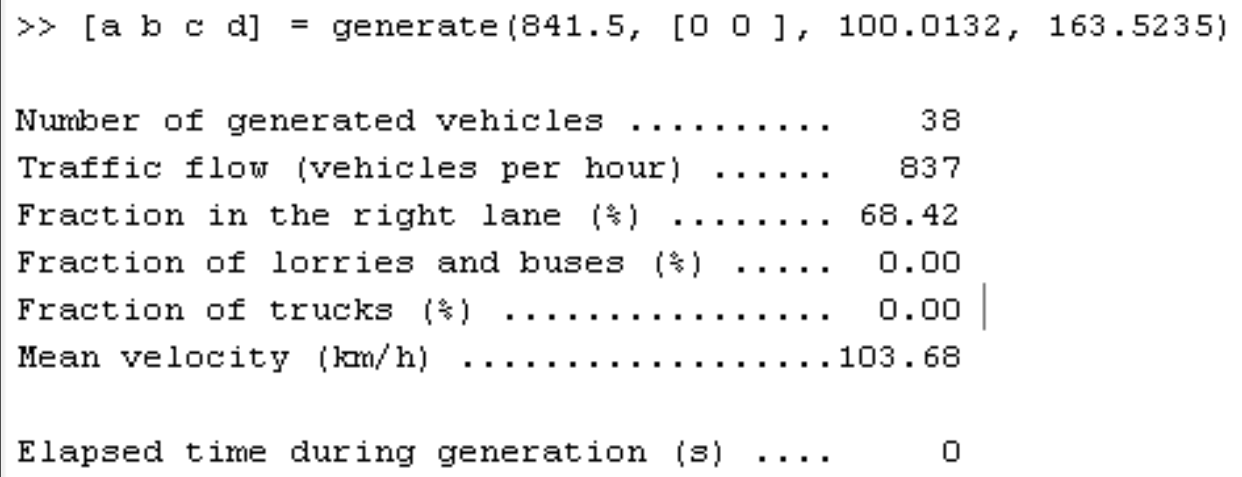

Figure 4.4: Matlab output values for alignment 2 LOS A

Table 4.4 generated headway time by applying equations 4.3 and 4.4 . The speed for each vehicle was also generated in the result. Once the values were generated and the exponential distribution function was applied, the headway times between 0 and 50 seconds (with an increment of 0.1 ) was obtained. The headway is then converted to distance by applying the simple equation: speed=distance/time. An Excel figure (Fig. 4.5) was obtained by plotting the headway time. Figure 4.5 shows the exponential distribution obtained by using the traffic flow data of LOS A for alignment 2. The graph was obtained by plotting headway time versus its respective probability taken from the table. Note that this is a normalized cumulative exponential distribution. 


\section{Normalized Exponential Distribution}

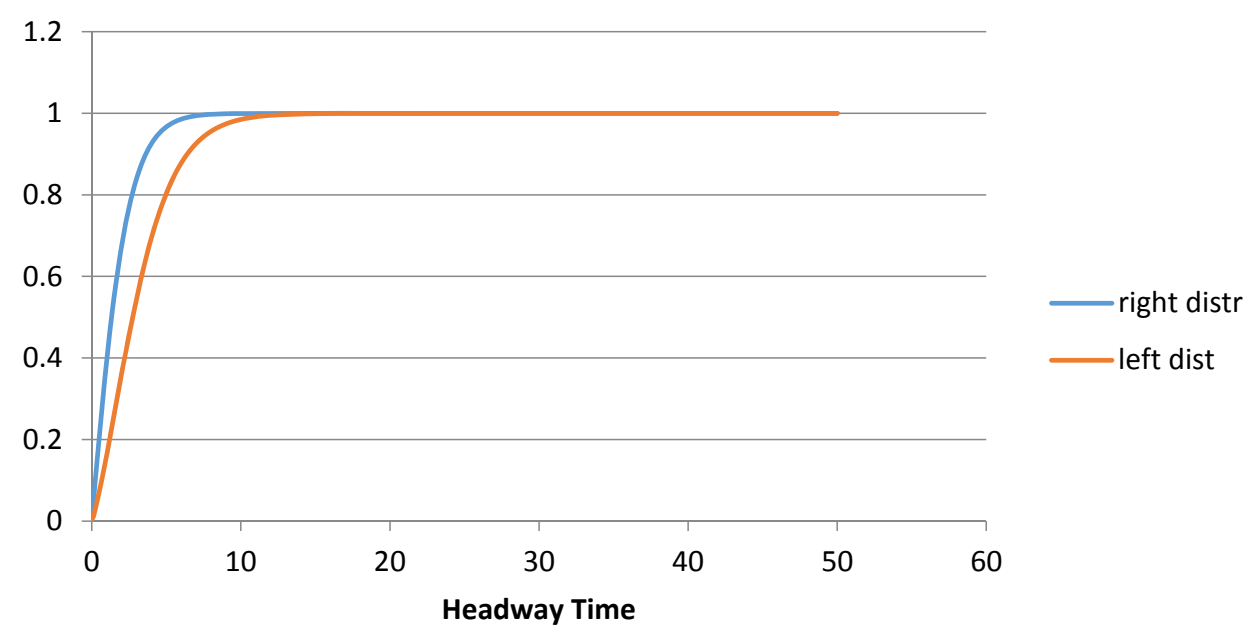

Figure 4.5: Normalized exponential distribution of alignment 2 LOS A

When comparing the figure obtained from the previous study (Figure 4.3 Headway time distribution from experiment) with the Figure 4.4, obtained by applying the distribution model, it is clear that the generated headway data is fitting and comparable. This demonstrates the appropriateness and correctness of the model that has been chosen to be applied to the experiments. In addition, such a model has been used in a number of existing studies, more specifically for cases where data has been generated for the purpose of simulation. Once the number of vehicles and headways distribution was determined, an Excel file was created. A script file on excel was created where the headway distribution was implemented into the Scenario Definition Language text file. Within it, the headway distribution as shown in Table 4.5 was used in a column along with the following Excel spreadsheet with all other pertaining information:

Table 4.5: Parameters for Alignment 2

\begin{tabular}{|c||c|}
\hline Length & $9608.07 \mathrm{~m}$ \\
\hline Speed & $62.12 \mathrm{miles} /$ hour \\
\hline Demand volume & $841.5 \mathrm{vehicl} / \mathrm{hour}$ \\
\hline Spped in ms/second & $100.0132 \mathrm{~km} / \mathrm{h}$ \\
\hline Time to drive & $0.096068019 \mathrm{hour}$ \\
\hline Time to drive & $5.764081141 \mathrm{mins}$ \\
\hline Number of Vehicle Need & 80.84123801 \\
\hline Density & $11.54636188 \mathrm{veh} / \mathrm{mi}$ \\
\hline Spacing & $389.772549 \mathrm{ft} / \mathrm{veh}$ \\
\hline
\end{tabular}




\subsection{Summary}

The same procedure as mentioned in Chapter 3 was followed, but a third scenario was introduced where traffic volume was removed from the roads. A total of three volume/capacity ratios were applied to the combined alignments: low, moderate and high. Data was collected for all 20 participants for the three combined alignments for low and moderate volume levels, as well as no traffic volume. The age range of participants was between 21 and 65 . It was found that with the combined results of the two traffic volumes and the "no volume" scenario, the results on SAS were promising. A total of 18 models were developed by using log link function regression on SAS. In Chapter 5, the developed models for curves as well as tangents are discussed. Three sets of equations for curves and tangents are found where the following relationships with visual demand as the dependent variable are explored: volume/capacity ratio, interaction terms, and no interaction terms. 


\section{Chapter 5}

\section{Analysis and Results}

\subsection{Analysis Procedure}

As mentioned in Chapter 3 of the pilot study, the combination of low and moderate volume levels did not provide good models using SAS. By increasing the number of participants, and by adding a "no volume" scenario for all three for the same alignments for the participants to drive, adequate models were obtained. This process was repeated for a total of 20 participants.

For each participant that ran a full experiment, there were a total of six files: three different files from the STISIM software (one for each: no volume, low volume and moderate volume level), and three different files from ToTaLcontrol 2 software (one for each volume level ). In total, 120 files were saved for all drivers that ran the experiments. These files were implemented into Excel and organized into columns in such a way to export into SAS. In the study, visual demand was calculated for curves and tangents separately using equation 3.2 mentioned in Chapter 3. For each element (curve or tangent), average visual demand was calculated for:

1. The first 30 meters of the element (VD30)

2. The first half of the total length of the element (VDH)

3. The full length of the element (VDF)

The average visual demand for each segment was calculated the same way it is described in Chapter 3. For example, when calculating the average visual demand for the entire length of the curve, the individual visual demand was calculated (using the visual demand equation found 
in Chapter 3) at each point when a request is made for the visual occlusion glasses to open. The average of those requests was then calculated. Table 5.1 demonstrates the way data was organized along with the geometric characteristic of the road:

Table 5.1: Driver 1 for no traffic volume for visual demand for the first $30 \mathrm{~m}$ of all curves

\begin{tabular}{|c|c|c|c|c|c|c|c|c|c|c|c|c|c|c|}
\hline Curve & VD 30 & $\mathrm{~L} / \mathrm{R}$ & $\mathrm{L}$ & $\mathrm{R}$ & Radius & 1/Radius & $\mathrm{DA}$ & $\mathrm{PE}$ & $\mathrm{T}$ & $\mathrm{CC}$ & $\mathrm{RC}$ & $\mathrm{PCR}$ & PICR & V/C ratio \\
\hline 1 & 0.36798 & $\mathrm{R}$ & 0 & 1 & 525 & 0.00190 & 60 & $\mathrm{~T}$ & 1 & 0 & 0 & 0 & 0 & 0 \\
\hline 2 & 0.64542 & $\mathrm{~L}$ & 1 & 0 & 750 & 0.00133 & 50 & $\mathrm{~T}$ & 1 & 0 & 0 & 0 & 0 & 0 \\
\hline 3 & 0.18746 & $\mathrm{~L}$ & 1 & 0 & 1300 & 0.00077 & 65 & $\mathrm{~T}$ & 1 & 0 & 0 & 0 & 0 & 0 \\
\hline 4 & 0.17029 & $\mathrm{R}$ & 0 & 1 & 1000 & 0.00100 & 50 & $\mathrm{~T}$ & 1 & 0 & 0 & 0 & 0 & 0 \\
\hline 5 & 0.27231 & $\mathrm{R}$ & 0 & 1 & 535 & 0.00187 & 45 & $\mathrm{~T}$ & 1 & 0 & 0 & 0 & 0 & 0 \\
\hline 6 & 0.47099 & $\mathrm{R}$ & 0 & 1 & 550 & 0.00182 & 80 & $\mathrm{~T}$ & 1 & 0 & 0 & 0 & 0 & 0 \\
\hline 7 & 0.21687 & $\mathrm{~L}$ & 1 & 0 & 1500 & 0.00067 & 35 & $\mathrm{~T}$ & 1 & 0 & 0 & 0 & 0 & 0 \\
\hline 8 & 0.51451 & $\mathrm{~L}$ & 1 & 0 & 525 & 0.00190 & 35 & $\mathrm{~T}$ & 1 & 0 & 0 & 0 & 0 & 0 \\
\hline 9 & 0.53234 & $\mathrm{R}$ & 0 & 1 & 650 & 0.00154 & 65 & $\mathrm{CC}$ & 0 & 1 & 0 & 525 & 0.00190 & 0 \\
\hline 10 & 0.17058 & $\mathrm{R}$ & 0 & 1 & 450 & 0.00222 & 45 & $\mathrm{~T}$ & 1 & 0 & 0 & 0 & 0 & 0 \\
\hline 11 & 0.59742 & $\mathrm{~L}$ & 1 & 0 & 750 & 0.00133 & 50 & $\mathrm{CC}$ & 0 & 1 & 0 & 450 & 0.00222 & 0 \\
\hline 12 & 0.99999 & $\mathrm{R}$ & 0 & 1 & 1100 & 0.00091 & 30 & $\mathrm{~T}$ & 1 & 0 & 0 & 0 & 0 & 0 \\
\hline 13 & 0.79966 & $\mathrm{R}$ & 0 & 1 & 900 & 0.00111 & 35 & $\mathrm{RC}$ & 0 & 0 & 1 & 1100 & 0.00091 & 0 \\
\hline 14 & 0.63730 & $\mathrm{R}$ & 0 & 1 & 525 & 0.00190 & 65 & $\mathrm{~T}$ & 1 & 0 & 0 & 0 & 0 & 0 \\
\hline 15 & 0.62925 & $\mathrm{~L}$ & 1 & 0 & 650 & 0.00154 & 50 & $\mathrm{CC}$ & 0 & 1 & 0 & 525 & 0.00190 & 0 \\
\hline 16 & 0.26921 & $\mathrm{R}$ & 0 & 1 & 1300 & 0.00077 & 30 & $\mathrm{~T}$ & 1 & 0 & 0 & 0 & 0 & 0 \\
\hline 17 & 0.48820 & $\mathrm{R}$ & 0 & 1 & 900 & 0.00111 & 50 & $\mathrm{RC}$ & 0 & 0 & 1 & 1300 & 0.00077 & 0 \\
\hline 18 & 0.21999 & $\mathrm{~L}$ & 1 & 0 & 500 & 0.00200 & 70 & $\mathrm{~T}$ & 1 & 0 & 0 & 0 & 0 & 0 \\
\hline 19 & 0.49318 & $\mathrm{~L}$ & 1 & 0 & 750 & 0.00133 & 50 & $\mathrm{RC}$ & 0 & 0 & 1 & 500 & 0.002 & 0 \\
\hline
\end{tabular}

where $\mathrm{L}=$ left turn, $\mathrm{R}=$ right turn, $\mathrm{DA}=$ deflection angle, $\mathrm{PE}=$ preceding element, $\mathrm{PICR}=$ preceding inverse curve radius, $\mathrm{V} / \mathrm{C}$ ratio $=$ volume capacity ratio, and VD30=average visual demand.

Note: Speed was not considered in this research study as it is directly correlated with traffic volume, which is considered by through volume/capacity ratio.

The data demonstrated in Table 5.1 was imported into SAS in order to develop models for $\mathrm{V} / \mathrm{C}$ ratio versus visual demand, where visual demand is the dependent variable, and $\mathrm{V} / \mathrm{C}$ ratio is the independent variable. Other relationships with the geometric characteristics of the road were also tested. In the proceeding sections, development of visual demand models and the models themselves will be discussed.

\subsection{Development of Visual Demand Models}

Using SAS Enterprise Guide 5.1, an analysis was performed in order to develop a model between visual demand (for VD30, VDH, and $\mathrm{VDF}$ ) and $\mathrm{V} / \mathrm{C}$ ratio for both curves and tangents. Generalized regression, using log as a link function, was used in order to study analysis of results. In past studies, the log link function was proven to be suitable for such analysis (Muneeb, 2006). 
An analysis was also performed between visual demand (for VD30, VDH, and VDF) and the different geometric characteristics of the road (as seen in the Table 5.1), including deflection angle, radius, inverse radius, etc.

\subsubsection{Preliminary Analysis Models}

The main purpose of this research study is to determine the effect of traffic volumes along with geometric characteristics of the road for curves and tangents. By statistical analysis, the effect of $\mathrm{V} / \mathrm{C}$ ratio on visual demand was examined. The approach used is the Generalized Linear Modeling, where the model Eq. 5.1 was developed:

$$
\log (\mathrm{VD})=\beta_{0}+\beta_{1} \times V / C_{\text {ratio }}
$$

The second objective is to explain VD with all available variables to get a model as described in Eq. 5.2:

$$
\log (\mathrm{VD})=\beta_{0}+\sum_{k=1}^{p} \beta_{k} \times V_{k}
$$

Before the analysis on SAS was performed, Visual Demand versus Volume/Capacity ratio were plotted (these can be found in Appendix 3). Then PROC GENMOD of SAS/STAT was used to try this approach (the script can be found in Appendix 3). PROC GENMOD gives different options for response distributions and link functions. In the current case, response distribution was assumed as normal and Log was used as the link function that gave an acceptable model of fit for both curve and tangent sections. The algorithm used, consist of using the backward selection by default, with all candidate effects in the model and then systematically removes effects that are not significantly associated with the target ("Pr $>$ ChiSq" > 5\%) until all effects in the model are significant.

\subsubsection{Final Models for Curves}

The objective of this research study was to examine the effect of $\mathrm{V} / \mathrm{C}$ ratios on visual demand and also the combined effects of design speed and other design variables for curves and tangents. This section describes the final equations attained for curves. By examining the visual demands at three different $\mathrm{V} / \mathrm{C}$ ratios, it was observed that visual demand varied for different $\mathrm{V} / \mathrm{C}$ ratios. Figure plots of $\mathrm{V} / \mathrm{C}$ ratios versus visual demand for curves (Figures 5.1 and 5.2 can be found in Appendix 3. It was observed that visual demand increased with the increasing of $\mathrm{V} / \mathrm{C}$ ratio. SAS was used to model three effect of design speed. The effect of $\mathrm{V} / \mathrm{C}$ ratio on visual demand (VD30, VDH, and VDF) was modelled as shown in Equations 5.3, 5.4, and 5.5.VD30 (Visual 
Demand for first 30 meters of curves):

$$
\begin{aligned}
& \log (\mathrm{VD} 30)=-1.0680+0.1842 \times V / C_{\text {ratio }} \\
& \log (\mathrm{VDH})=-1.0955+0.2665 \times V / C_{\text {ratio }} \\
& \log (\mathrm{VDF})=-1.0729+0.2478 \times V / C_{\text {ratio }}
\end{aligned}
$$

where $V / C_{\text {ratio }}=$ Volume/Capacity ratio

For equations, the p-values were found to be: $0.0365,0.0320$, and 0.0207 , respectively. This indicates that the models hold significant relationships as their values are below $5 \%$. By examining the models as well as the plots in Appendix 3 , it can be observed that visual demand changed with respect to volume capacity ratio. It was also observed that visual demand varied depending on which element preceded the current element. The characteristics of individual elements were carefully studied and were categorized into three types, depending upon their combination with the preceding element. These three types of preceding element characteristics were then considered as three nominal variables for statistical modeling in SAS and are described follows:

1. Compound curve $(\mathrm{CC})$ : where two curves followed, and the turning direction of the second curve remained the same as the previous curve's turning direction

2. Reverse curve (RC): where two curves followed, and the turning direction of the second curve was opposite of the previous curve's turning direction

3. Tangent $(\mathrm{T})$ : tangential element preceding the current element

Another analysis conducted on SAS involved the turning directions (nominal variables on SAS left or right) by also considering the radii of current elements as well as preceding elements. The summary outputs for the selected models of VDF, VDH, and VD30 for curves are given in Appendix 3. The effect of $\mathrm{V} / \mathrm{C}$ ratio on visual demand (VD30, VDH, and VDF) without interaction terms was modelled in Eqs. 5.6 to 5.8 .

$$
\begin{array}{r}
\log (\mathrm{VD} 30)=-1.0572-0.0003 \times \text { Radius }+0.0002 \times \text { PrcCrvRad }+ \\
197.0988 \times \text { PEINV }+0.2048 \times V / C_{\text {ratio }} \\
\log (\mathrm{VDH})=-1.2573-0.0001 \times \text { Radius }+0.0004 \times \text { PrcCrvRad }+ \\
253.0074 \times \text { PEINV }+0.2639 \times V / C_{\text {ratio }} \\
\log (\mathrm{VDF})=-1.2669+0.2578 \times V / C_{\text {ratio }}+0.4624 \times C C+0.5536 \times R C
\end{array}
$$


where PrcCrvRad= Preceding curve radius and PEINV= Preceding curve's inverse radius. For equations 5.6, 5.7, and 5.8, the p-values were found to be: $0.0271,0.0148$, and 0.0115, respectively. This indicates that the models hold significant relationships. Lastly, for curves, the effect of $\mathrm{V} / \mathrm{C}$ ratio on visual demand (VD30, VDH, and VDF) with interaction terms was modelled as listed in Eqs. 5.9 to 5.11 ;

$$
\begin{aligned}
& \log (\text { VD30 })=-1.4286-0.0002 \times \text { Radius }-0.2550 \times \text { PrcCrvRad }+93840.78 \times \text { PEINV+ } \\
& 0.1969 \times V / C_{\text {ratio }}+0.0003 \times \text { Radius } \times \text { PrcCrvRad }-110.888 \times \text { Radius } \times \text { PEINV- } \\
& 0.0057 \times C C \times \text { Radius }-0.0001 \times \text { PrcCrvRad } \times \text { Def Angl }-0.0067 \times L \times \text { Def Angl+ } \\
& 0.0069 \times R \times \text { Def Angl }+0.5745 \times T \times L \\
& \log (\mathrm{VDH})=-1.2573-0.0001 \times \text { Radius }+0.0004 \times \text { PrcCrvRad }+ \\
& 253.0074 \times P E I N V+0.2639 \times V / C_{\text {ratio }} \\
& \log (\mathrm{VDF})=-1.2524+0.0007 \times \operatorname{PrcCrvRad}+0.2187 \times V / C_{\text {ratio }}-0.8034 \times C C- \\
& 0.6102 \times R C+0.5368 \times P E I N V \times \text { Radius }-0.0033 \times P r c C r v R a d \times V / C_{\text {ratio }^{-}} \\
& 1760.37 \times V / C_{\text {ratio }} \times P E I N V+5.3657 \times C C \times V / C_{\text {ratio }}+5.3248 \times R C \times V / C_{\text {ratio }}
\end{aligned}
$$

For equations 5.9 to 5.11 , the p-values were found to be: $0.0258,0.0148$, and 0.0113 , respectively. This indicates that the models hold significant relationships. All statistical analysis was carried out atthe 0.05 significance level. The response distribution as log was used as a link function. The inverse of radius of curvature crossed with the turning direction of the current element was observed as the most significant variable for all types of visual demand models.

\subsubsection{Final Models for Tangents}

Visual demand models for tangents were also developed using the same procedure as for curves. The effect of V/C Ratio on visual demand (VD30, VDH, and VDF) was modelled as follows (Eqs. 5.12 to 5.14 :

$$
\begin{gathered}
\log (\mathrm{VD} 30)=-0.8116+0.2980 \times V / C_{\text {ratio }} \\
\log (\mathrm{VDH})=-0.7662+0.3923 \times V / C_{\text {ratio }}
\end{gathered}
$$




$$
\log (\mathrm{VDF})=-0.8522+0.3590 \times V / C_{\text {ratio }}
$$

For equations 5.12, 5.13, 5.14, the p-values were found to be: $0.0321,0.0204$, and 0.0149 , respectively. This indicates that the models hold significant relationships. Summary outputs for developed models are given in Appendix 3. Observed VD values showed that VD varied with the variations in other design variables. Therefore, other variables were also used to develop VD models for tangents. The effect of V/C Ratio on visual demand (VD30, VDH, and VDF) without interaction terms was modelled as follows (Eqs. 5.15 to 5.17):

$$
\begin{gathered}
\log (\mathrm{VD} 30)=-0.8116+0.2980 \times V / C_{\text {ratio }} \\
\log (\mathrm{VDH})=-0.7662+0.3923 \times V / C_{\text {ratio }} \\
\log (\mathrm{VDF})=-0.9928+105.7508 \times P E I N V+0.3561 \times V / C_{\text {ratio }}
\end{gathered}
$$

For equations 5.15, 5.16, 5.17, the p-values were found to be: $0.0321,0.0204$, and 0.0145 , respectively. This indicates that the models hold significant relationships. The effect of V/C Ratio on visual demand (VD30, VDH, and VDF) without interaction terms was modelled as follows (Eqs. 5.18 to 5.20 ):

$$
\begin{array}{r}
\log (\mathrm{VD} 30)=-1.1094+0.9571 \times V / C_{\text {ratio }}+0.0055 \times L \times P E D E L+ \\
0.0063 \times R \times P E D E L-0.0132 \times V / C_{\text {ratio }} \times P E D E L
\end{array}
$$

For equations 5.18, 5.19, 5.20, the p-values were found to be: 0.0314, 0.0202, and 0.014, respectively. This indicates that the models hold significant relationships. All the variables are well within the $95 \%$ confidence interval. The reliability of all the explanatory variables considered for evaluation of VDH and VD30 for tangent sections, as obtained from the analysis, is given in Appendix 3 . 


\subsection{Discussion}

The objective as previously mentioned is to develop models for visual demand in terms of VD30, $\mathrm{VDH}$, and VDF for curves and tangents. SAS analysis was used to determine the variability of visual demand with respect to $\mathrm{V} / \mathrm{C}$ ratio, as well as geometric characteristics of the road. Two different traffic volumes and a no traffic volume level were considered (low and moderate levels). Average visual demand was calculated for the entire length of the elements, half of the length of the elements, as well as the first 30 meters of the elements.

\subsubsection{Visual Demand on Curves}

The V/C ratio showed a statistically significant relationship with visual demand when considered alone as an explanatory variable and also when considered with other design variables. The design speed showed a statistically significant relationship with visual demand when considered alone as an explanatory variable and also when considered with other design variables. The plots in Appendix A clearly show that visual demand in terms of VDF, VDH, and VD30 increases with the increase in $\mathrm{V} / \mathrm{C}$ ratio. Figure 5.1 shows the variation of VD with respect to $\mathrm{V} / \mathrm{C}$ ratio. The figure highlights that visual demand in terms of VDF, VDH, and VD30 increases with the increase in V/C ratio. Moreover, it shows that VDF is higher than VD30 and VDF, indicating that as the driver travel a curve, visual demand is low at the start and increases as the driver travels along the curve. It also shows that for low $\mathrm{V} / \mathrm{C}$ ratio, visual demand is quasi equal, no matter how the driver travelled. Figure 5.1 shows that VDH increases more rapidly than VDF and VD30 as the V/C ratio increases, which indicates that the driver's visual demand is higher on the middle of curve than in extremities (the beginning and the end).

These observations hold true for all three measures of visual demand (VD30, VDH, and VDF). It clearly shows that visual demand value is always greater for a left-turning curve as compared to a right-turning curve although the difference is small. The effect of the preceding element type (tangent, curve turning in the same direction, curve turning in the opposite direction) also proved to be statistically significant when crossed with $\mathrm{V} / \mathrm{C}$ ratio. Also, when a driver travels from a tangent section to a curve section, visual demand is higher as compared to a situation when traveling from one curve to another curve. Secondly, if a driver travels from one curve to a curve having the same turning direction as the previous curve (i.e., the case of a circular curve), visual demand is less as compared to the visual demand on a curve turning in a direction opposite to the previous curve (i.e., the case of a reverse curve). It reflects the concept of ad hoc expectancy, for when the driver travels from a tangent to a curve, he or she has to face a shift over in VD due to the type of element being traveled, i.e., from a tangent to a curve as compared to a curve-to-curve situation. 


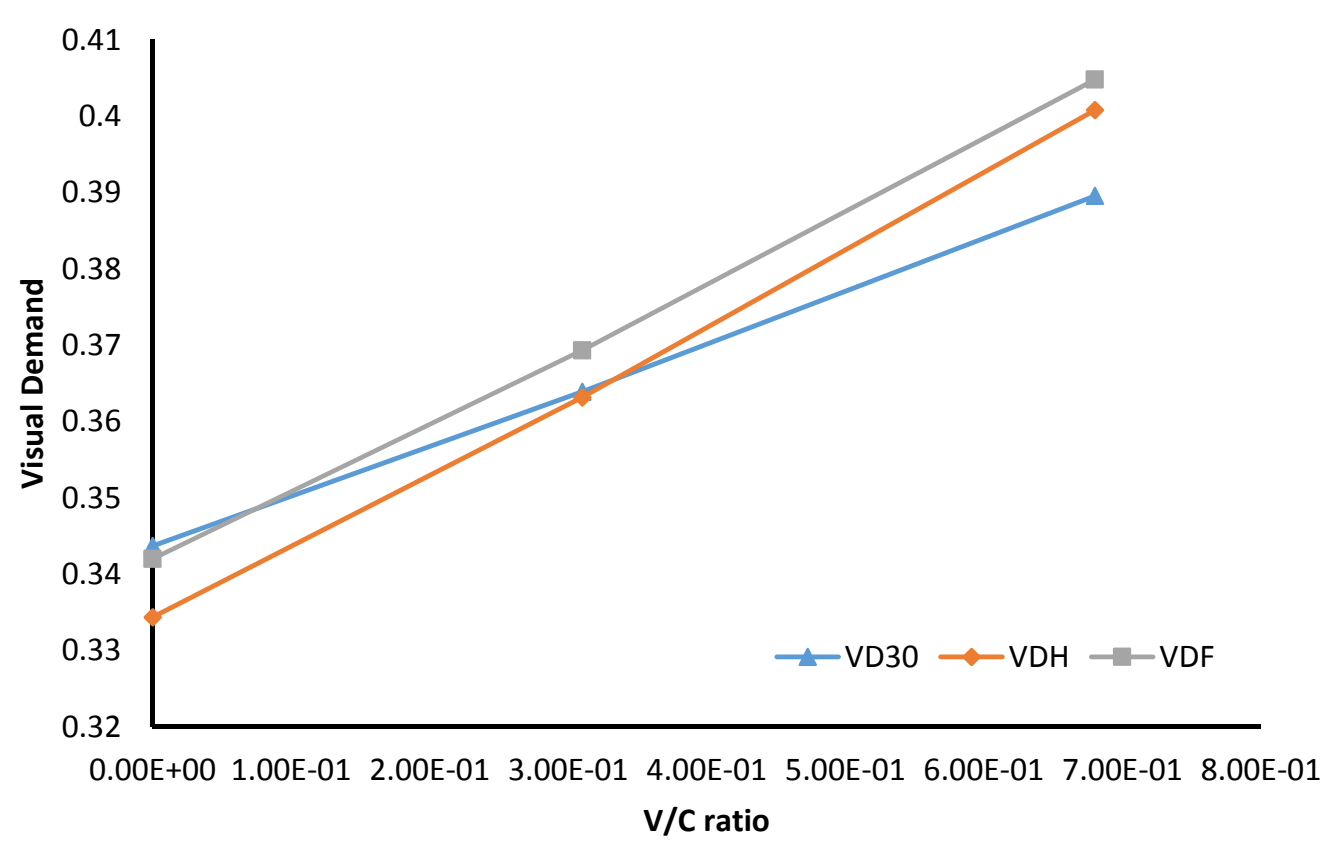

Figure 5.1: Sensitivity of VDF, VDH and VD30 with Varying V/C Ratio (For Curve Sections)

\subsubsection{Visual Demand on Tangents}

As for curve, $\mathrm{V} / \mathrm{C}$ ratio showed a statistically significant relationship with visual demand when considered alone as an explanatory variable and also when considered with other design variables. The plots clearly demonstrates that as the $\mathrm{V} / \mathrm{C}$ ratio increases, visual demand also increases on tangent sections. Moreover, at lower speeds, the difference between VDF (visual demand for full element length) and VDH (visual demand for half-element length) is small, but it increases as the $\mathrm{V} / \mathrm{C}$ ratio increases. It is also clear that VD30 (visual demand for the first 30 meters of element length) is always higher as compared to VDF and VDH, indicating that as the driver travels a tangent section of an alignment, visual demand is higher at the start and then gradually decreases as the driver covers more distance. Figure 5.2 shows the variation of VD with respect to $\mathrm{V} / \mathrm{C}$ ratio. It clearly shows that visual demand in terms of VDF, VDH, and VD30 increases with the increase in $\mathrm{V} / \mathrm{C}$ ratio. Moreover, it shows that VDH is higher than VD30 and VDF, indicating that as the driver travels a curve, visual demand is low at the start and increases as the driver travels along to reach a maximum then decreases again. It shows also that when the $\mathrm{V} / \mathrm{C}$ ratio is high, visual demand is quasi equal for VDF and VD30, which indicates that the drivers have the same visual demand for start and end of trajectory. The same can be seen when the curve of the VDH increases more rapidly than VDF and VD30 with V/C ratio increase, which indicate that the driver's visual demand is higher on the middle of curve than in the extremities (beginning and end). 


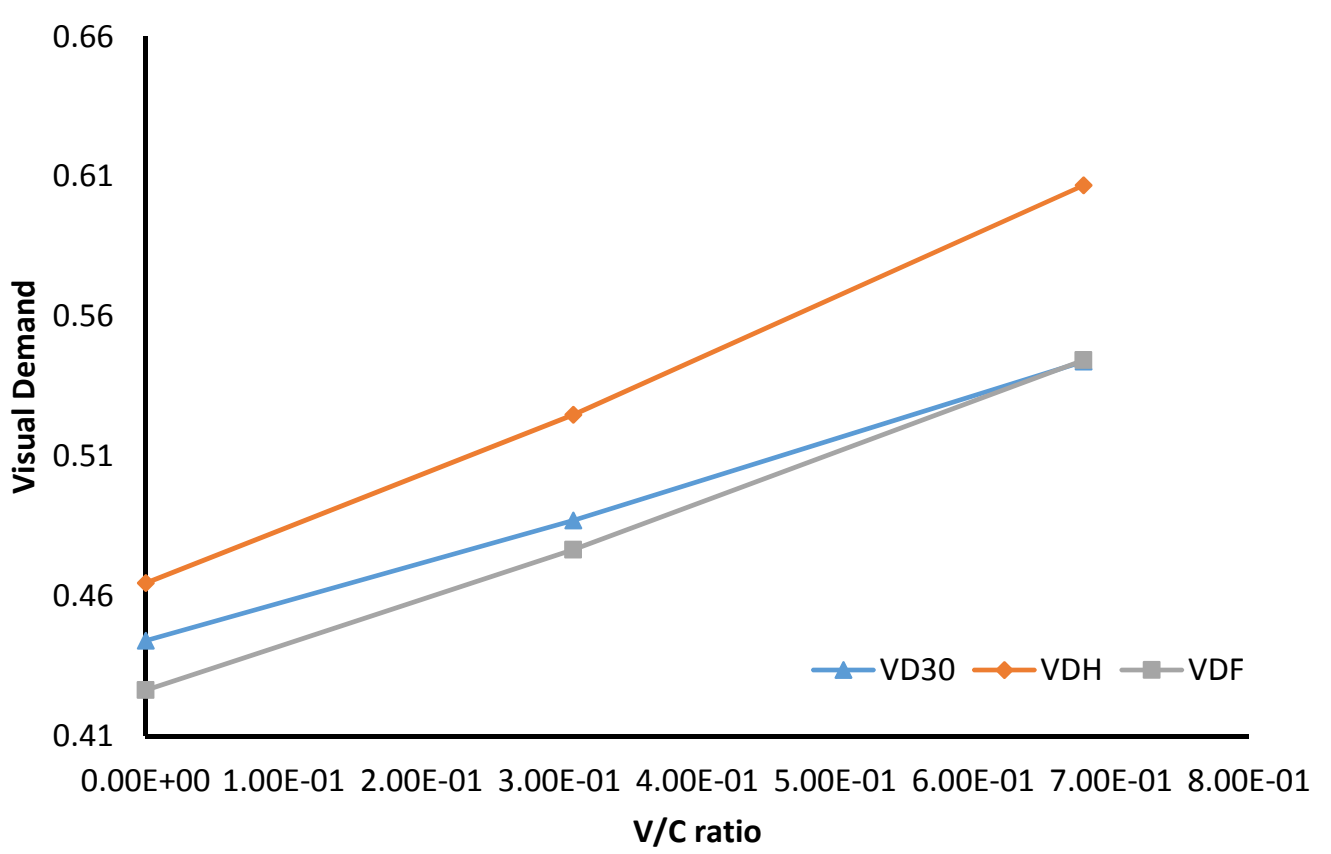

Figure 5.2: Sensitivity of VDF, VDH and VD30 with Varying V/C Ratio (For Tangent Sections)

In the second step of model development for the tangent sections, $\mathrm{V} / \mathrm{C}$ ratio was considered along with other design variables, in particular the characteristics of the preceding curve element. The developed model indicated that PEINVR (inverse of radius of preceding curve element), when crossed with PEDEL (deflection angle of preceding curve), was statistically significant. This significance was greater at higher V/C ratios. Figure 5.1 shows that visual demand increases as PEINVR increases and has higher value for a higher $\mathrm{V} / \mathrm{C}$ ratio. This is true for all three measures of visual demand, i.e., VDF, VDH. and VD30. The V/C ratio, when crossed with the turning direction of the preceding curve, was also statistically significant. The turning direction of the preceding curve element was divided into two categories, PETD (R) and PETD (L), which indicate the directions of the preceding curve as right and left, respectively. These two variables were considered as Nominal Variables in SAS for the purpose of analysis. Figure 5.1 shows the impact of this variable on visual demand for different speeds in terms of VDF; visual demand has higher value on the current tangent element when coming from a left-turning curve as compared to visual demand value when coming from a right-turning curve. This finding is the same for VDF and VDH. However, in case of VD30, this effect is opposite, as shown in Figure 5.2. It is likely that in the case of VD30, this is due to the sight-distance issue as available sight distance for a given right-turning curve always becomes less than that for a left-turning curve. Moreover, in case of VD30, it has been observed that the difference between VD values for the two variables (preceding curve turning in a right direction and preceding curve turning in a left direction) is higher compared with VD values for VDF andVDH. 


\section{Chapter 6}

\section{Model Validation and Application}

\subsection{Preliminary Evaluation}

In Chapter 5, mathematical models were obtained from the experiments conducted, however these models were not previously validated. A comparative study was conducted to compare the results of this research study with FHWA models for VDF and VD30. The study performed by FHWA obtained the following equations 6.1 and 6.2 (Fitzpatrick et al., 2000):

$$
\begin{aligned}
& V D F=0.202+19.0 \times \frac{1}{R} \\
& V D 30=0.195+27.1 \times \frac{1}{R}
\end{aligned}
$$

where $\frac{1}{R}=$ Inverse of radius of curves $(1 / \mathrm{m})$. The study of a $2 \mathrm{D}$ horizontal alignment was carried out by following the AASHTO and TAC standards. The alignment consists of curves followed and preceded by tangents, where the radii satisfied the minimum radius requirement for its design speed of $100 \mathrm{~km} / \mathrm{h}$. Table 6.1 provides details of the FHWA's alignment geometric characteristics. It should be noted that the FHWA models were obtained for a design speed of $100 \mathrm{~km} / \mathrm{h}$, whereas design speed for the current research is $110 \mathrm{~km} / \mathrm{h}$.

By using the models developed by the FHWA, and the ones obtained in this current research, a series of visual demand values for each curve element was calculated. The objective of this comparative study was to determine and validate the effectiveness of the models developed in this research in evaluating visual demand on two-dimensional highway alignments. Figures 6.1 and 6.2 display Excel plots that compares the visual demand between of the FHWA and 


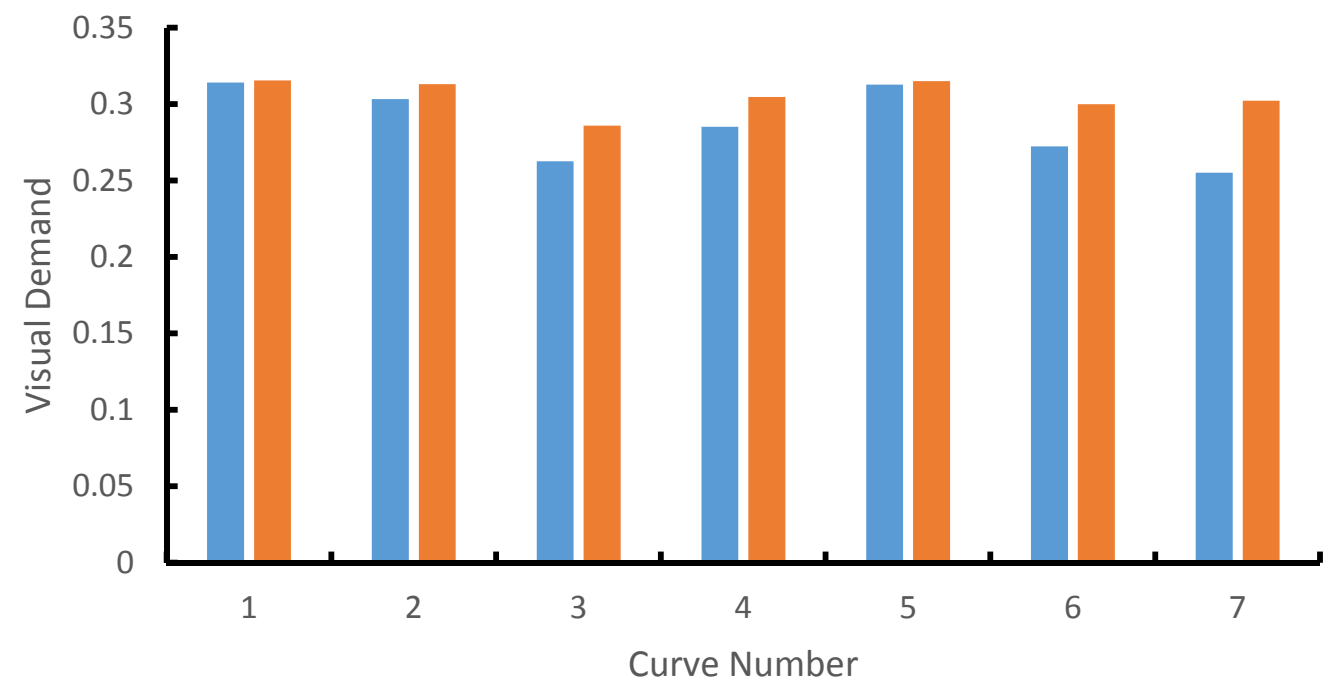

FHWA Model Research Model

Figure 6.1: A comparison between FHWA and research models (VDF)

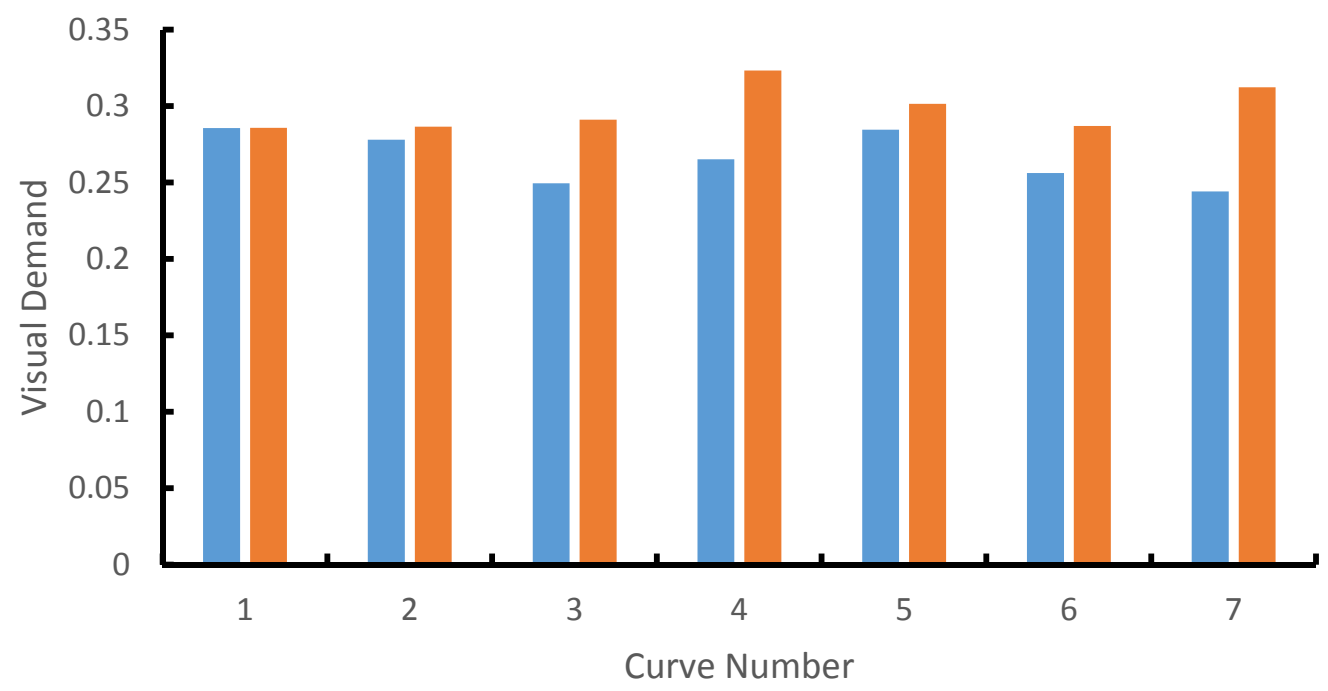

\section{- FHWA Model $\quad$ Research Model}

Figure 6.2: A comparison between FHWA and research models (VD30) 
CHAPTER 6. MODEL VALIDATION AND APPLICATION

Table 6.1: Geometric characteristics of FHWA alignment for100 km/hr (horizontal curves)

\begin{tabular}{|c|c|c|c|c|c|c|c|}
\hline Element & $\begin{array}{c}\text { Element } \\
\text { Length }\end{array}$ & $\begin{array}{c}\text { Raidus } \\
(\mathrm{m})\end{array}$ & $\begin{array}{c}1 / \\
\text { Radius }(\mathrm{m})\end{array}$ & $\begin{array}{c}\text { PC } \\
(\mathrm{m})\end{array}$ & $\begin{array}{c}\text { PT } \\
(\mathrm{m})\end{array}$ & $\begin{array}{c}\text { Deflection } \\
\text { Angle (Degree) }\end{array}$ & $\begin{array}{c}\text { Lane } \\
\text { Width (m) }\end{array}$ \\
\hline \hline Tangent & 200 & - & - & - & - & - & 3.7 \\
\hline Curve & 460.95 & 440 & 0.002273 & 200 & 660.95 & 60 & 3.7 \\
\hline Tangent & 300 & - & & - & - & - & 3.7 \\
\hline Curve & 436.51 & 500 & 0.002 & 960.95 & 1397.46 & 50 & 3.7 \\
\hline Tangent & 300 & - & & - & - & - & 3.7 \\
\hline Curve & 680.95 & 600 & 0.001667 & 1697.46 & 2378.41 & 65 & 3.7 \\
\hline Tangent & 250 & - & & - & - & - & 3.7 \\
\hline Curve & 392.86 & 450 & 0.002222 & 2628.41 & 3021.27 & 50 & 3.7 \\
\hline Tangent & 300 & - & & - & - & - & 3.7 \\
\hline Curve & 589.29 & 750 & 0.001333 & 3321.27 & 3910.56 & 45 & 3.7 \\
\hline Tangent & 200 & - & & - & - & - & 3.7 \\
\hline Curve & 768.25 & 550 & 0.001818 & 4110.56 & 4878.81 & 80 & 3.7 \\
\hline Tangent & 400 & - & & - & - & - & 3.7 \\
\hline Curve & 550 & 900 & 0.001111 & 5278.81 & 5828.81 & 35 & 3.7 \\
\hline Tangent & 300 & - & & - & - & - & 3.7 \\
\hline
\end{tabular}

${ }^{*} \mathrm{PC}=$ Point of curvature; $\mathrm{PT}=$ Point of tangency

research models for both VD30 and VDF.

The comparison between the two models indicates that the values provided by both models demonstrate a similar trend, but that the FHWA model underestimates the visual demand for both VD30, as well as VDF as shown respectively in Figures 6.1 and 6.2. It should be noted, however, that the design speed of the FHWA model is lower than the design speed of the research model and that this comparison does not take into account the higher design speed difference. Comparing the visual demand for the first 30 meters of the research model with the FHWA model, by using the alignment characteristics in Table 6.1, it is evident that the models demonstrate a similar trend.

\subsection{Speed Profile Design Consistency}

A speed profile is developed by using the $85^{\text {th }}$ percentile operating speeds of the new roads or the measure $85^{\text {th }}$ percentile speeds for existing roads. Table 6.2 displays regression equations for $2 \mathrm{D}$ curves recommended by the TAC Design Guide. This guide suggests for highways with long tangents, the observed $85^{\text {th }}$ percentile speed has a range between $94 \mathrm{~km} / \mathrm{h}$ and $104 \mathrm{~km} / \mathrm{h}$. A tangent section is considered to be long if its length allows the driver to accelerate to a desired speed over a distance. This may be calculated by using the following equations 6.3 to 
6.5 (Muneeb, 2006):

$$
\begin{gathered}
T L_{c}=X_{l a}+X_{l d} \\
X_{l a}=\frac{V_{f}^{2}-V_{n}^{2}}{25.92 a} \\
X_{l d}=\frac{V_{f}^{2}-V_{n+1}^{2}}{25.92 d}
\end{gathered}
$$

where $T L_{c}$ is the critical length for speed changes between speed-limiting curves - it is the distance required for a vehicle to accelerate from one curve speed to the desired speed, and then decelerate to the next curve speed, $X_{l a}=$ length of road for acceleration from curve $\mathrm{n}$ speed to desired speed, $X_{l d}=$ Length of road for deceleration from desired speed to curve $\mathrm{n}+1$ speed, $V_{f}=$ Desired speed, and $V_{n}$ and $V_{n+1}=85^{\text {th }}$ percentile speeds for curve $n$ and $n+1$ (using equations in Table6.2. If $T L_{c}$ is less than $100 \mathrm{~m}$, then it is a long tangent.

Table 6.2: Equations for estimating operating speed (2D horizontal curves only)

\begin{tabular}{|l|l|l|}
\hline Type & 2D Alignment Conditions & Corresponding Equation \\
\hline \hline 1 & Horizontal curve on grade: $-9 \% \leq \mathrm{G} \leq-4 \%$ & $\mathrm{~V} 85=102.10-3077.13 / \mathrm{R}$ \\
\hline 2 & Horizontal curve on grade: $-9 \% \leq \mathrm{G} \leq-4 \%$ & $\mathrm{~V} 85=105.98-3709.90 / \mathrm{R}$ \\
\hline 3 & Horizontal curve on grade: $-9 \% \leq \mathrm{G} \leq-4 \%$ & $\mathrm{~V} 85=104.82-3574.51 / \mathrm{R}$ \\
\hline 4 & Horizontal curve on grade: $-9 \% \leq \mathrm{G} \leq-4 \%$ & $\mathrm{~V} 85=96.91-2572.19 / \mathrm{R}$ \\
\hline $\begin{array}{l}\mathrm{V} 85=85^{\text {th }} \text { percentile speed of passenger cars }(\mathrm{km} / \mathrm{h}), \mathrm{G}=\text { Grade. Lowest speed among predicted speeds is } \\
\text { to be used from Type 1 or Type 2 (for downgrade) and Type 3 or 4 (for upgrade) }\end{array}$ \\
\hline
\end{tabular}

It can be concluded that the main objectives of this research study have been investigated. All of the independent variables of the study were considered when developing the models for different visual demand. The variables that were not considered statistically significant were not interpreted in the proposed models. A total of 18 models were developed for both curves and tangents at a confidence level of $95 \%$. The explanatory variables found to be significant included visual demand for the first 30 meters of the road, half of the total length, as well as the entire length of the road. In this research study, the volume/capacity ratio was the main explanatory variable, whereas in previous research it was concluded to be the design speed. The developed models demonstrated that visual demand increases as the $\mathrm{V} / \mathrm{C}$ ratio increases. 


\subsubsection{Description of Test Alignments}

Two previously used test alignments (Muneeb, 2006) are required to evaluate highway design consistency. These alignments are described below:

- Alignment 1: A simple 2D horizontal alignment consisting of ten elements including five tangents and five simple horizontal curves with different turning directions each curve is preceded and followed by a tangent.

- Alignment 2: A complex 2D horizontal alignment consisting of nine elements including four tangents and five curves with different turning directions having a combination of reverse curves, compound curves and simple curves.

Figures 6.3 and 6.4 display the plan view of each alignment respectively.

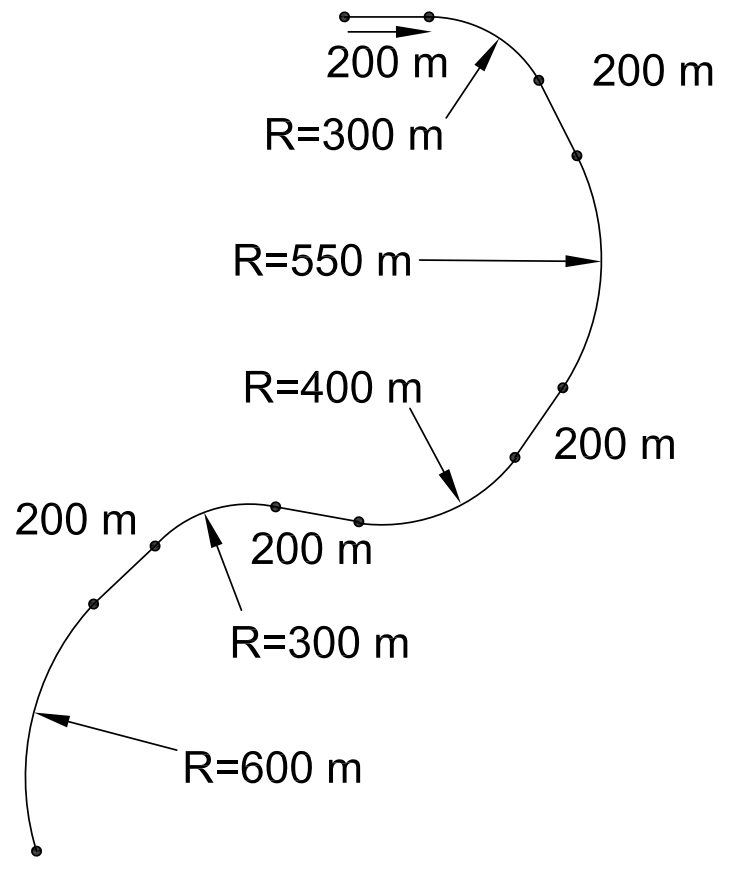

Figure 6.3: Test alignment 1 for consistency evaluation

The visual demand and operating speeds for each element of test alignments 1 and 2 were calculated. A summary of the results of test alignment 1 can be found in the Table 64 . The summary of results of test alignment 2 can be found in Appendix A. The test alignment 1 suggests a consistent operating speed as the maximum difference in operating speed is 2.44 $\mathrm{km} / \mathrm{h}$ with a limit of $10 \mathrm{~km} / \mathrm{h}$. The test alignment 2 was also investigated and demonstrated a consistent operating speed as well since the maximum difference in operating speed is 3.17 $\mathrm{km} / \mathrm{h}$. 


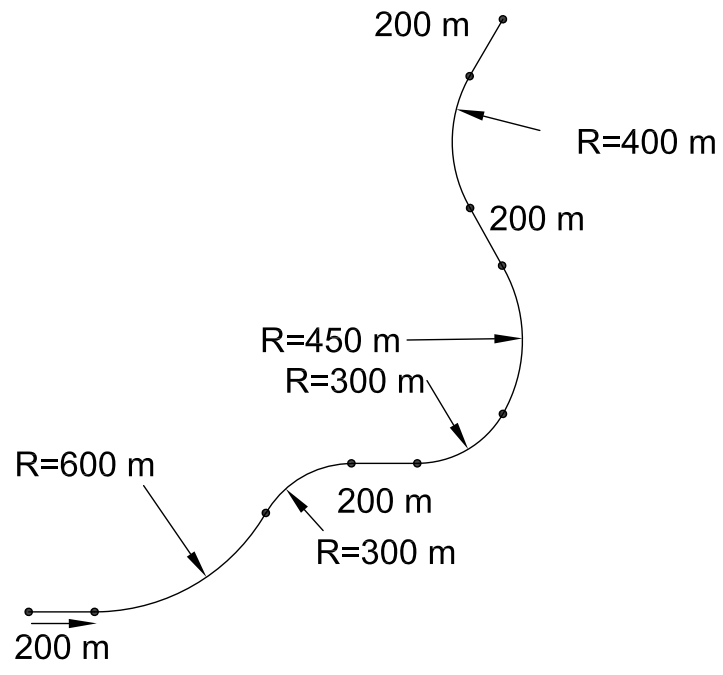

Figure 6.4: Test alignment 2 for consistency evaluation

Visual demand profiles and operating speed profiles for test alignment 1 and 2 are shown in Figures 6.5 and 6.6. The trend lines for test alignment 1, as seen in Figure 6.5, are similar and comparable, which suggests design consistency in terms of visual demand and design speed consistency. However, the trend lines for test alignment 2, as seen in Figure 6.6 suggest otherwise. The trend lines between operating speed and visual demand are somewhat comparable, however the relationship is not as clearly demonstrated as in Figure 6.6. 
Table 6.3: Detailed geometric properties of test alignment 1 (simple 2D horizontal alignment)

\begin{tabular}{|c|c|c|c|c|c|c|c|c|}
\hline $\begin{array}{c}\text { Element } \\
\text { number }\end{array}$ & Element & $\begin{array}{c}\text { Turning } \\
\text { Direction }\end{array}$ & $\begin{array}{c}\text { Element } \\
\text { Length }\end{array}$ & $\begin{array}{c}1 / \\
\text { Radius }(\mathrm{m})\end{array}$ & $\begin{array}{c}\text { PC } \\
(\mathrm{m})\end{array}$ & $\begin{array}{c}\text { PT } \\
(\mathrm{m})\end{array}$ & $\begin{array}{c}\text { Deflection } \\
\text { Angle } \\
\text { (degree) }\end{array}$ & $\begin{array}{c}\text { Lane } \\
\text { Width (m) }\end{array}$ \\
\hline \hline 1 & Curve & $\mathrm{R}$ & 314.29 & 0.00333 & 200 & 514.29 & 60 & 3.7 \\
\hline 2 & Tangent & - & 200 & & 514.29 & 714.29 & - & 3.7 \\
\hline 3 & Curve & $\mathrm{R}$ & 576.19 & 0.00182 & 714.29 & 1290.48 & 60 & 3.7 \\
\hline 4 & Tangent & - & 200 & & 1290.48 & 1490.48 & - & 3.7 \\
\hline 5 & Curve & $\mathrm{R}$ & 419.05 & 0.0025 & 1490.48 & 1909.52 & 60 & 3.7 \\
\hline 6 & Tangent & - & 200 & & 1909.52 & 2109.52 & - & 3.7 \\
\hline 7 & Curve & $\mathrm{L}$ & 314.29 & 0.00333 & 2109.52 & 2423.81 & 60 & 3.7 \\
\hline 8 & Tangent & - & 200 & & 2423.81 & 2623.81 & - & 3.7 \\
\hline 9 & Curve & $\mathrm{L}$ & 628.57 & 0.00167 & 2623.81 & 3252.38 & 60 & 3.7 \\
\hline
\end{tabular}

Table 6.4: Detailed geometric properties of test alignment 2 (complex 2D horizontal alignment)

\begin{tabular}{|c|c|c|c|c|c|c|c|c|}
\hline $\begin{array}{c}\text { Element } \\
\text { number }\end{array}$ & Element & $\begin{array}{c}\text { Turning } \\
\text { Direction }\end{array}$ & $\begin{array}{c}\text { Element } \\
\text { Length }\end{array}$ & $\begin{array}{c}1 / \\
\text { Radius }(\mathrm{m})\end{array}$ & $\begin{array}{c}\text { PC } \\
(\mathrm{m})\end{array}$ & $\begin{array}{c}\text { PT } \\
(\mathrm{m})\end{array}$ & $\begin{array}{c}\text { Deflection } \\
\text { Angle } \\
\text { degree) }\end{array}$ & $\begin{array}{c}\text { Lane } \\
\text { Width (m) }\end{array}$ \\
\hline \hline 1 & Curve & $\mathrm{L}$ & 628.6 & 0.00167 & 200 & 828.6 & 60 & 3.7 \\
\hline 2 & Curve & $\mathrm{R}$ & 314.3 & 0.00333 & 828.6 & 1142.9 & 60 & 3.7 \\
\hline 3 & Tangent & - & 200 & - & 1142.9 & 1342.9 & - & 3.7 \\
\hline 4 & Curve & $\mathrm{L}$ & 314.3 & 0.00333 & 1342.9 & 1657.1 & 60 & 3.7 \\
\hline 5 & Curve & $\mathrm{L}$ & 471.4 & 0.00222 & 1657.1 & 2128.6 & 60 & 3.7 \\
\hline 6 & Tangent & - & 200 & - & 2128.6 & 2328.6 & - & 3.7 \\
\hline 7 & Curve & $\mathrm{R}$ & 419 & 0.0025 & 2328.6 & 2747.6 & 60 & 3.7 \\
\hline 8 & Tangent & - & 200 & - & 2747.6 & 2947.6 & - & 3.7 \\
\hline
\end{tabular}




\subsubsection{Results for Test Alignments 1 and 2}

The visual demand and operating speeds for each element of test alignments 1 and 2 were calculated. A summary of the results of test alignment 1 can be found in the tables 6.5 to 6.7 . The summary of results of test alignment 2 can be found in Appendix 3 . The test alignment 1 suggests a consistent operating speed as the maximum difference in operating speed is 2.44 $\mathrm{km} / \mathrm{h}$ with a limit of $10 \mathrm{~km} / \mathrm{h}$. The test alignment 2 was also investigated and demonstrated a consistent operating speed as well since the maximum difference in operating speed is 3.17 $\mathrm{km} / \mathrm{h}$.

Table 6.5: Visual Demand and Operating Speed for Test Alignment 1 (low V/C ratio))

\begin{tabular}{|c|c|c|c|c|c|c|c|c|}
\hline $\begin{array}{c}\text { Element } \\
\text { number }\end{array}$ & Element & $\begin{array}{c}\text { Element } \\
\text { length }\end{array}$ & $\begin{array}{c}1 / \\
\text { Radius } \\
(\mathrm{m})\end{array}$ & Chainage & VDF & $\begin{array}{c}\text { VDF } \\
\text { (Absolute } \\
\text { Difference) }\end{array}$ & V85 & $\begin{array}{c}\text { Speed } \\
\text { (Absolute } \\
\text { Difference) }\end{array}$ \\
\hline 1 & Curve & 314.29 & 0.00333 & 200 & 0.28 & & 98.011 & \\
\hline 2 & Tangent & 200 & & 514.29 & 0.45 & 16.74 & 100 & 1.98 \\
\hline 3 & Curve & 576.19 & 0.00182 & 714.29 & 0.28 & 16.74 & 100.05 & 3.05 \\
\hline 4 & Tangent & 200 & & 1290.48 & 0.42 & 14.08 & 101 & 2.05 \\
\hline 5 & Curve & 419.05 & 0.0025 & 1490.48 & 0.28 & 14.08 & 103.07 & 2.07 \\
\hline 6 & Tangent & 200 & & 1909.52 & 0.40 & 11.61 & 102 & 1.07 \\
\hline 7 & Curve & 314.29 & 0.00333 & 2109.52 & 0.28 & 11.61 & 103.24 & 1.24 \\
\hline 8 & Tangent & 200 & & 2423.81 & 0.41 & 12.60 & 102 & 1.24 \\
\hline 9 & Curve & 628.57 & 0.00167 & 2623.81 & 0.28 & 12.60 & 100.13 & 1.86 \\
\hline
\end{tabular}

Table 6.6: Visual Demand and Operating Speed for Test Alignment 1 (moderate V/C ratio)

\begin{tabular}{|c|c|c|c|c|c|c|c|c|}
\hline $\begin{array}{c}\text { Element } \\
\text { number }\end{array}$ & Element & $\begin{array}{c}\text { Element } \\
\text { length }\end{array}$ & $\begin{array}{c}1 / \\
\text { Radius } \\
(\mathrm{m})\end{array}$ & Chainage & VDF & $\begin{array}{c}\text { VDF } \\
\text { (Absolute } \\
\text { Difference) }\end{array}$ & V85 & $\begin{array}{c}\text { Speed } \\
\text { (Absolute } \\
\text { Difference) }\end{array}$ \\
\hline 1 & Curve & 314.29 & 0.00333 & 200 & 0.30 & & 98.011 & \\
\hline 2 & Tangent & 200 & & 514.29 & 0.50 & 20.02 & 100 & 1.98 \\
\hline 3 & Curve & 576.19 & 0.00182 & 714.29 & 0.30 & 20.02 & 100.05 & 3.05 \\
\hline 4 & Tangent & 200 & & 1290.48 & 0.47 & 17.05 & 101 & 2.05 \\
\hline 5 & Curve & 419.05 & 0.0025 & 1490.48 & 0.30 & 17.05 & 103.07 & 2.07 \\
\hline 6 & Tangent & 200 & & 1909.52 & 0.44 & 14.29 & 102 & 2.07 \\
\hline 7 & Curve & 314.29 & 0.00333 & 2109.52 & 0.30 & 14.29 & 103.24 & 1.24 \\
\hline 8 & Tangent & 200 & & 2423.81 & 0.45 & 15.40 & 102 & 1.24 \\
\hline 9 & Curve & 628.57 & 0.00167 & 2623.81 & 0.30 & 15.40 & 100.13 & 1.86 \\
\hline
\end{tabular}


Table 6.7: Visual Demand and Operating Speed for test Alignment 1 (high V/C ratio)

\begin{tabular}{|c|c|c|c|c|c|c|c|c|}
\hline $\begin{array}{c}\text { Element } \\
\text { number }\end{array}$ & Element & $\begin{array}{c}\text { Element } \\
\text { length }\end{array}$ & $\begin{array}{c}1 / \\
\text { Radius } \\
(\mathrm{m})\end{array}$ & Chainage & VDF & $\begin{array}{c}\text { VDF } \\
\text { (Absolute } \\
\text { Difference) }\end{array}$ & V85 & $\begin{array}{c}\text { Speed } \\
\text { (Absolute } \\
\text { Difference) }\end{array}$ \\
\hline 1 & Curve & 314.29 & 0.00333 & 200 & 0.33 & 24.57 & 98.011 & \\
\hline 2 & Tangent & 200 & & 514.29 & 0.57 & 24.57 & 100 & 1.98 \\
\hline 3 & Curve & 576.19 & 0.00182 & 714.29 & 0.33 & 21.18 & 100.05 & 3.05 \\
\hline 4 & Tangent & 200 & & 1290.48 & 0.54 & 21.18 & 101 & 2.05 \\
\hline 5 & Curve & 419.05 & 0.0025 & 1490.48 & 0.33 & 18.04 & 103.07 & 2.07 \\
\hline 6 & Tangent & 200 & & 1909.52 & 0.51 & 18.04 & 102 & 2.07 \\
\hline 7 & Curve & 314.29 & 0.00333 & 2109.52 & 0.33 & 19.30 & 103.24 & 1.24 \\
\hline 8 & Tangent & 200 & & 2423.81 & 0.52 & 19.30 & 102 & 1.24 \\
\hline 9 & Curve & 628.57 & 0.00167 & 2623.81 & 0.33 & 24.35 & 100.13 & 1.86 \\
\hline
\end{tabular}


Visual demand profiles and operating speed profiles for test alignment 1 and 2 are shown in Figures 6.5 and 6.6. The trend lines for test alignment 1, as seen in Figure 6.5. are similar and comparable, which suggests design consistency in terms of visual demand and design speed consistency. However, the trend lines for test alignment 2, as seen in Figure 6.6 suggests otherwise. The trend lines between operating speed and visual demand are somewhat comparable, however the relationship is not as clearly demonstrated as in Figure 6.5.

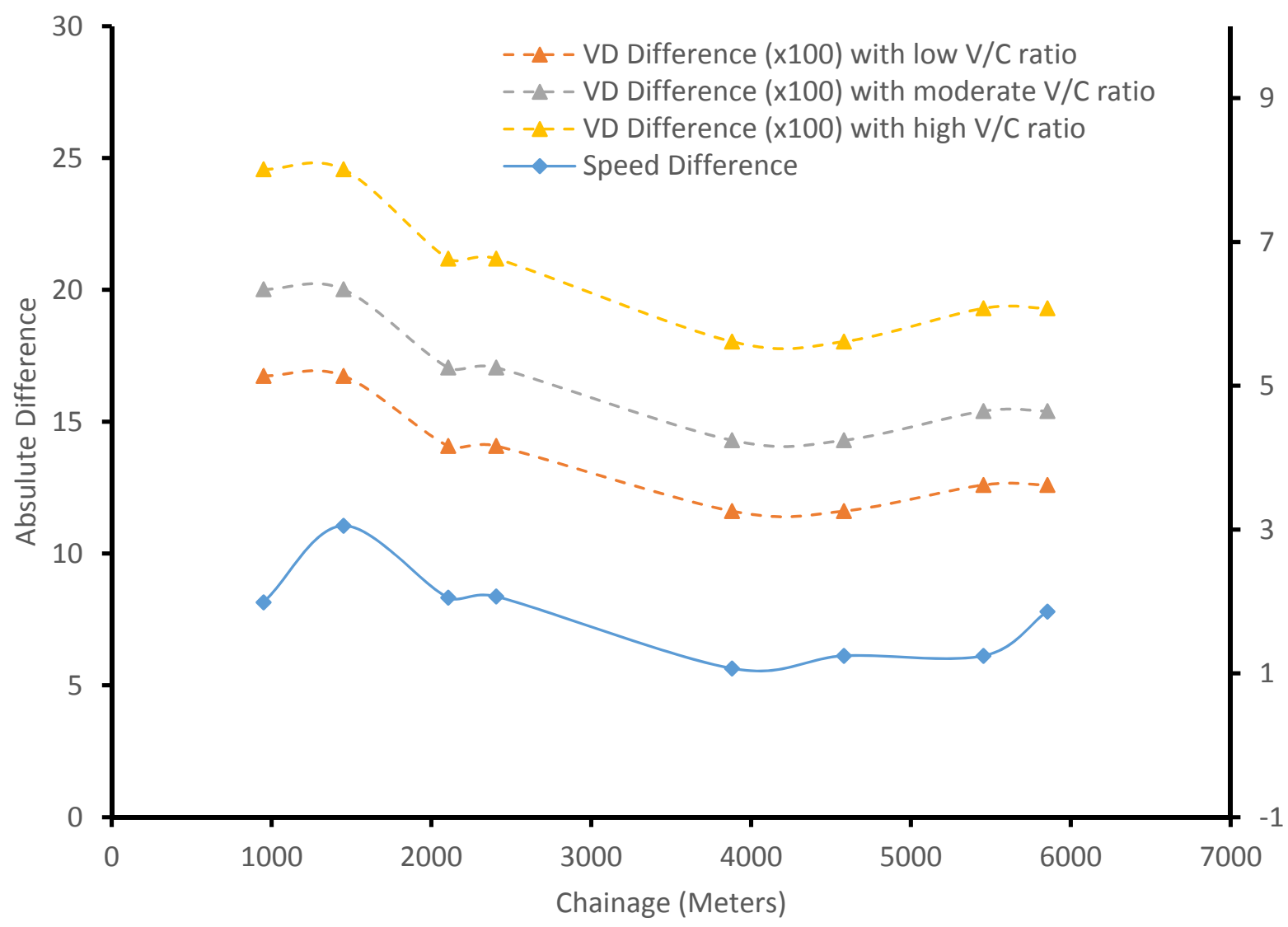

Figure 6.5: VD Profile vs. Speed Profile Test Alignment 1

\subsection{Discussion}

Using the mentioned test alignments, a consistency evaluation was performed with results achieved from the operating-speed consistency method and visual demand method using the visual demand models obtained by the research study. The objective of the discussed methods was to demonstrate comparable results and conclude the usefulness of the developed visual demand models. By looking at Figure 6.5, describing results from test alignment 1, it can be 


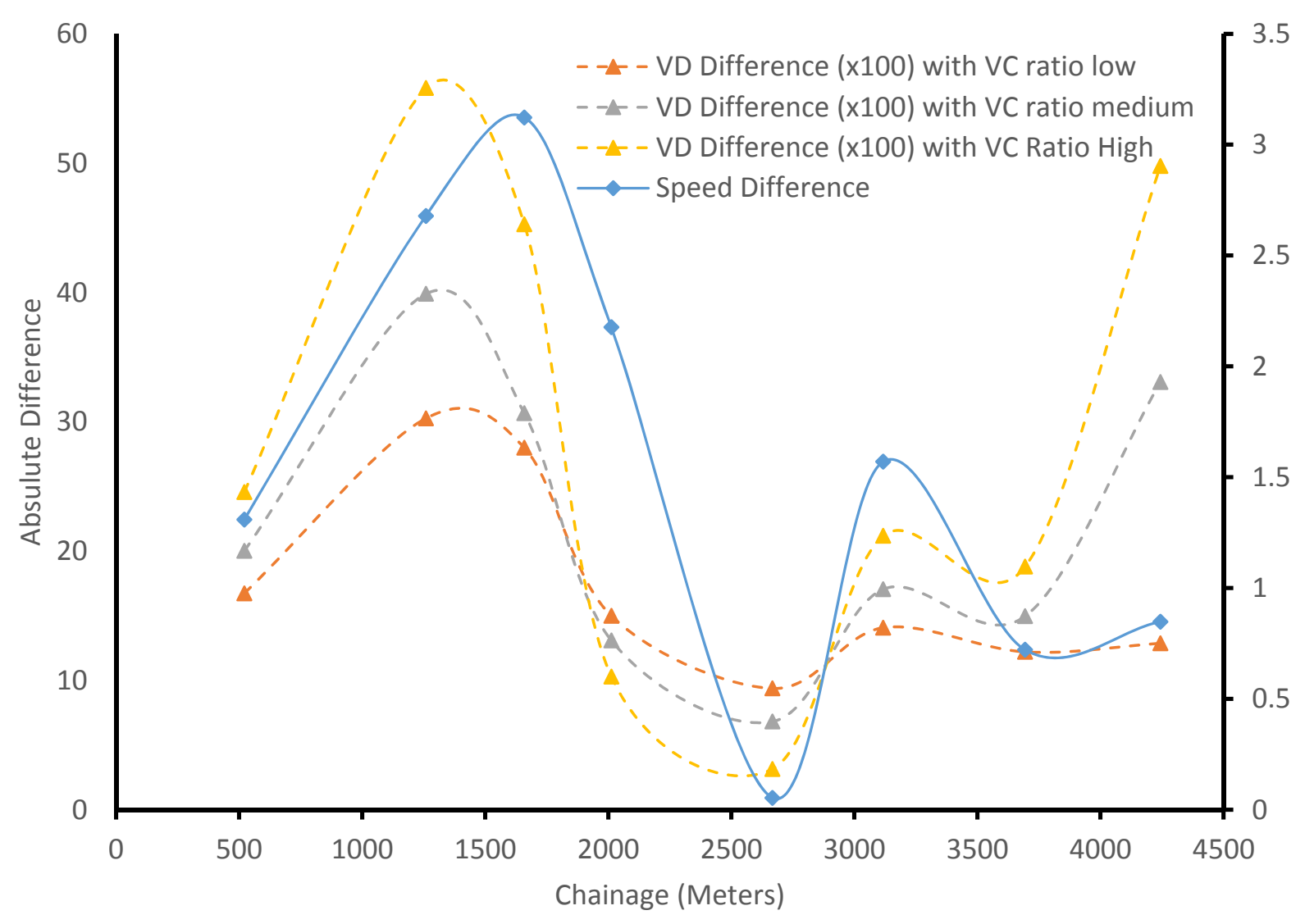

Figure 6.6: VD Profile vs. Speed Profile Test Alignment 2

concluded that visual demand in fact increases as the radius of curvature decreases. Also, it can be noted that the visual demand decreases from the curved section to the following tangent and increases from the preceding tangent to the curve. Moreover, Figure 6.6 demonstrates that the operating speed increases from the curve to the following tangent and decreases from the preceding tangent to the curve. By observing these two methods, it can be concluded that the alignment is in fact a consistent alignment as its operating speed difference value is well below $10 \mathrm{~km} / \mathrm{h}$. Observing test alignment 2, similar interpretation can be concluded with respect to operating speed consistency, however, the trend lines obtained in Figure 6.6 demonstrate a somewhat unclear relationship between design speed and visual demand. The following points may be highlighted:

The visual demand and speed difference may be used to evaluate the consistency of highway design as the profiles seem to be comparable. The workload consistency results conclusions may be drawn by comparing the difference in operating speeds and the difference in visual demand values. There has yet to be critical threshold values for visual demand consistency to be developed for highway design consistency. 


\section{Chapter 7}

\section{Conclusions and Recommendations}

\subsection{Conclusions}

Previous research studies have conducted experiments and developed models where visual demand is used as a measure of highway design consistency, however, the models did not take into consideration $\mathrm{V} / \mathrm{C}$ ratio. This research work explores the effect of $\mathrm{V} / \mathrm{C}$ ratio on a driver's visual demand for 2D multilane highways by initially studying its influence on visual demand, and then by considering the effects of the highway design variables such as geometric characteristics of the road. A detailed pilot study and experimental design procedure were followed in order to ensure validity of the procedure and most importantly, adequacy of results. The V/C ratio proved to have a notable effect on driver visual demand through the developed models of the current research. Three different simulation scenarios were studied in which three different V/C ratios were applied. The end goal was to obtain models where the dependent variable consisted of visual demand and considered V/C ratio as an explanatory variable. After conducting the experiments and obtaining significant models, the following observations may be highlighted:

- The $\mathrm{V} / \mathrm{C}$ ratio was found to have a significant effect on visual demand. It has been concluded that visual demand increases as $\mathrm{V} / \mathrm{C}$ ratio increases. These findings hold true for models for the first 30 meters, the first half of an element, as well as the entire length of an element for both curves and tangents.

- For curved sections of the highway alignments, the preceding element was found to be statistically significant in terms of its relationship with $\mathrm{V} / \mathrm{C}$ ratio.

- A driver traveling from a tangential to a curved section experiences higher visual demand as opposed to traveling from a curved section onto another curved section. 
- When a driver travels from a curved section onto another curved section with the same turning direction (compound curve), visual demand decreases compared to a driver traveling from a curved section onto another curved section with opposite turning direction (reverse curve).

- Left turning curves compared to right turning curves demonstrated an increase in visual demand. This increase of visual demand increases as V/C ratio increases.

\subsection{Recommendations}

The following recommendations are made for future research:

- These research findings evaluate the effect of highway alignments when considering geometric parameters with traffic flow. Pedestrians, intersections, road signs and pavement markings are other factors that are expected to affect visual demand. Thus a visual demand study for highway alignments that include the preceding factors should be conducted.

- The developed visual demand models consider $\mathrm{V} / \mathrm{C}$ ratio as an explanatory variable and therefore should be verified by four-lane highways for the same $\mathrm{V} / \mathrm{C}$ ratios.

- The research study results and conclusions suggest that there exists a strong relationship between visual demand and traffic volume/different characteristics of the road. The threshold for different visual demand levels should be calculated in such a way that a standardized chart may be used.

- This research did not take into account visual acuity, inclement weather, and the effect of a driver's age as contributing factors, and should therefore be considered in future research as they could potentially improve the models.

- A similar type of study should be conducted where the lengths of the alignments are shorter in length allowing the possibility to collect data for visual demand for other $\mathrm{V} / \mathrm{C}$ ratios, in order to enhance the models.

- While developing models for visual demand by this research, traffic parameters such as traffic volume were considered, however, traffic signals and road signs were not considered as explanatory variables. It is expected that other such traffic parameters may have considerable effect on driver visual demand, therefore future research should focus on these parameters as well.

- The experiments were conducted in this study using a daytime environment only. Previous research has shown that driver performance in a nighttime environment varies as compared to that of a daytime environment, so visual demand experiments for the same type of research should be conducted for a nighttime environment as well. 


\section{Appendix 1}

\section{SAS Code}

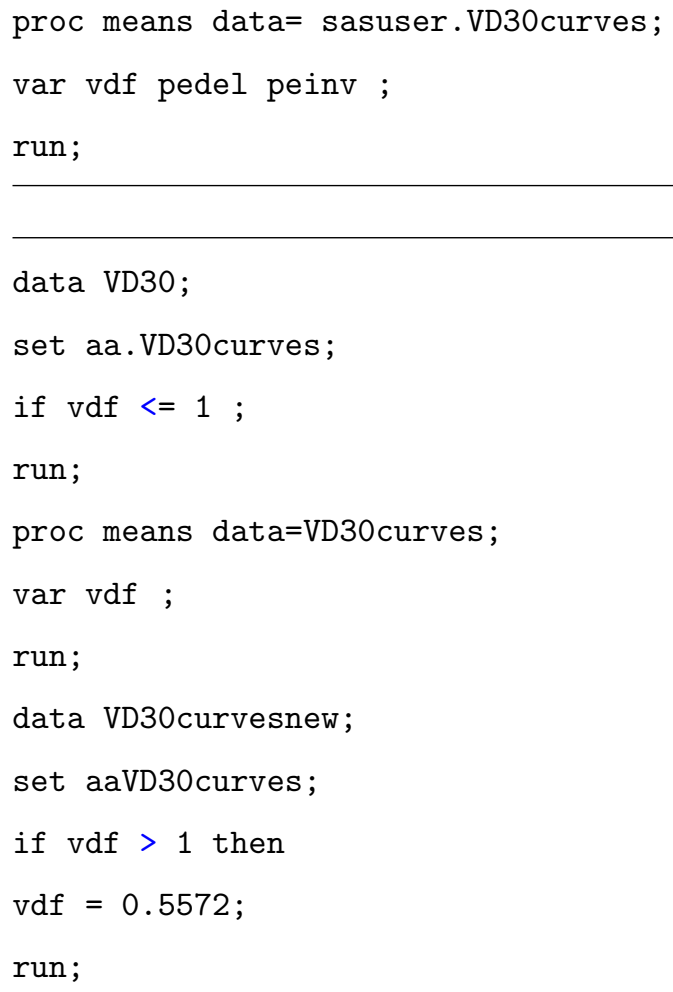


run;

libname road 'C: \Temp \SAS model 2\Workspace\Data';

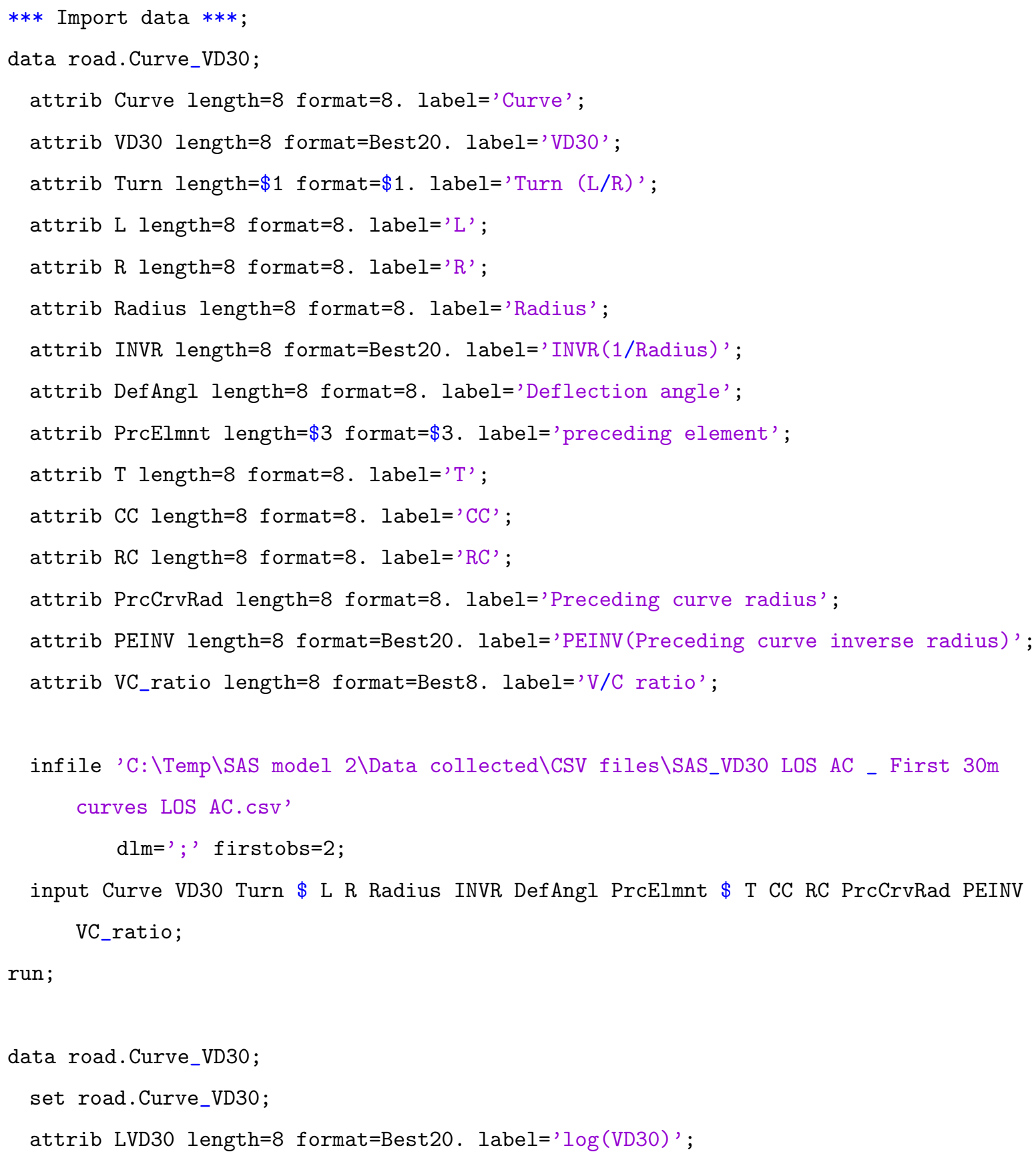




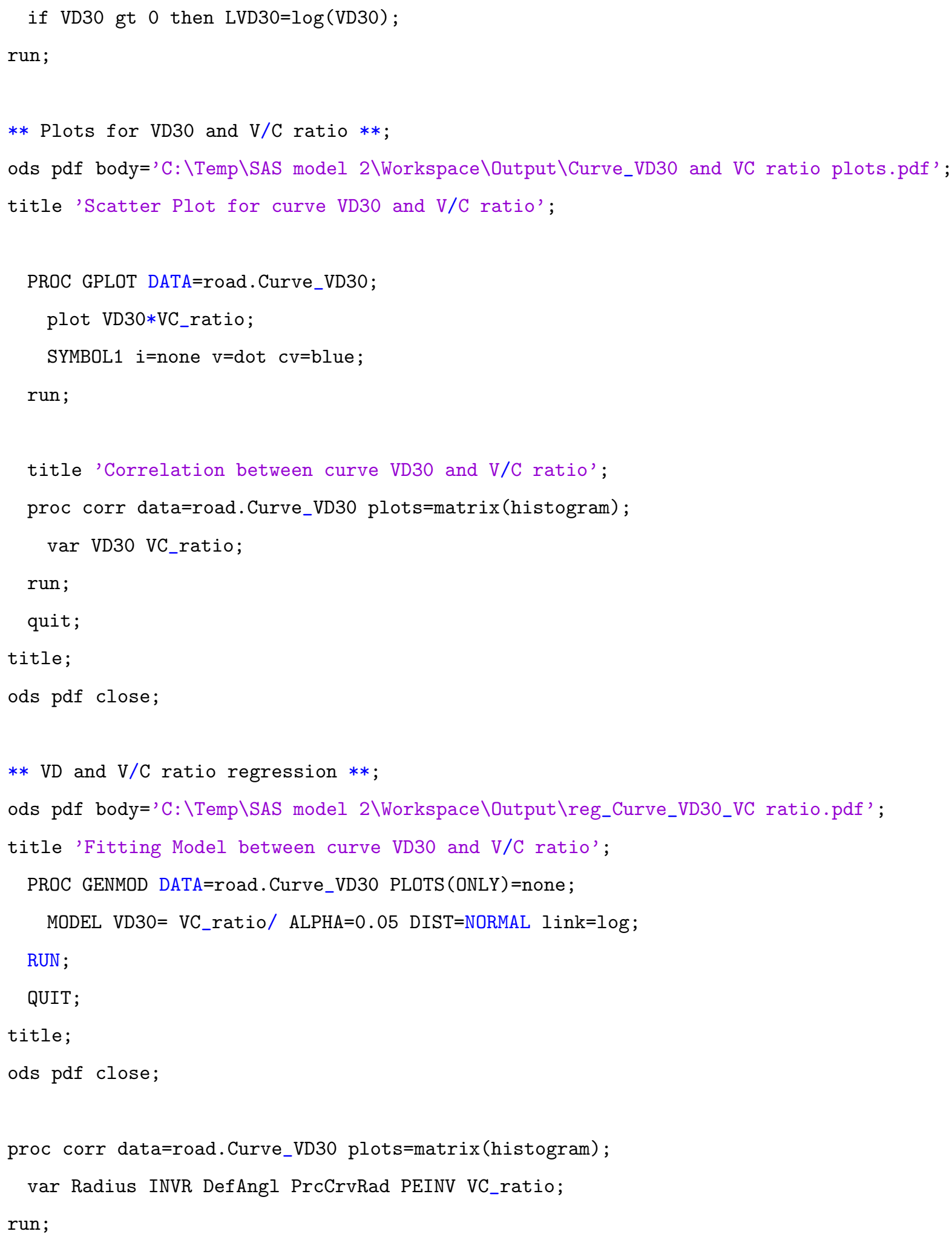


quit;

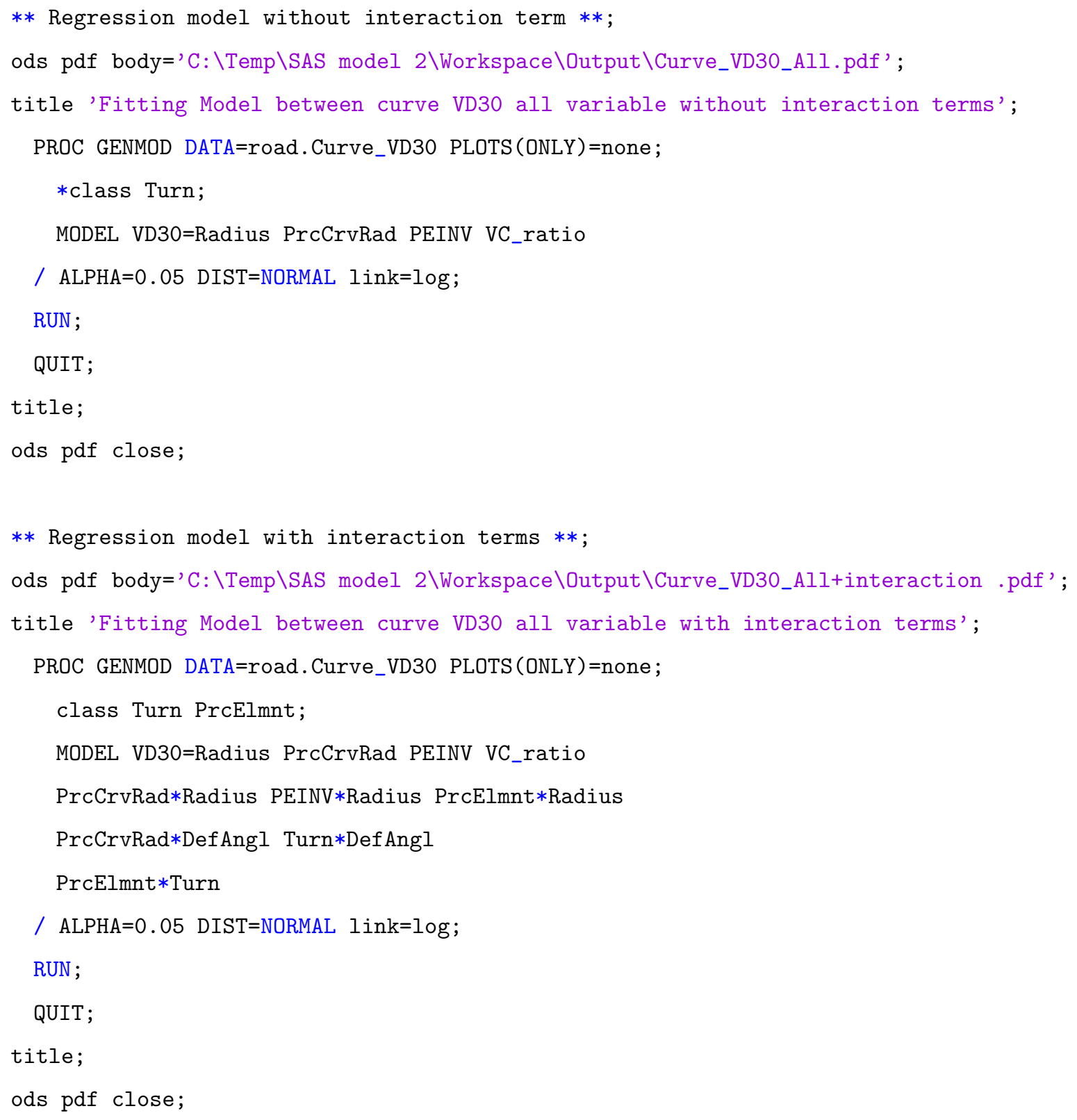




\section{Appendix 2}

\section{List of Alignments}

Table 2.1: Geometry of Horizontal Curves for Alignment 1

\begin{tabular}{|c|c|c|c|c|c|c|c|c|}
\hline Element & $\begin{array}{c}\text { Element } \\
\text { Length }\end{array}$ & $\begin{array}{c}\text { Turning } \\
\text { Direction } \\
\text { of Curve }\end{array}$ & $\begin{array}{l}\text { Radius of } \\
\text { Curve }(m)\end{array}$ & $\begin{array}{c}1 / \\
\text { Radius }\end{array}$ & $\begin{array}{l}\mathrm{PC} \\
(\mathrm{m})\end{array}$ & $\begin{array}{l}\text { PT } \\
(\mathrm{m})\end{array}$ & $\begin{array}{c}\text { Deflection } \\
\text { angle }\end{array}$ & $\begin{array}{r}\text { Lane } \\
\text { width }\end{array}$ \\
\hline Tangent & 400 & & & & & & & 3.7 \\
\hline Curve (1) & 549.78 & $\mathrm{R}$ & 525 & 0.00227 & 400 & 860.95 & 60 & 3.7 \\
\hline Tangent & 500 & & & & & & & 3.7 \\
\hline Curve (2) & 654.76 & $\mathrm{~L}$ & 750 & 0.00133 & 1360.95 & 2015.71 & 50 & 3.7 \\
\hline Tangent & 300 & & & & & & & 3.7 \\
\hline Curve (3) & 1475.4 & $\mathrm{~L}$ & 1300 & 0.00077 & 2315.71 & 3791.11 & 65 & 3.7 \\
\hline Tangent & 700 & & & & & & & 3.7 \\
\hline Curve (4) & 873.02 & $\mathrm{R}$ & 1000 & 0.001 & 4491.11 & 5364.13 & 50 & 3.7 \\
\hline Tangent & 400 & & & & & & & 3.7 \\
\hline Curve (5) & 420.19 & $\mathrm{R}$ & 535 & 0.00222 & 5764.13 & 6117.7 & 45 & 3.7 \\
\hline Tangent & 750 & & & & & & & 3.7 \\
\hline Curve (6) & 768.25 & $\mathrm{R}$ & 550 & 0.00182 & 6867.7 & 7635.95 & 80 & 3.7 \\
\hline Tangent & 500 & & & & & & & 3.7 \\
\hline Curve (7) & 916.67 & $\mathrm{~L}$ & 1500 & 0.00067 & 8135.95 & 9052.62 & 35 & 3.7 \\
\hline Tangent & 400 & & & & & & & 3.7 \\
\hline
\end{tabular}

${ }^{*} \mathrm{PC}=$ Point of curvature; $\mathrm{PT}=$ Point of tangency 
Table 2.2: Geometry of Horizontal Curves for Alignment 2

\begin{tabular}{|c|c|c|c|c|c|c|c|c|}
\hline Element & $\begin{array}{c}\text { Element } \\
\text { Length }\end{array}$ & $\begin{array}{c}\text { Turning } \\
\text { Direction } \\
\text { of Curve }\end{array}$ & $\begin{array}{c}\text { Radius of } \\
\text { Curve(m) }\end{array}$ & $\begin{array}{c}1 / \\
\text { Radius }\end{array}$ & $\begin{array}{c}\text { PC } \\
(\mathrm{m})\end{array}$ & $\begin{array}{c}\text { PT } \\
(\mathrm{m})\end{array}$ & $\begin{array}{c}\text { Deflection } \\
\text { angle }\end{array}$ & $\begin{array}{c}\text { Lane } \\
\text { width }\end{array}$ \\
\hline \hline Tangent & 200 & & & & & & & 3.7 \\
Curve (1) & 320.7 & $\mathrm{~L}$ & 525 & 0.00227 & 200 & 468.89 & 35 & 3.7 \\
Curve (2) & 737.7 & $\mathrm{R}$ & 650 & 0. & 200 & 468.89 & 35 & 3.7 \\
Tangent & 400 & & & & & & & 3.7 \\
Curve (3) & 353.57 & $\mathrm{R}$ & 525 & 0.00222 & 1606.59 & 1960.16 & 45 & 3.7 \\
Curve (4) & 654.76 & $\mathrm{~L}$ & 750 & 0.00133 & 1960.16 & 2614.92 & 50 & 3.7 \\
Tangent & 450 & & & & & & & 3.7 \\
Curve (5) & 576.19 & $\mathrm{R}$ & 1100 & 0.00091 & $3064 . .92$ & 3641.11 & 30 & 3.7 \\
Curve (6) & 550 & $\mathrm{R}$ & 900 & 0.00111 & 3641.11 & 4191.11 & 35 & 3.7 \\
Tangent & 300 & & & & & & 3.7 \\
\hline
\end{tabular}

${ }^{*} \mathrm{PC}=$ Point of curvature; $\mathrm{PT}=$ Point of tangency

Table 2.3: Geometry of Horizontal Curves for Alignment 3

\begin{tabular}{|c|c|c|c|c|c|c|c|c|}
\hline Element & $\begin{array}{c}\text { Element } \\
\text { Length }\end{array}$ & $\begin{array}{c}\text { Turning } \\
\text { Direction } \\
\text { of Curve }\end{array}$ & $\begin{array}{c}\text { Radius of } \\
\text { Curve(m) }\end{array}$ & $\begin{array}{c}1 / \\
\text { Radius }\end{array}$ & $\begin{array}{c}\text { PC } \\
(\mathrm{m})\end{array}$ & $\begin{array}{c}\text { PT } \\
(\mathrm{m})\end{array}$ & $\begin{array}{c}\text { Deflection } \\
\text { angle }\end{array}$ & $\begin{array}{c}\text { Lane } \\
\text { width }\end{array}$ \\
\hline \hline Tangent & 200 & & & & & & & 3.7 \\
Curve (1) & 595.59 & $\mathrm{R}$ & 525 & 0.00227 & 200 & 699.37 & 65 & 3.7 \\
Curve (2) & 567.46 & $\mathrm{~L}$ & 650 & 0.00154 & 699.37 & 1266.83 & 50 & 3.7 \\
Tangent & 400 & & & & & & & 3.7 \\
Curve (3) & 680.95 & $\mathrm{R}$ & 1300 & 0.00077 & 1666.83 & 2347.78 & 30 & 3.7 \\
Curve (4) & 785.71 & $\mathrm{R}$ & 900 & 0.00111 & 2347.78 & 3133.49 & 50 & 3.7 \\
Tangent & 350 & & & & & & & 3.7 \\
Curve (5) & 611.11 & $\mathrm{~L}$ & 500 & 0.002 & 3483.49 & 4094.6 & 70 & 3.7 \\
Curve (6) & 654.76 & $\mathrm{~L}$ & 750 & 0.00133 & 4094.6 & 4749.37 & 50 & 3.7 \\
Tangent & 300 & & & & & & & 3.7 \\
\hline
\end{tabular}

${ }^{*} \mathrm{PC}=$ Point of curvature; $\mathrm{PT}=$ Point of tangency 


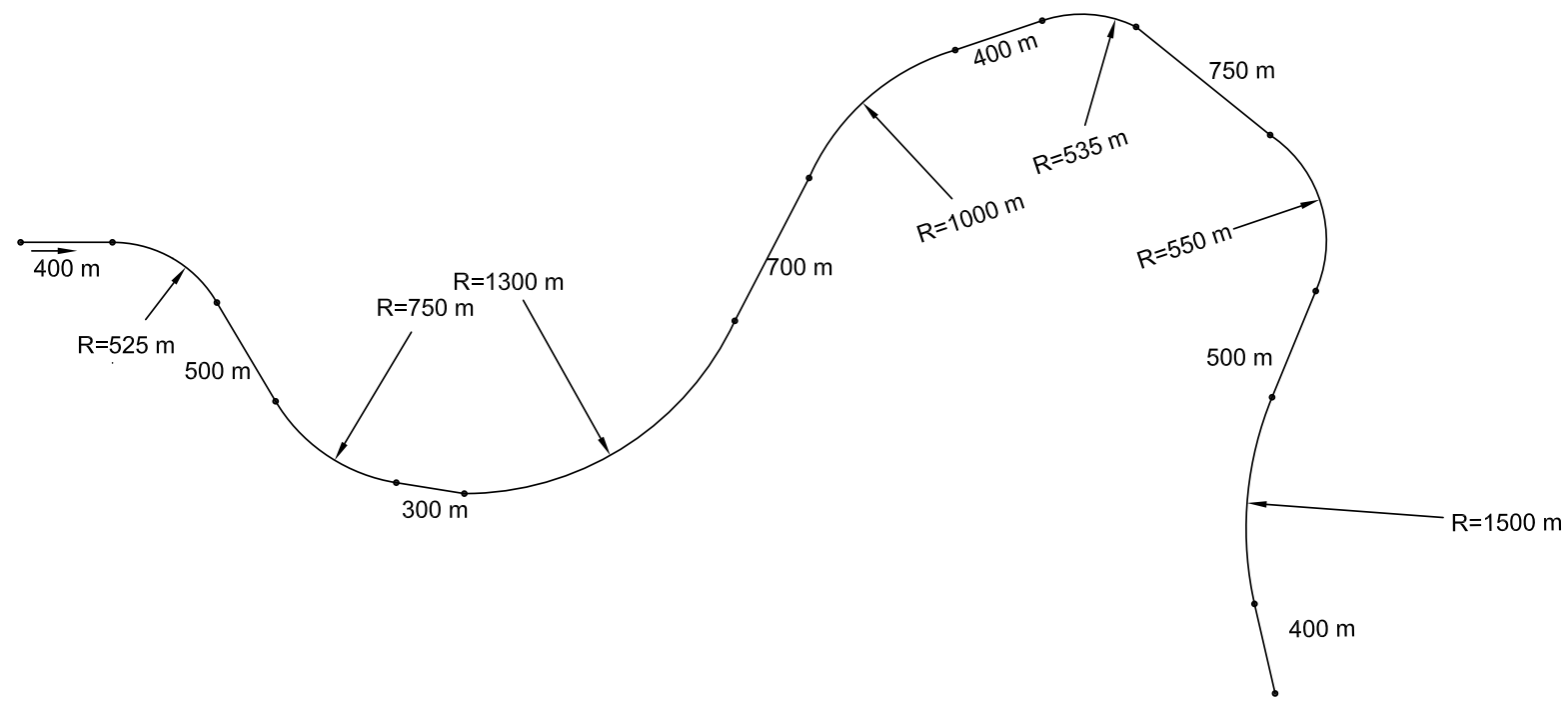

Figure 2.1: Geometric Alignment 1 


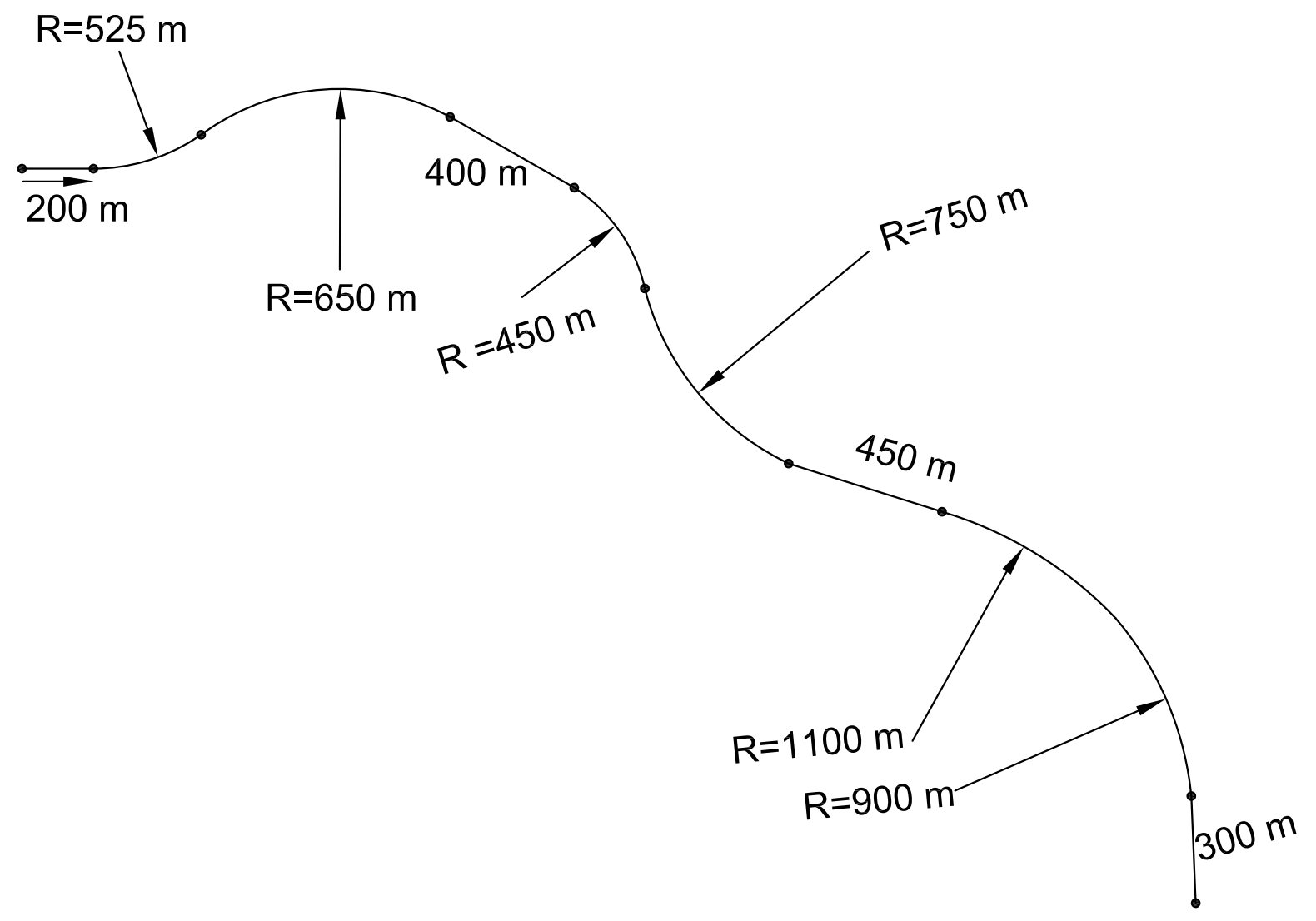

Figure 2.2: Geometric Alignment 2 


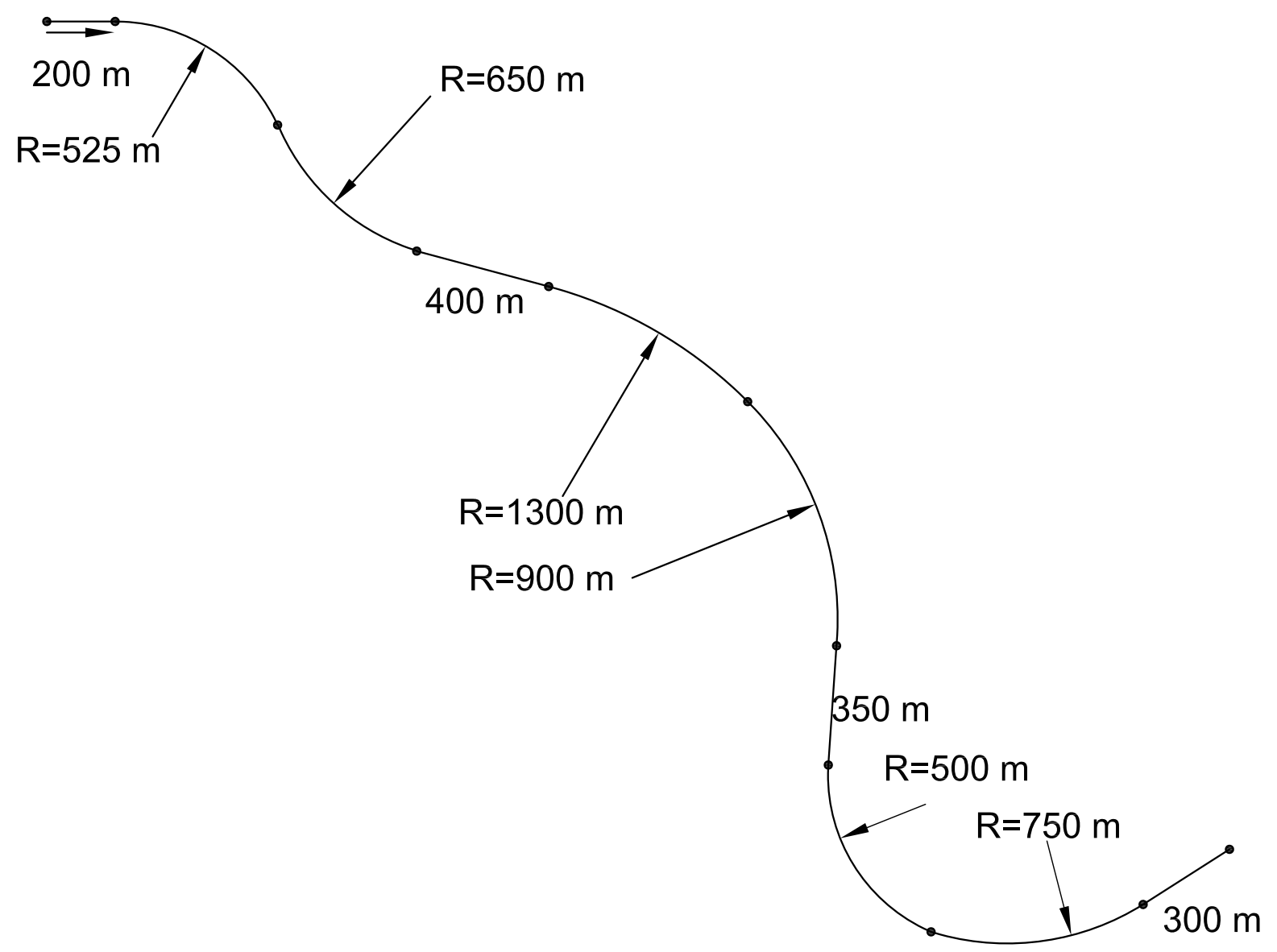

Figure 2.3: Geometric Alignment 3 


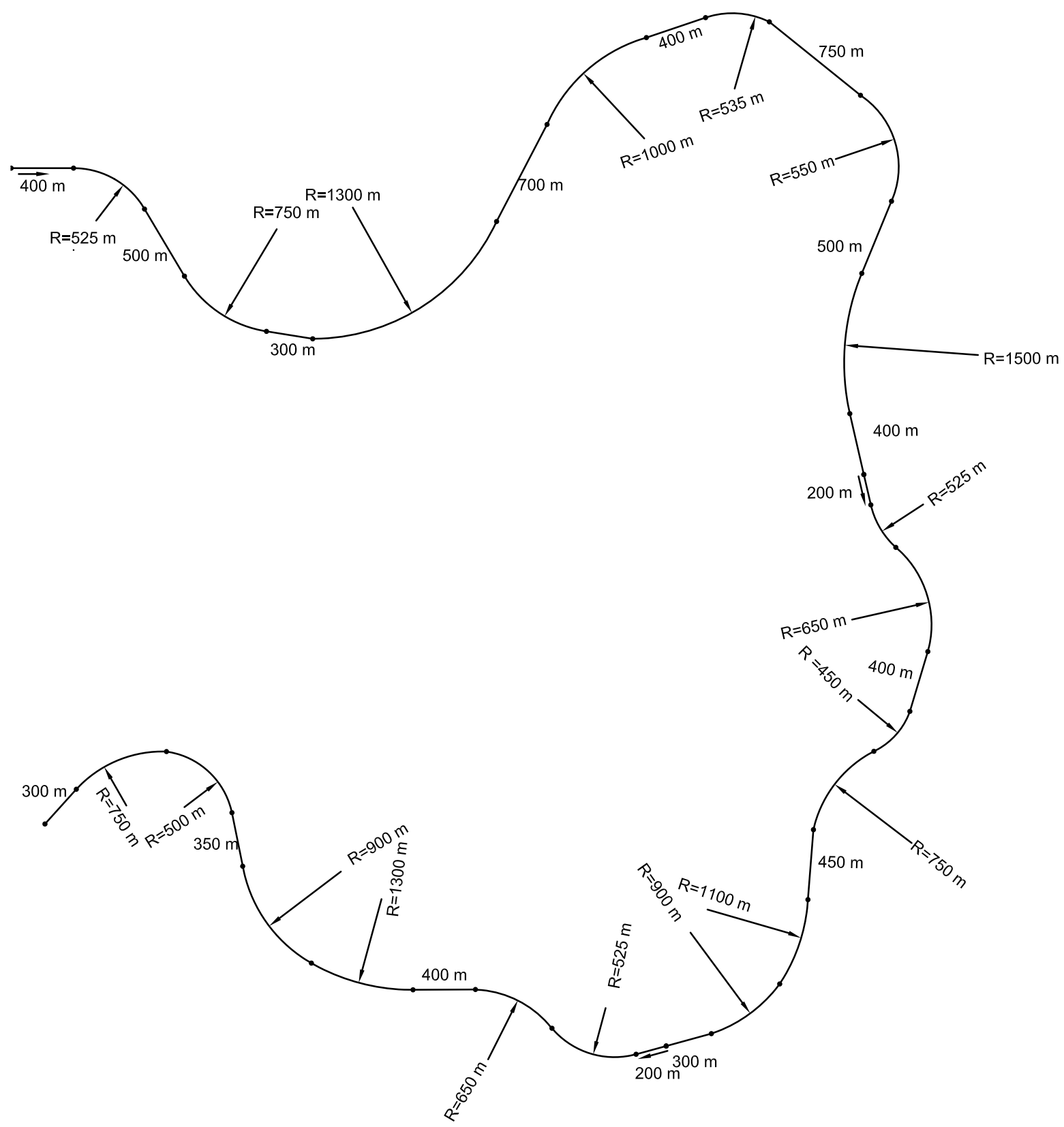

Figure 2.4: Combined Geometric Alignment 

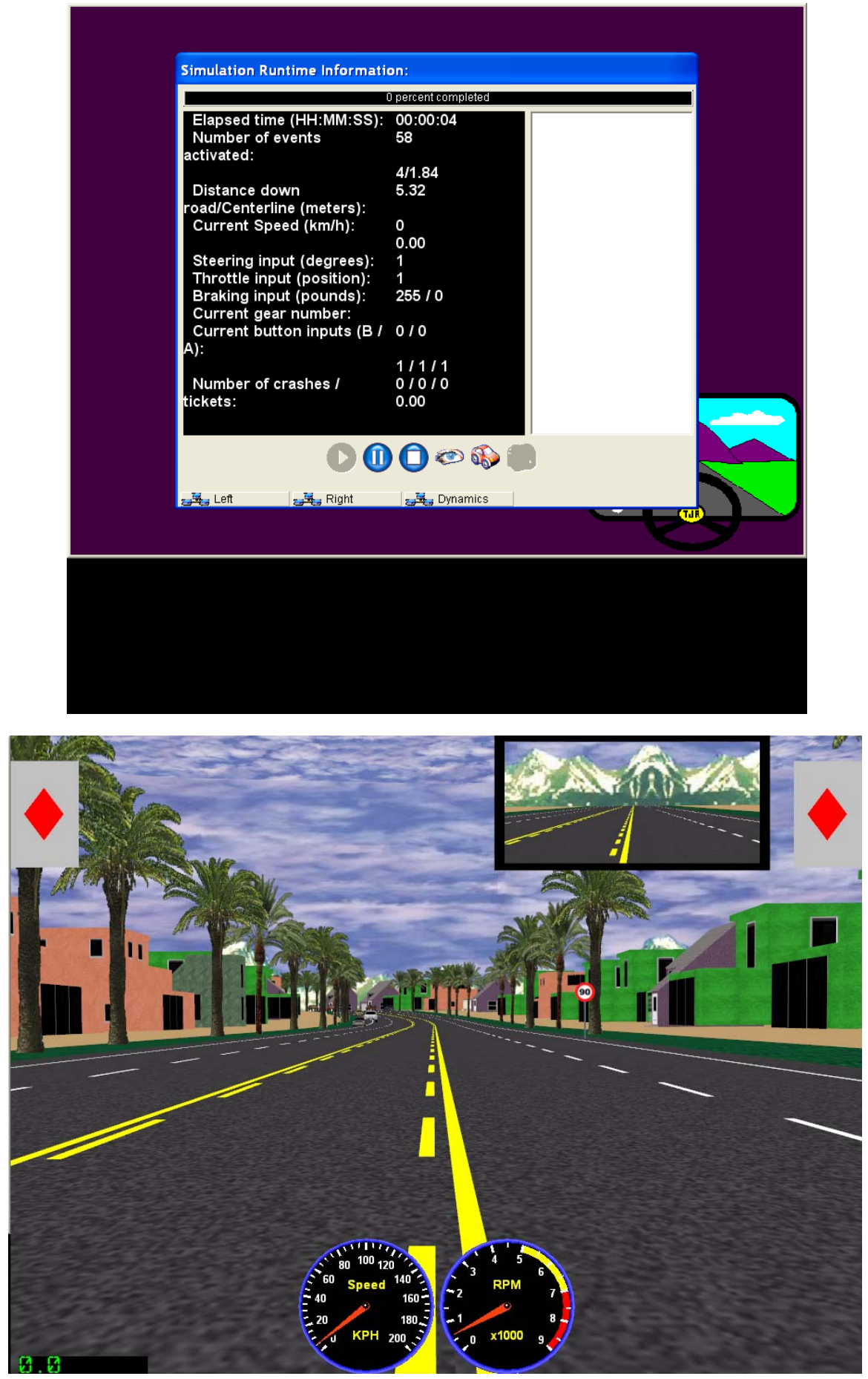

Figure 2.5: Driving Simulator Display 
Appendix 3

\section{Scatter Plot Results}


Fitting Model between curve VD30 all variable without interaction terms

\section{The GENMOD Procedure}

\begin{tabular}{|l|r|l|}
\hline \multicolumn{3}{|c|}{ Model Information } \\
\hline Data Set & ROAD.CURVE_VD30 & \\
\hline Distribution & Normal & \\
\hline Link Function & Log & \\
\hline Dependent Variable & VD30 & VD30 \\
\hline
\end{tabular}

\begin{tabular}{|l|l|}
\hline Number of Observations Read & 684 \\
\hline Number of Observations Used & 684 \\
\hline
\end{tabular}

\section{Criteria For Assessing Goodness Of Fit}

\begin{tabular}{|l|r|r|r|}
\hline Criterion & DF & Value & Value/DF \\
\hline Deviance & 679 & 18.4270 & 0.0271 \\
\hline Scaled Deviance & 679 & 684.0000 & 1.0074 \\
\hline Pearson Chi-Square & 679 & 18.4270 & 0.0271 \\
\hline Scaled Pearson X2 & 679 & 684.0000 & 1.0074 \\
\hline Log Likelihood & & 265.4823 & \\
\hline Full Log Likelihood & & 265.4823 & \\
\hline AIC (smaller is better) & & -518.9647 & \\
\hline AICC (smaller is better) & & -518.8406 & \\
\hline BIC (smaller is better) & & -491.7969 & \\
\hline
\end{tabular}

Algorithm converged.

\begin{tabular}{|l|r|r|r|r|r|r|r|}
\hline \multicolumn{7}{|c|}{ Analysis Of Maximum Likelihood Parameter Estimates } \\
\hline Parameter & DF & Estimate & $\begin{array}{r}\text { Standard } \\
\text { Error }\end{array}$ & $\begin{array}{c}\text { Wald 95\% } \\
\text { Confidence Limits }\end{array}$ & $\begin{array}{r}\text { Wald } \\
\text { Chi-Square }\end{array}$ & Pr > ChiSq \\
\hline Intercept & 1 & -1.0572 & 0.0643 & -1.1832 & -0.9313 & 270.68 & $<.0001$ \\
\hline Radius & 1 & -0.0003 & 0.0001 & -0.0004 & -0.0001 & 12.68 & 0.0004 \\
\hline PrcCrvRad & 1 & 0.0002 & 0.0000 & 0.0002 & 0.0003 & 27.41 & $<.0001$ \\
\hline PEINV & 1 & 197.0988 & 21.1871 & 155.5729 & 238.6246 & 86.54 & $<.0001$ \\
\hline VC_ratio & 1 & 0.2048 & 0.0585 & 0.0901 & 0.3195 & 12.24 & 0.0005 \\
\hline Scale & 1 & 0.1641 & 0.0044 & 0.1557 & 0.1731 & & \\
\hline
\end{tabular}

Note: The scale parameter was estimated by maximum likelihood. 
Fitting Model between curve VD30 all variable with interaction terms

\section{The GENMOD Procedure}

\begin{tabular}{|l|r|l|}
\hline \multicolumn{3}{|c|}{ Model Information } \\
\hline Data Set & ROAD.CURVE_VD30 & \\
\hline Distribution & Normal & \\
\hline Link Function & Log & \\
\hline Dependent Variable & VD30 & VD30 \\
\hline
\end{tabular}

\begin{tabular}{|l|l|}
\hline Number of Observations Read & 684 \\
\hline Number of Observations Used & 684 \\
\hline
\end{tabular}

\begin{tabular}{|l|r|l|}
\hline \multicolumn{2}{|c|}{ Class Level Information } \\
\hline Class & Levels & Values \\
\hline Turn & 2 & L R \\
\hline PrcElmnt & 3 & CC RC T \\
\hline
\end{tabular}

\begin{tabular}{|l|r|r|r|}
\hline \multicolumn{4}{|c|}{ Criteria For Assessing Goodness Of Fit } \\
\hline Criterion & DF & Value & Value/DF \\
\hline Deviance & 672 & 17.3320 & 0.0258 \\
\hline Scaled Deviance & 672 & 684.0001 & 1.0179 \\
\hline Pearson Chi-Square & 672 & 17.3320 & 0.0258 \\
\hline Scaled Pearson X2 & 672 & 684.0001 & 1.0179 \\
\hline Log Likelihood & & 286.4341 & \\
\hline Full Log Likelihood & & 286.4341 & \\
\hline AIC (smaller is better) & & -546.8682 & \\
\hline AICC (smaller is better) & & -546.3250 & \\
\hline BIC (smaller is better) & & -488.0048 & \\
\hline
\end{tabular}

Algorithm converged. 
Fitting Model between curve VD30 all variable with interaction terms

\section{The GENMOD Procedure}

\begin{tabular}{|c|c|c|c|c|c|c|c|c|c|}
\hline \multicolumn{10}{|c|}{ Analysis Of Maximum Likelihood Parameter Estimates } \\
\hline \multirow{2}{*}{$\begin{array}{l}\text { Parameter } \\
\text { Intercept }\end{array}$} & & & \multirow{2}{*}{$\begin{array}{r}\text { DF } \\
1\end{array}$} & \multirow{2}{*}{$\begin{array}{r}\text { Estimate } \\
-1.4286\end{array}$} & \multirow{2}{*}{\begin{tabular}{|r|}
$\begin{array}{r}\text { Standard } \\
\text { Error }\end{array}$ \\
0.1485 \\
\end{tabular}} & \multicolumn{2}{|c|}{$\begin{array}{c}\text { Wald 95\% } \\
\text { Confidence Limits }\end{array}$} & \multirow{2}{*}{$\begin{array}{r}\begin{array}{r}\text { Wald } \\
\text { Chi-Square }\end{array} \\
92.53\end{array}$} & \multirow{2}{*}{\begin{tabular}{|r|}
$\mathbf{P r}>\mathbf{C h i S g}$ \\
$<.0001$
\end{tabular}} \\
\hline & & & & & & -1.7197 & -1.1375 & & \\
\hline Radius & & & 1 & -0.0002 & 0.0001 & -0.0004 & -0.0000 & 5.02 & 0.0250 \\
\hline PrcCrvRad & & & 1 & -0.2550 & 0.0663 & -0.3849 & -0.1251 & 14.80 & 0.0001 \\
\hline PEINV & & & 1 & 93840.78 & 24355.54 & 46104.81 & 141576.8 & 14.85 & 0.0001 \\
\hline VC_ratio & & & 1 & 0.1969 & 0.0566 & 0.0860 & 0.3079 & 12.10 & 0.0005 \\
\hline Radius*PrcCrvRad & & & 1 & 0.0003 & 0.0001 & 0.0001 & 0.0004 & 14.89 & 0.0001 \\
\hline Radius*PEINV & & & 1 & -110.888 & 28.8810 & -167.494 & -54.2824 & 14.74 & 0.0001 \\
\hline Radius*PrcElmnt & $\mathrm{CC}$ & & 1 & -0.0057 & 0.0015 & -0.0087 & -0.0028 & 14.62 & 0.0001 \\
\hline Radius*PrcElmnt & $\mathrm{RC}$ & & 0 & 0.0000 & 0.0000 & 0.0000 & 0.0000 & & \\
\hline Radius*PrcElmnt & $\mathrm{T}$ & & 0 & 0.0000 & 0.0000 & 0.0000 & 0.0000 & & \\
\hline PrcCrvRad*DefAngl & & & 1 & -0.0001 & 0.0000 & -0.0002 & -0.0001 & 19.15 & $<.0001$ \\
\hline DefAngl*Turn & $\mathrm{L}$ & & 1 & -0.0067 & 0.0030 & -0.0125 & -0.0009 & 5.06 & 0.0245 \\
\hline DefAngl*Turn & $\mathrm{R}$ & & 1 & 0.0069 & 0.0020 & 0.0030 & 0.0108 & 11.74 & 0.0006 \\
\hline Turn*PrcElmnt & $\mathrm{L}$ & $\mathrm{CC}$ & 0 & 0.0000 & 0.0000 & 0.0000 & 0.0000 & & \\
\hline Turn*PrcElmnt & $\mathrm{L}$ & $\mathrm{RC}$ & 0 & 0.0000 & 0.0000 & 0.0000 & 0.0000 & & \\
\hline Turn*PrcElmnt & $\mathrm{L}$ & $\mathrm{T}$ & 1 & 0.5745 & 0.1826 & 0.2166 & 0.9325 & 9.90 & 0.0017 \\
\hline Turn*PrcElmnt & $\mathrm{R}$ & $\mathrm{CC}$ & 0 & 0.0000 & 0.0000 & 0.0000 & 0.0000 & & \\
\hline Turn*PrcElmnt & $\mathrm{R}$ & $\mathrm{RC}$ & 0 & 0.0000 & 0.0000 & 0.0000 & 0.0000 & & \\
\hline Turn*PrcElmnt & $\mathrm{R}$ & $\mathrm{T}$ & 0 & 0.0000 & 0.0000 & 0.0000 & 0.0000 & & \\
\hline Scale & & & 1 & 0.1592 & 0.0043 & 0.1510 & 0.1678 & & \\
\hline
\end{tabular}

Note: The scale parameter was estimated by maximum likelihood. 
Scatter Plot for curve VD30 and V/C ratio

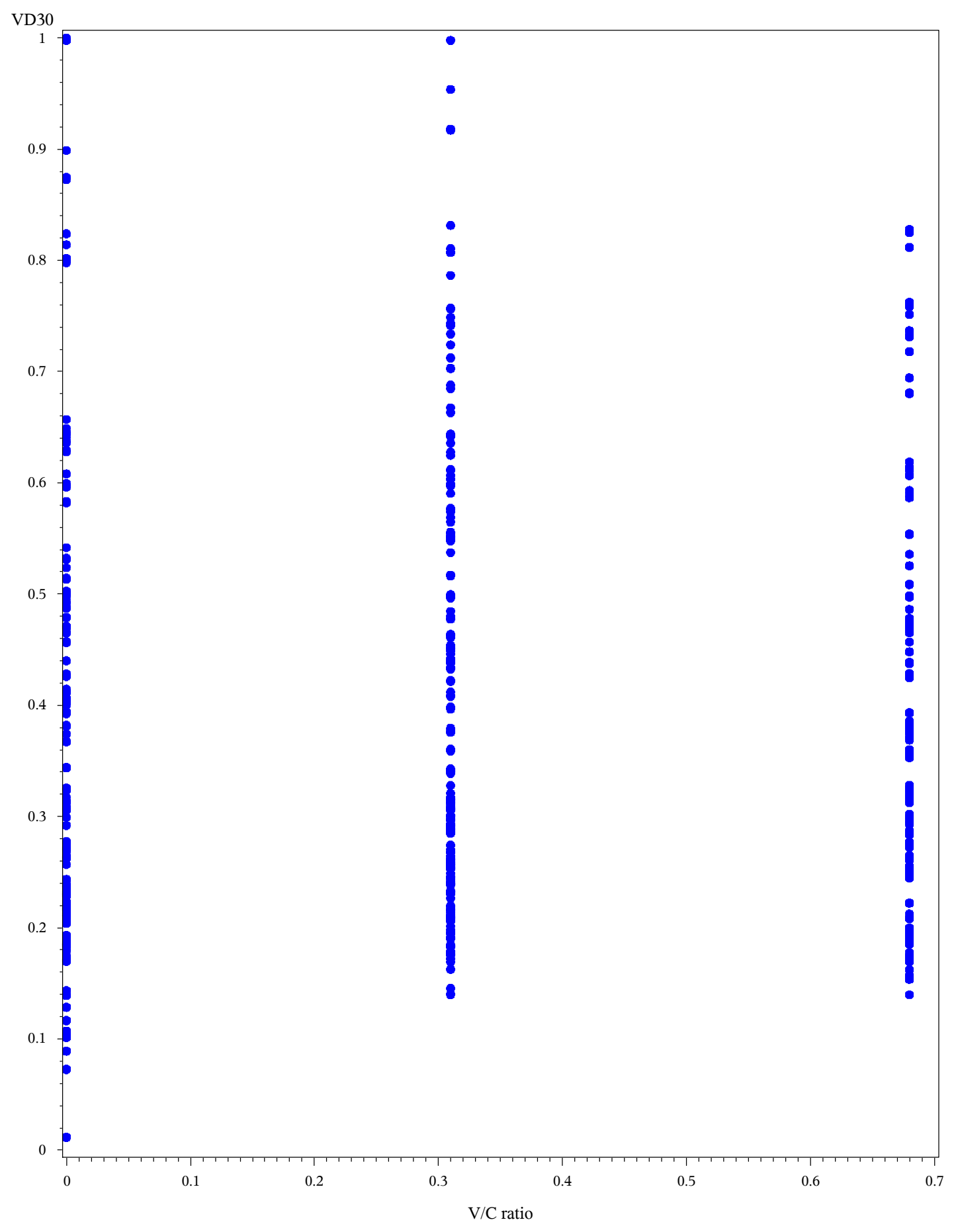




\section{Correlation between curve VD30 and V/C ratio}

\section{The CORR Procedure}

2 Variables: VD30 VC_ratio

\begin{tabular}{|l|r|r|r|r|r|r|l|}
\hline \multicolumn{7}{|c|}{ Simple Statistics } \\
\hline Variable & $\mathbf{N}$ & Mean & Std Dev & Sum & Minimum & Maximum & Label \\
\hline VD30 & 684 & 0.36571 & 0.19181 & 250.14669 & 0.01169 & 0.99999 & VD30 \\
\hline VC_ratio & 684 & 0.33000 & 0.27817 & 225.72000 & 0 & 0.68000 & V/C ratio \\
\hline
\end{tabular}

\begin{tabular}{|l|r|r|}
\hline \multicolumn{3}{|c|}{$\begin{array}{c}\text { Pearson Correlation Coefficients, } \mathbf{N}=\mathbf{6 8 4} \\
\text { Prob }>|\mathbf{r}| \text { under H0: }\end{array}$ Rho=0 } \\
\hline & VD30 & VC_ratio \\
\hline VD30 & 1.00000 & 0.10112 \\
VD30 & & 0.0081 \\
\hline VC_ratio & 0.10112 & 1.00000 \\
V/C ratio & 0.0081 & \\
\hline
\end{tabular}


Correlation between curve VD30 and V/C ratio

The CORR Procedure

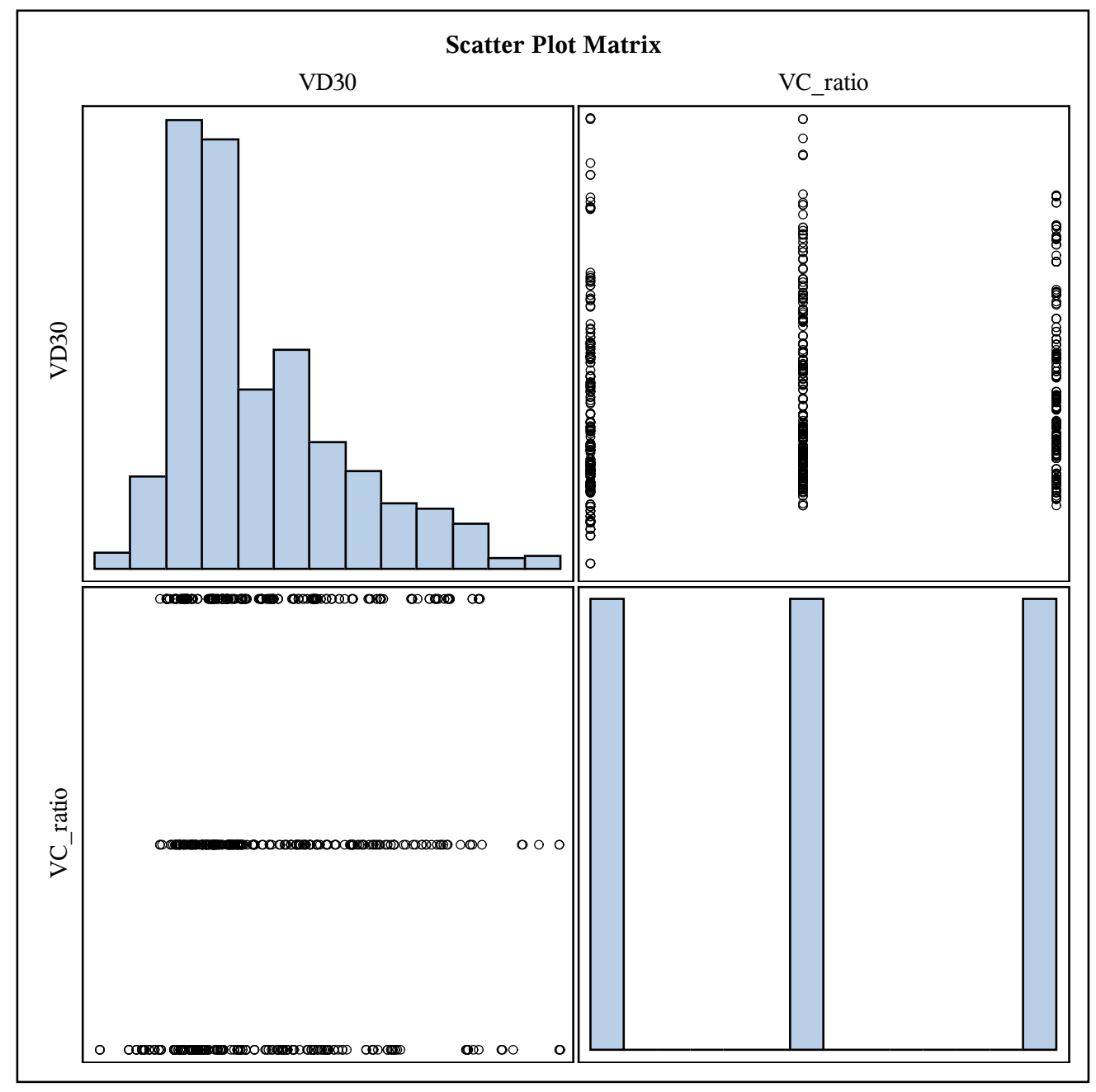


Fitting Model between curve VDF all variable without interaction terms

\section{The GENMOD Procedure}

\begin{tabular}{|l|r|l|}
\hline \multicolumn{3}{|c|}{ Model Information } \\
\hline Data Set & ROAD.CURVE_VDF & \\
\hline Distribution & Normal & \\
\hline Link Function & Log & \\
\hline Dependent Variable & VDF & VDF \\
\hline
\end{tabular}

\begin{tabular}{|l|l|}
\hline Number of Observations Read & 684 \\
\hline Number of Observations Used & 684 \\
\hline
\end{tabular}

\begin{tabular}{|l|r|l|}
\hline \multicolumn{3}{|c|}{ Class Level Information } \\
\hline Class & Levels & Values \\
\hline PrcElmnt & 3 & CC RC T \\
\hline
\end{tabular}

\begin{tabular}{|l|r|r|r|}
\hline \multicolumn{4}{|c|}{ Criteria For Assessing Goodness Of Fit } \\
\hline Criterion & DF & Value & Value/DF \\
\hline Deviance & 680 & 7.8166 & 0.0115 \\
\hline Scaled Deviance & 680 & 684.0001 & 1.0059 \\
\hline Pearson Chi-Square & 680 & 7.8166 & 0.0115 \\
\hline Scaled Pearson X2 & 680 & 684.0001 & 1.0059 \\
\hline Log Likelihood & & 558.7707 & \\
\hline Full Log Likelihood & & 558.7707 & \\
\hline AIC (smaller is better) & & -1107.5414 & \\
\hline AICC (smaller is better) & & -1107.4529 & \\
\hline BIC (smaller is better) & & -1084.9016 & \\
\hline
\end{tabular}

Algorithm converged. 
Fitting Model between curve VDF all variable with interaction terms

The GENMOD Procedure

\begin{tabular}{|l|r|l|}
\hline \multicolumn{3}{|c|}{ Model Information } \\
\hline Data Set & ROAD.CURVE_VDF & \\
\hline Distribution & Normal & \\
\hline Link Function & Log & \\
\hline Dependent Variable & VDF & VDF \\
\hline
\end{tabular}

\begin{tabular}{|l|l|}
\hline Number of Observations Read & 684 \\
\hline Number of Observations Used & 684 \\
\hline
\end{tabular}

\begin{tabular}{|l|r|l|}
\hline \multicolumn{2}{|c|}{ Class Level Information } \\
\hline Class & Levels & Values \\
\hline Turn & 2 & L R \\
\hline PrcElmnt & 3 & CC RC T \\
\hline
\end{tabular}

\begin{tabular}{|l|r|r|r|}
\hline \multicolumn{4}{|c|}{ Criteria For Assessing Goodness Of Fit } \\
\hline Criterion & DF & Value & Value/DF \\
\hline Deviance & 674 & 7.6019 & 0.0113 \\
\hline Scaled Deviance & 674 & 684.0001 & 1.0148 \\
\hline Pearson Chi-Square & 674 & 7.6019 & 0.0113 \\
\hline Scaled Pearson X2 & 674 & 684.0001 & 1.0148 \\
\hline Log Likelihood & & 568.2936 & \\
\hline Full Log Likelihood & & 568.2936 & \\
\hline AIC (smaller is better) & & -1114.5873 & \\
\hline AICC (smaller is better) & & -1114.1944 & \\
\hline BIC (smaller is better) & & -1064.7798 & \\
\hline
\end{tabular}

Algorithm converged. 


\section{Fitting Model between curve VDF all variable with interaction terms}

\section{The GENMOD Procedure}

\begin{tabular}{|c|c|c|c|c|c|c|c|c|}
\hline \multicolumn{9}{|c|}{ Analysis Of Maximum Likelihood Parameter Estimates } \\
\hline Parameter & & DF & Estimate & $\begin{array}{r}\text { Standard } \\
\text { Error }\end{array}$ & $\begin{array}{l}\text { Walc } \\
\text { Conf } \\
\text { Li }\end{array}$ & $\begin{array}{l}95 \% \\
\text { dence } \\
\text { nits }\end{array}$ & $\begin{array}{r}\text { Wald } \\
\text { Chi-Square }\end{array}$ & $\operatorname{Pr}>$ ChiSq \\
\hline Intercept & & 1 & -1.2524 & 0.0258 & -1.3029 & -1.2020 & 2364.15 & $<.0001$ \\
\hline PrcCrvRad & & 1 & 0.0007 & 0.0002 & 0.0004 & 0.0011 & 13.72 & 0.0002 \\
\hline VC_ratio & & 1 & 0.2187 & 0.0559 & 0.1091 & 0.3282 & 15.31 & $<.0001$ \\
\hline PrcElmnt & $\mathrm{CC}$ & 1 & -0.8034 & 0.3476 & -1.4847 & -0.1221 & 5.34 & 0.0208 \\
\hline PrcElmnt & $\mathrm{RC}$ & 1 & -0.6102 & 0.3186 & -1.2347 & 0.0143 & 3.67 & 0.0555 \\
\hline PrcElmnt & $\mathrm{T}$ & 0 & 0.0000 & 0.0000 & 0.0000 & 0.0000 & & \\
\hline PEINV*Radius & & 1 & 0.5368 & 0.1595 & 0.2241 & 0.8495 & 11.32 & 0.0008 \\
\hline PrcCrvRad*VC_ratio & & 1 & -0.0033 & 0.0009 & -0.0050 & -0.0016 & 14.64 & 0.0001 \\
\hline VC_ratio*PEINV & & 1 & -1760.37 & 503.6704 & -2747.54 & -773.190 & 12.22 & 0.0005 \\
\hline VC_ratio*PrcElmnt & $\mathrm{CC}$ & 1 & 5.3657 & 1.4419 & 2.5396 & 8.1918 & 13.85 & 0.0002 \\
\hline VC_ratio*PrcElmnt & $\mathrm{RC}$ & 1 & 5.3248 & 1.4433 & 2.4960 & 8.1537 & 13.61 & 0.0002 \\
\hline VC_ratio*PrcElmnt & $\mathrm{T}$ & 0 & 0.0000 & 0.0000 & 0.0000 & 0.0000 & . & \\
\hline Scale & & 1 & 0.1054 & 0.0029 & 0.1000 & 0.1112 & & \\
\hline
\end{tabular}

Note: The scale parameter was estimated by maximum likelihood. 
Scatter Plot for curve VDH and V/C ratio

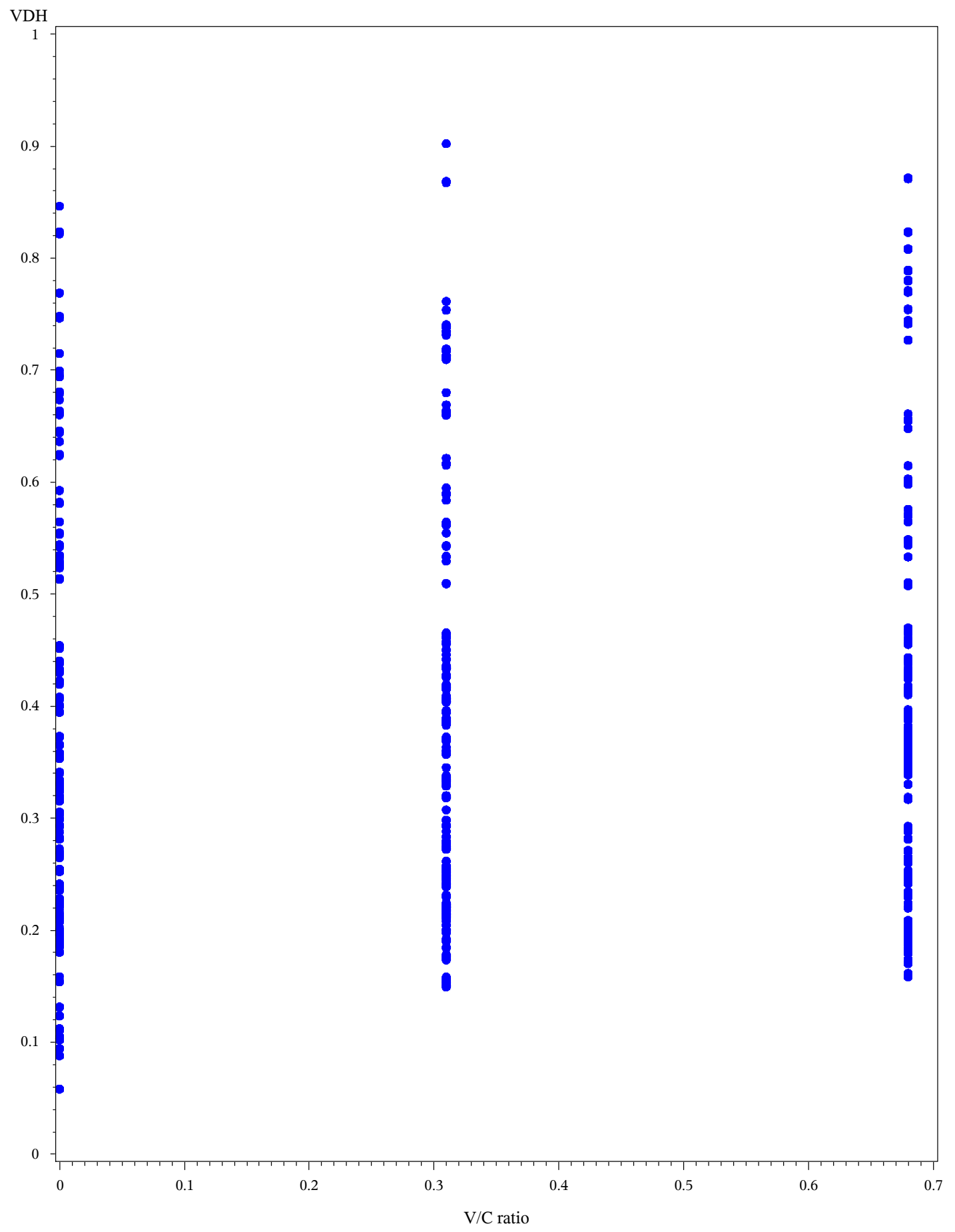




\section{Correlation between curve $V D H$ and $V / C$ ratio}

\section{The CORR Procedure}

2 Variables: VDH VC_ratio

\begin{tabular}{|l|r|r|r|r|r|r|l|}
\hline \multicolumn{10}{|c|}{ Simple Statistics } \\
\hline Variable & $\mathbf{N}$ & Mean & Std Dev & Sum & Minimum & Maximum & Label \\
\hline VDH & 684 & 0.36608 & 0.18090 & 250.39578 & 0.05830 & 0.90233 & VDH \\
\hline VC_ratio & 684 & 0.33000 & 0.27817 & 225.72000 & 0 & 0.68000 & V/C ratio \\
\hline
\end{tabular}

\begin{tabular}{|l|r|r|}
\hline \multicolumn{3}{|c|}{$\begin{array}{r}\text { Pearson Correlation Coefficients, } \mathbf{N}=\mathbf{6 8 4} \\
\text { Prob }>|\mathbf{r}| \text { under H0: }\end{array}$} \\
\hline & VDH $=\mathbf{0}$ & VC_ratio \\
\hline VDH & 1.00000 & 0.15348 \\
VDH & & $<.0001$ \\
\hline VC_ratio & 0.15348 & 1.00000 \\
V/C ratio & $<.0001$ & \\
\hline
\end{tabular}


Correlation between curve VDH and V/C ratio

The CORR Procedure

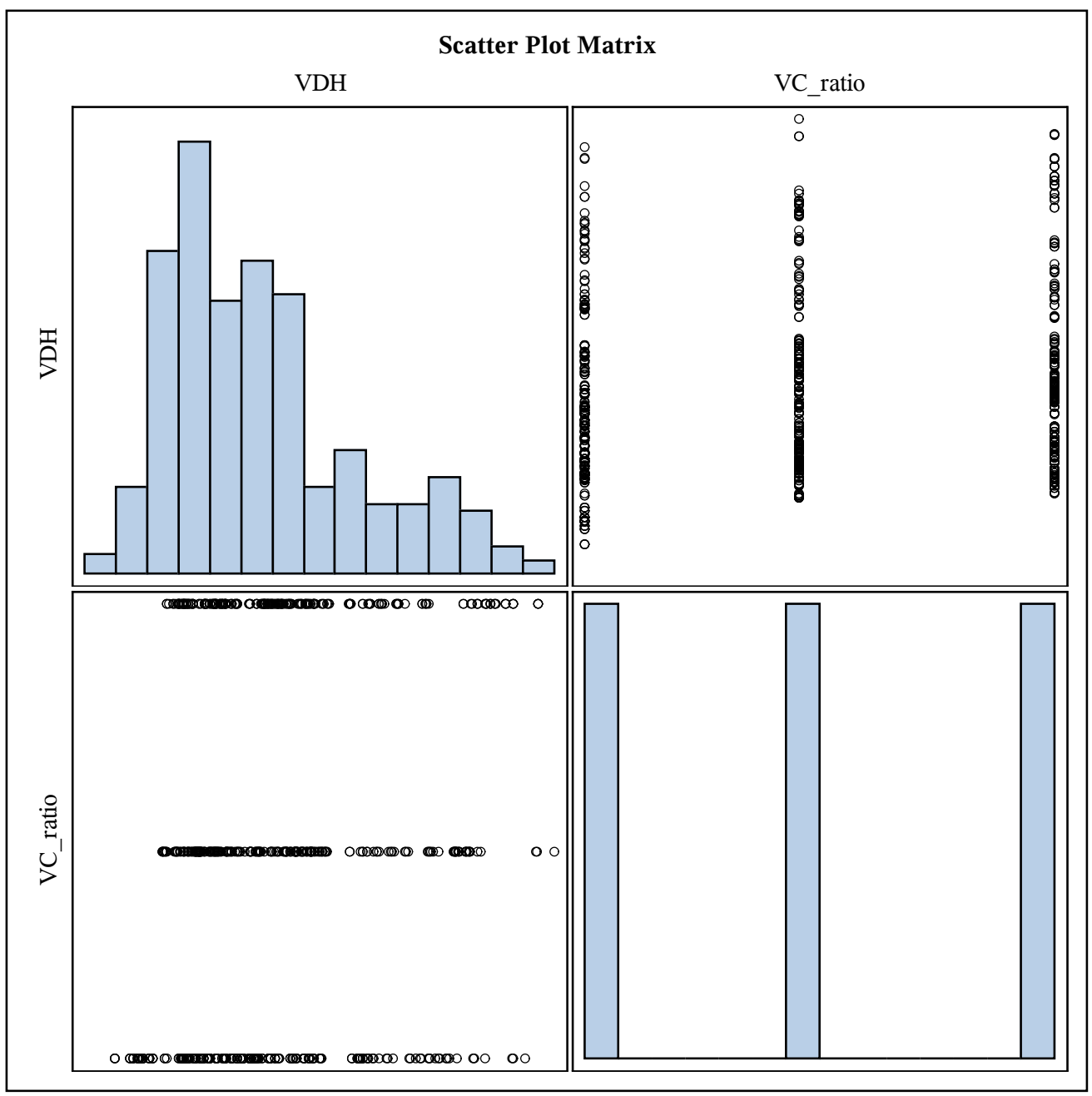


Fitting Model between curve VD30 and V/C ratio

\section{The GENMOD Procedure}

\begin{tabular}{|l|r|l|}
\hline \multicolumn{3}{|c|}{ Model Information } \\
\hline Data Set & ROAD.CURVE_VD30 & \\
\hline Distribution & Normal & \\
\hline Link Function & Log & \\
\hline Dependent Variable & VD30 & VD30 \\
\hline
\end{tabular}

\begin{tabular}{|l|l|}
\hline Number of Observations Read & 684 \\
\hline Number of Observations Used & 684 \\
\hline
\end{tabular}

\section{Criteria For Assessing Goodness Of Fit}

\begin{tabular}{|l|r|r|r|}
\hline Criterion & DF & Value & Value/DF \\
\hline Deviance & 682 & 24.8798 & 0.0365 \\
\hline Scaled Deviance & 682 & 684.0001 & 1.0029 \\
\hline Pearson Chi-Square & 682 & 24.8798 & 0.0365 \\
\hline Scaled Pearson X2 & 682 & 684.0001 & 1.0029 \\
\hline Log Likelihood & & 162.8004 & \\
\hline Full Log Likelihood & & 162.8004 & \\
\hline AIC (smaller is better) & & -319.6008 & \\
\hline AICC (smaller is better) & & -319.5655 & \\
\hline BIC (smaller is better) & & -306.0169 & \\
\hline
\end{tabular}

Algorithm converged.

\begin{tabular}{|l|r|r|r|r|r|r|r|}
\hline \multicolumn{7}{|c|}{ Analysis Of Maximum Likelihood Parameter Estimates } \\
\hline Parameter & DF & Estimate & $\begin{array}{r}\text { Standard } \\
\text { Error }\end{array}$ & $\begin{array}{c}\text { Wald 95\% } \\
\text { Confidence } \\
\text { Limits }\end{array}$ & $\begin{array}{r}\text { Wald } \\
\text { Chi-Square }\end{array}$ & Pr > ChiSq \\
\hline Intercept & 1 & -1.0680 & 0.0322 & -1.1310 & -1.0050 & 1103.47 & $<.0001$ \\
\hline VC_ratio & 1 & 0.1842 & 0.0704 & 0.0463 & 0.3222 & 6.85 & 0.0089 \\
\hline Scale & 1 & 0.1907 & 0.0052 & 0.1809 & 0.2011 & & \\
\hline
\end{tabular}

Note: The scale parameter was estimated by maximum likelihood. 
Fitting Model between curve VDF and V/C ratio

\section{The GENMOD Procedure}

\begin{tabular}{|l|r|l|}
\hline \multicolumn{3}{|c|}{ Model Information } \\
\hline Data Set & ROAD.CURVE_VDF & \\
\hline Distribution & Normal & \\
\hline Link Function & Log & \\
\hline Dependent Variable & VDF & VDF \\
\hline
\end{tabular}

\begin{tabular}{|l|l|}
\hline Number of Observations Read & 684 \\
\hline Number of Observations Used & 684 \\
\hline
\end{tabular}

\section{Criteria For Assessing Goodness Of Fit}

\begin{tabular}{|l|r|r|r|}
\hline Criterion & DF & Value & Value/DF \\
\hline Deviance & 682 & 14.1224 & 0.0207 \\
\hline Scaled Deviance & 682 & 684.0000 & 1.0029 \\
\hline Pearson Chi-Square & 682 & 14.1224 & 0.0207 \\
\hline Scaled Pearson X2 & 682 & 684.0000 & 1.0029 \\
\hline Log Likelihood & & 356.4736 & \\
\hline Full Log Likelihood & & 356.4736 & \\
\hline AIC (smaller is better) & & -706.9472 & \\
\hline AICC (smaller is better) & & -706.9119 & \\
\hline BIC (smaller is better) & & -693.3633 & \\
\hline
\end{tabular}

Algorithm converged.

\begin{tabular}{|l|r|r|r|r|r|r|r|}
\hline \multicolumn{7}{|c|}{ Analysis Of Maximum Likelihood Parameter Estimates } \\
\hline Parameter & DF & Estimate & $\begin{array}{r}\text { Standard } \\
\text { Error }\end{array}$ & $\begin{array}{c}\text { Wald 95\% } \\
\text { Confidence } \\
\text { Limits }\end{array}$ & $\begin{array}{r}\text { Wald } \\
\text { Chi-Square }\end{array}$ & Pr > ChiSq \\
\hline Intercept & 1 & -1.0729 & 0.0242 & -1.1204 & -1.0254 & 1959.94 & $<.0001$ \\
\hline VC_ratio & 1 & 0.2478 & 0.0522 & 0.1454 & 0.3502 & 22.51 & $<.0001$ \\
\hline Scale & 1 & 0.1437 & 0.0039 & 0.1363 & 0.1515 & & \\
\hline
\end{tabular}

Note: The scale parameter was estimated by maximum likelihood. 
Fitting Model between curve VDH and V/C ratio

\section{The GENMOD Procedure}

\begin{tabular}{|l|r|l|}
\hline \multicolumn{3}{|c|}{ Model Information } \\
\hline Data Set & ROAD.CURVE_VDH & \\
\hline Distribution & Normal & \\
\hline Link Function & Log & \\
\hline Dependent Variable & VDH & VDH \\
\hline
\end{tabular}

\begin{tabular}{|l|l|}
\hline Number of Observations Read & 684 \\
\hline Number of Observations Used & 684 \\
\hline
\end{tabular}

\section{Criteria For Assessing Goodness Of Fit}

\begin{tabular}{|l|r|r|r|}
\hline Criterion & DF & Value & Value/DF \\
\hline Deviance & 682 & 21.8352 & 0.0320 \\
\hline Scaled Deviance & 682 & 684.0000 & 1.0029 \\
\hline Pearson Chi-Square & 682 & 21.8352 & 0.0320 \\
\hline Scaled Pearson X2 & 682 & 684.0000 & 1.0029 \\
\hline Log Likelihood & & 207.4419 & \\
\hline Full Log Likelihood & & 207.4419 & \\
\hline AIC (smaller is better) & & -408.8839 & \\
\hline AICC (smaller is better) & & -408.8486 & \\
\hline BIC (smaller is better) & & -395.3000 & \\
\hline
\end{tabular}

Algorithm converged.

\begin{tabular}{|l|r|r|r|r|r|r|r|}
\hline \multicolumn{7}{|c|}{ Analysis Of Maximum Likelihood Parameter Estimates } \\
\hline Parameter & DF & Estimate & $\begin{array}{r}\text { Standard } \\
\text { Error }\end{array}$ & $\begin{array}{c}\text { Wald 95\% } \\
\text { Confidence } \\
\text { Limits }\end{array}$ & $\begin{array}{r}\text { Wald } \\
\text { Chi-Square }\end{array}$ & Pr > ChiSq \\
\hline Intercept & 1 & -1.0955 & 0.0309 & -1.1560 & -1.0351 & 1260.35 & $<.0001$ \\
\hline VC_ratio & 1 & 0.2665 & 0.0663 & 0.1365 & 0.3964 & 16.15 & $<.0001$ \\
\hline Scale & 1 & 0.1787 & 0.0048 & 0.1694 & 0.1884 & & \\
\hline
\end{tabular}

Note: The scale parameter was estimated by maximum likelihood. 
Fitting Model between Tangent VD30 and V/C ratio

\section{The GENMOD Procedure}

\begin{tabular}{|l|r|l|}
\hline \multicolumn{3}{|c|}{ Model Information } \\
\hline Data Set & ROAD.TANGENT_VD30 & \\
\hline Distribution & Normal & \\
\hline Link Function & Log & \\
\hline Dependent Variable & VD30 & VD30 \\
\hline
\end{tabular}

\begin{tabular}{|l|l|}
\hline Number of Observations Read & 468 \\
\hline Number of Observations Used & 468 \\
\hline
\end{tabular}

\section{Criteria For Assessing Goodness Of Fit}

\begin{tabular}{|l|r|r|r|}
\hline Criterion & DF & Value & Value/DF \\
\hline Deviance & 466 & 14.9514 & 0.0321 \\
\hline Scaled Deviance & 466 & 468.0000 & 1.0043 \\
\hline Pearson Chi-Square & 466 & 14.9514 & 0.0321 \\
\hline Scaled Pearson X2 & 466 & 468.0000 & 1.0043 \\
\hline Log Likelihood & & 141.7536 & \\
\hline Full Log Likelihood & & 141.7536 & \\
\hline AIC (smaller is better) & & -277.5072 & \\
\hline AICC (smaller is better) & & -277.4555 & \\
\hline BIC (smaller is better) & & -265.0618 & \\
\hline
\end{tabular}

Algorithm converged.

\begin{tabular}{|l|r|r|r|r|r|r|r|}
\hline \multicolumn{7}{|c|}{ Analysis Of Maximum Likelihood Parameter Estimates } \\
\hline Parameter & DF & Estimate & $\begin{array}{r}\text { Standard } \\
\text { Error }\end{array}$ & $\begin{array}{c}\text { Wald 95\% } \\
\text { Confidence } \\
\text { Limits }\end{array}$ & $\begin{array}{r}\text { Wald } \\
\text { Chi-Square }\end{array}$ & Pr > ChiSq \\
\hline Intercept & 1 & -0.8116 & 0.0276 & -0.8656 & -0.7575 & 865.07 & $<.0001$ \\
\hline VC_ratio & 1 & 0.2980 & 0.0583 & 0.1837 & 0.4122 & 26.11 & $<.0001$ \\
\hline Scale & 1 & 0.1787 & 0.0058 & 0.1676 & 0.1906 & & \\
\hline
\end{tabular}

Note: The scale parameter was estimated by maximum likelihood. 
Fitting Model between Tangent VDF and V/C ratio

\section{The GENMOD Procedure}

\begin{tabular}{|l|r|l|}
\hline \multicolumn{3}{|c|}{ Model Information } \\
\hline Data Set & ROAD.TANGENT_VDF & \\
\hline Distribution & Normal & \\
\hline Link Function & Log & \\
\hline Dependent Variable & VDF & VDF \\
\hline
\end{tabular}

\begin{tabular}{|l|l|}
\hline Number of Observations Read & 468 \\
\hline Number of Observations Used & 468 \\
\hline
\end{tabular}

\section{Criteria For Assessing Goodness Of Fit}

\begin{tabular}{|l|r|r|r|}
\hline Criterion & DF & Value & Value/DF \\
\hline Deviance & 466 & 6.9288 & 0.0149 \\
\hline Scaled Deviance & 466 & 468.0000 & 1.0043 \\
\hline Pearson Chi-Square & 466 & 6.9288 & 0.0149 \\
\hline Scaled Pearson X2 & 466 & 468.0000 & 1.0043 \\
\hline Log Likelihood & & 321.7281 & \\
\hline Full Log Likelihood & & 321.7281 & \\
\hline AIC (smaller is better) & & -637.4562 & \\
\hline AICC (smaller is better) & & -637.4044 & \\
\hline BIC (smaller is better) & & -625.0108 & \\
\hline
\end{tabular}

Algorithm converged.

\begin{tabular}{|l|r|r|r|r|r|r|r|}
\hline \multicolumn{7}{|c|}{ Analysis Of Maximum Likelihood Parameter Estimates } \\
\hline Parameter & DF & Estimate & $\begin{array}{r}\text { Standard } \\
\text { Error }\end{array}$ & $\begin{array}{c}\text { Wald 95\% } \\
\text { Confidence } \\
\text { Limits }\end{array}$ & $\begin{array}{r}\text { Wald } \\
\text { Chi-Square }\end{array}$ & Pr > ChiSq \\
\hline Intercept & 1 & -0.8522 & 0.0196 & -0.8906 & -0.8137 & 1886.23 & $<.0001$ \\
\hline VC_ratio & 1 & 0.3590 & 0.0411 & 0.2785 & 0.4394 & 76.45 & $<.0001$ \\
\hline Scale & 1 & 0.1217 & 0.0040 & 0.1141 & 0.1297 & & \\
\hline
\end{tabular}

Note: The scale parameter was estimated by maximum likelihood. 
Fitting Model between Tangent VDH and V/C ratio

\section{The GENMOD Procedure}

\begin{tabular}{|l|r|r|}
\hline \multicolumn{3}{|c|}{ Model Information } \\
\hline Data Set & ROAD.TANGENT_VDH & \\
\hline Distribution & Normal & \\
\hline Link Function & Log & \\
\hline Dependent Variable & VDH & VDH \\
\hline
\end{tabular}

\begin{tabular}{|l|l|}
\hline Number of Observations Read & 468 \\
\hline Number of Observations Used & 468 \\
\hline
\end{tabular}

\section{Criteria For Assessing Goodness Of Fit}

\begin{tabular}{|l|r|r|r|}
\hline Criterion & DF & Value & Value/DF \\
\hline Deviance & 466 & 9.4992 & 0.0204 \\
\hline Scaled Deviance & 466 & 468.0000 & 1.0043 \\
\hline Pearson Chi-Square & 466 & 9.4992 & 0.0204 \\
\hline Scaled Pearson X2 & 466 & 468.0000 & 1.0043 \\
\hline Log Likelihood & & 247.8965 & \\
\hline Full Log Likelihood & & 247.8965 & \\
\hline AIC (smaller is better) & & -489.7930 & \\
\hline AICC (smaller is better) & & -489.7412 & \\
\hline BIC (smaller is better) & & -477.3475 & \\
\hline
\end{tabular}

Algorithm converged.

\begin{tabular}{|l|r|r|r|r|r|r|r|}
\hline \multicolumn{7}{|c|}{ Analysis Of Maximum Likelihood Parameter Estimates } \\
\hline Parameter & DF & Estimate & $\begin{array}{r}\text { Standard } \\
\text { Error }\end{array}$ & $\begin{array}{c}\text { Wald 95\% } \\
\text { Confidence } \\
\text { Limits }\end{array}$ & $\begin{array}{r}\text { Wald } \\
\text { Chi-Square }\end{array}$ & Pr > ChiSq \\
\hline Intercept & 1 & -0.7662 & 0.0210 & -0.8073 & -0.7251 & 1334.38 & $<.0001$ \\
\hline VC_ratio & 1 & 0.3923 & 0.0435 & 0.3070 & 0.4775 & 81.35 & $<.0001$ \\
\hline Scale & 1 & 0.1425 & 0.0047 & 0.1336 & 0.1519 & & \\
\hline
\end{tabular}

Note: The scale parameter was estimated by maximum likelihood. 
Fitting Model between Tangent VD30 all variable without interaction terms

\section{The GENMOD Procedure}

\begin{tabular}{|l|r|l|}
\hline \multicolumn{3}{|c|}{ Model Information } \\
\hline Data Set & ROAD.TANGENT_VD30 & \\
\hline Distribution & Normal & \\
\hline Link Function & Log & \\
\hline Dependent Variable & VD30 & VD30 \\
\hline
\end{tabular}

\begin{tabular}{|l|l|}
\hline Number of Observations Read & 468 \\
\hline Number of Observations Used & 468 \\
\hline
\end{tabular}

\begin{tabular}{|l|r|r|r|}
\hline \multicolumn{4}{|c|}{ Criteria For Assessing Goodness Of Fit } \\
\hline Criterion & DF & Value & Value/DF \\
\hline Deviance & 466 & 14.9514 & 0.0321 \\
\hline Scaled Deviance & 466 & 468.0000 & 1.0043 \\
\hline Pearson Chi-Square & 466 & 14.9514 & 0.0321 \\
\hline Scaled Pearson X2 & 466 & 468.0000 & 1.0043 \\
\hline Log Likelihood & & 141.7536 & \\
\hline Full Log Likelihood & & 141.7536 & \\
\hline AIC (smaller is better) & & -277.5072 & \\
\hline AICC (smaller is better) & & -277.4555 & \\
\hline BIC (smaller is better) & & -265.0618 & \\
\hline
\end{tabular}

Algorithm converged.

\begin{tabular}{|l|r|r|r|r|r|r|r|}
\hline \multicolumn{7}{|c|}{ Analysis Of Maximum Likelihood Parameter Estimates } \\
\hline Parameter & DF & Estimate & $\begin{array}{r}\text { Standard } \\
\text { Error }\end{array}$ & $\begin{array}{c}\text { Wald 95\% } \\
\text { Confidence } \\
\text { Limits }\end{array}$ & $\begin{array}{r}\text { Wald } \\
\text { Chi-Square }\end{array}$ & Pr > ChiSq \\
\hline Intercept & 1 & -0.8116 & 0.0276 & -0.8656 & -0.7575 & 865.07 & $<.0001$ \\
\hline VC_ratio & 1 & 0.2980 & 0.0583 & 0.1837 & 0.4122 & 26.11 & $<.0001$ \\
\hline Scale & 1 & 0.1787 & 0.0058 & 0.1676 & 0.1906 & & \\
\hline
\end{tabular}

Note: The scale parameter was estimated by maximum likelihood. 
Fitting Model between Tangent VD30 all variable with interaction terms

\section{The GENMOD Procedure}

\begin{tabular}{|l|r|l|}
\hline \multicolumn{3}{|c|}{ Model Information } \\
\hline Data Set & ROAD.TANGENT_VD30 & \\
\hline Distribution & Normal & \\
\hline Link Function & Log & \\
\hline Dependent Variable & VD30 & VD30 \\
\hline
\end{tabular}

\begin{tabular}{|l|l|}
\hline Number of Observations Read & 468 \\
\hline Number of Observations Used & 468 \\
\hline
\end{tabular}

\begin{tabular}{|l|r|l|}
\hline \multicolumn{3}{|c|}{$\begin{array}{c}\text { Class Level } \\
\text { Information }\end{array}$} \\
\hline Class & Levels & Values \\
\hline Turn & 2 & L R \\
\hline
\end{tabular}

\begin{tabular}{|l|r|r|r|}
\hline \multicolumn{4}{|c|}{ Criteria For Assessing Goodness Of Fit } \\
\hline Criterion & DF & Value & Value/DF \\
\hline Deviance & 463 & 14.5369 & 0.0314 \\
\hline Scaled Deviance & 463 & 468.0000 & 1.0108 \\
\hline Pearson Chi-Square & 463 & 14.5369 & 0.0314 \\
\hline Scaled Pearson X2 & 463 & 468.0000 & 1.0108 \\
\hline Log Likelihood & & 148.3324 & \\
\hline Full Log Likelihood & & 148.3324 & \\
\hline AIC (smaller is better) & & -284.6649 & \\
\hline AICC (smaller is better) & & -284.4827 & \\
\hline BIC (smaller is better) & & -259.7741 & \\
\hline
\end{tabular}

Algorithm converged. 
Fitting Model between Tangent VD30 all variable with interaction terms

\section{The GENMOD Procedure}

\begin{tabular}{|l|r|r|r|r|r|r|r|r|}
\hline \multicolumn{7}{|c|}{ Analysis Of Maximum Likelihood Parameter Estimates } \\
\hline Parameter & & & DF & Estimate & $\begin{array}{r}\text { Standard } \\
\text { Error }\end{array}$ & $\begin{array}{c}\text { Wald 95\% } \\
\text { Confidence } \\
\text { Limits }\end{array}$ & $\begin{array}{r}\text { Wald } \\
\text { Chi-Square }\end{array}$ & Pr > ChiSq \\
\hline Intercept & & 1 & -1.1094 & 0.0984 & -1.3023 & -0.9166 & 127.15 & $<.0001$ \\
\hline VC_ratio & & 1 & 0.9571 & 0.2078 & 0.5497 & 1.3644 & 21.21 & $<.0001$ \\
\hline PEDEL*Turn & L & 1 & 0.0055 & 0.0019 & 0.0018 & 0.0092 & 8.63 & 0.0033 \\
\hline PEDEL*Turn & R & 1 & 0.0063 & 0.0018 & 0.0027 & 0.0099 & 11.75 & 0.0006 \\
\hline VC_ratio*PEDEL & & 1 & -0.0132 & 0.0040 & -0.0209 & -0.0054 & 11.08 & 0.0009 \\
\hline Scale & & 1 & 0.1762 & 0.0058 & 0.1653 & 0.1879 & & \\
\hline
\end{tabular}

Note: The scale parameter was estimated by maximum likelihood. 
Scatter Plot for tangent VD30 and V/C ratio

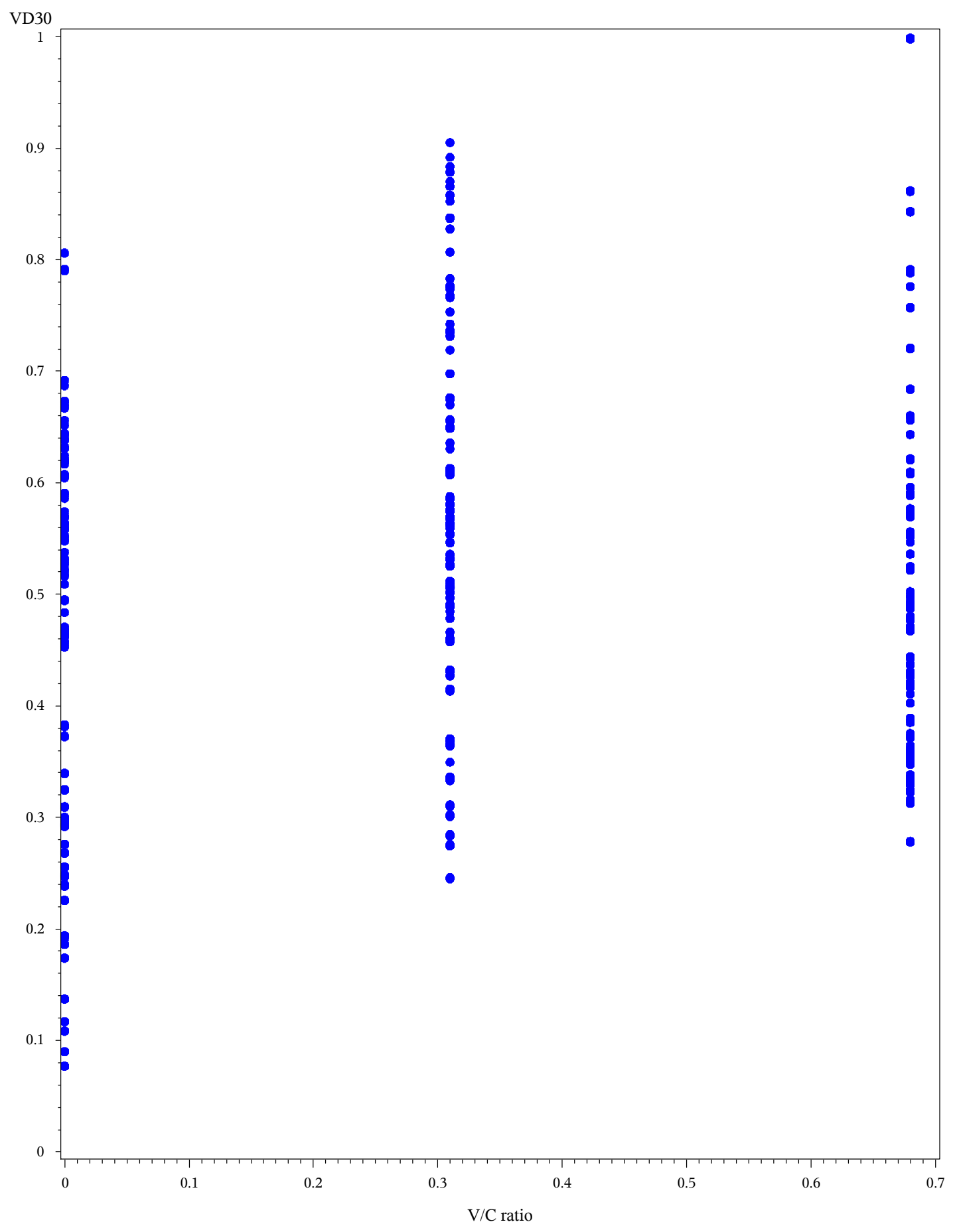


Correlation between tangent $\mathrm{VD} 30$ and $\mathrm{V} / \mathrm{C}$ ratio

\section{The CORR Procedure}

\begin{tabular}{|l|ll|}
\hline 2 Variables: & VD30 VC_ratio \\
\hline
\end{tabular}

\begin{tabular}{|l|r|r|r|r|r|r|l|}
\hline \multicolumn{7}{|c|}{ Simple Statistics } \\
\hline Variable & $\mathbf{N}$ & Mean & Std Dev & Sum & Minimum & Maximum & Label \\
\hline VD30 & 468 & 0.49163 & 0.18387 & 230.08121 & 0.07697 & 0.99899 & VD30 \\
\hline VC_ratio & 468 & 0.33000 & 0.27827 & 154.44000 & 0 & 0.68000 & V/C ratio \\
\hline
\end{tabular}

\begin{tabular}{|l|r|r|}
\hline \multicolumn{3}{|c|}{$\begin{array}{c}\text { Pearson Correlation Coefficients, } \mathbf{N}=\mathbf{4 6 8} \\
\text { Prob }>|\mathbf{r}| \text { under H0: }\end{array}$ Rho=0 } \\
\hline & VD30 & VC_ratio \\
\hline VD30 & 1.00000 & $\begin{array}{r}0.23813 \\
<.0001\end{array}$ \\
VD30 & & 1.00000 \\
\hline VC_ratio & 0.23813 & \\
V/C ratio & $<.0001$ & \\
\hline
\end{tabular}


Correlation between tangent VD30 and V/C ratio

The CORR Procedure

\begin{tabular}{|l|l|l|l|l||}
\hline \multicolumn{3}{|c|}{ Scatter Plot Matrix } & & VC_ratio \\
\hline
\end{tabular}


Fitting Model between Tangent VDF all variable without interaction terms

\section{The GENMOD Procedure}

\begin{tabular}{|l|r|l|}
\hline \multicolumn{3}{|c|}{ Model Information } \\
\hline Data Set & ROAD.TANGENT_VDF & \\
\hline Distribution & Normal & \\
\hline Link Function & Log & \\
\hline Dependent Variable & VDF & VDF \\
\hline
\end{tabular}

\begin{tabular}{|l|l|}
\hline Number of Observations Read & 468 \\
\hline Number of Observations Used & 468 \\
\hline
\end{tabular}

\section{Criteria For Assessing Goodness Of Fit}

\begin{tabular}{|l|r|r|r|}
\hline Criterion & DF & Value & Value/DF \\
\hline Deviance & 465 & 6.7466 & 0.0145 \\
\hline Scaled Deviance & 465 & 468.0000 & 1.0065 \\
\hline Pearson Chi-Square & 465 & 6.7466 & 0.0145 \\
\hline Scaled Pearson X2 & 465 & 468.0000 & 1.0065 \\
\hline Log Likelihood & & 327.9639 & \\
\hline Full Log Likelihood & & 327.9639 & \\
\hline AIC (smaller is better) & & -647.9279 & \\
\hline AICC (smaller is better) & & -647.8415 & \\
\hline BIC (smaller is better) & & -631.3340 & \\
\hline
\end{tabular}

Algorithm converged.

\begin{tabular}{|l|r|r|r|r|r|r|r|}
\hline \multicolumn{7}{|c|}{ Analysis Of Maximum Likelihood Parameter Estimates } \\
\hline Parameter & DF & Estimate & $\begin{array}{r}\text { Standard } \\
\text { Error }\end{array}$ & $\begin{array}{r}\text { Wald 95\% } \\
\text { Confidence } \\
\text { Limits }\end{array}$ & $\begin{array}{r}\text { Wald } \\
\text { Chi-Square }\end{array}$ & Pr > ChiSq \\
\hline Intercept & 1 & -0.9928 & 0.0448 & -1.0806 & -0.9051 & 492.20 & $<.0001$ \\
\hline PEINV & 1 & 105.7508 & 29.8161 & 47.3123 & 164.1893 & 12.58 & 0.0004 \\
\hline VC_ratio & 1 & 0.3561 & 0.0405 & 0.2768 & 0.4355 & 77.38 & $<.0001$ \\
\hline Scale & 1 & 0.1201 & 0.0039 & 0.1126 & 0.1280 & & \\
\hline
\end{tabular}

Note: The scale parameter was estimated by maximum likelihood. 
Fitting Model between Tangent VDF all variable with interaction terms

\section{The GENMOD Procedure}

\begin{tabular}{|l|r|l|}
\hline \multicolumn{3}{|c|}{ Model Information } \\
\hline Data Set & ROAD.TANGENT_VDF & \\
\hline Distribution & Normal & \\
\hline Link Function & Log & \\
\hline Dependent Variable & VDF & VDF \\
\hline
\end{tabular}

\begin{tabular}{|l|l|}
\hline Number of Observations Read & 468 \\
\hline Number of Observations Used & 468 \\
\hline
\end{tabular}

\begin{tabular}{|l|r|l|}
\hline \multicolumn{3}{|c|}{$\begin{array}{c}\text { Class Level } \\
\text { Information }\end{array}$} \\
\hline Class & Levels & Values \\
\hline Turn & 2 & L R \\
\hline
\end{tabular}

\begin{tabular}{|l|r|r|r|}
\hline \multicolumn{4}{|c|}{ Criteria For Assessing Goodness Of Fit } \\
\hline Criterion & DF & Value & Value/DF \\
\hline Deviance & 465 & 6.7466 & 0.0145 \\
\hline Scaled Deviance & 465 & 468.0000 & 1.0065 \\
\hline Pearson Chi-Square & 465 & 6.7466 & 0.0145 \\
\hline Scaled Pearson X2 & 465 & 468.0000 & 1.0065 \\
\hline Log Likelihood & & 327.9639 & \\
\hline Full Log Likelihood & & 327.9639 & \\
\hline AIC (smaller is better) & & -647.9279 & \\
\hline AICC (smaller is better) & & -647.8415 & \\
\hline BIC (smaller is better) & & -631.3340 & \\
\hline
\end{tabular}

Algorithm converged. 
Fitting Model between Tangent VDF all variable with interaction terms

\section{The GENMOD Procedure}

\begin{tabular}{|l|r|r|r|r|r|r|r|}
\hline \multicolumn{7}{|c|}{ Analysis Of Maximum Likelihood Parameter Estimates } \\
\hline Parameter & DF & Estimate & $\begin{array}{r}\text { Standard } \\
\text { Error }\end{array}$ & $\begin{array}{c}\text { Wald 95\% } \\
\text { Confidence } \\
\text { Limits }\end{array}$ & $\begin{array}{r}\text { Wald } \\
\text { Chi-Square }\end{array}$ & Pr > ChiSq \\
\hline Intercept & 1 & -0.9928 & 0.0448 & -1.0806 & -0.9051 & 492.20 & $<.0001$ \\
\hline PEINV & 1 & 105.7508 & 29.8161 & 47.3123 & 164.1893 & 12.58 & 0.0004 \\
\hline VC_ratio & 1 & 0.3561 & 0.0405 & 0.2768 & 0.4355 & 77.38 & $<.0001$ \\
\hline Scale & 1 & 0.1201 & 0.0039 & 0.1126 & 0.1280 & & \\
\hline
\end{tabular}

Note: The scale parameter was estimated by maximum likelihood. 
Scatter Plot for tangent VDF and $\mathrm{V} / \mathrm{C}$ ratio

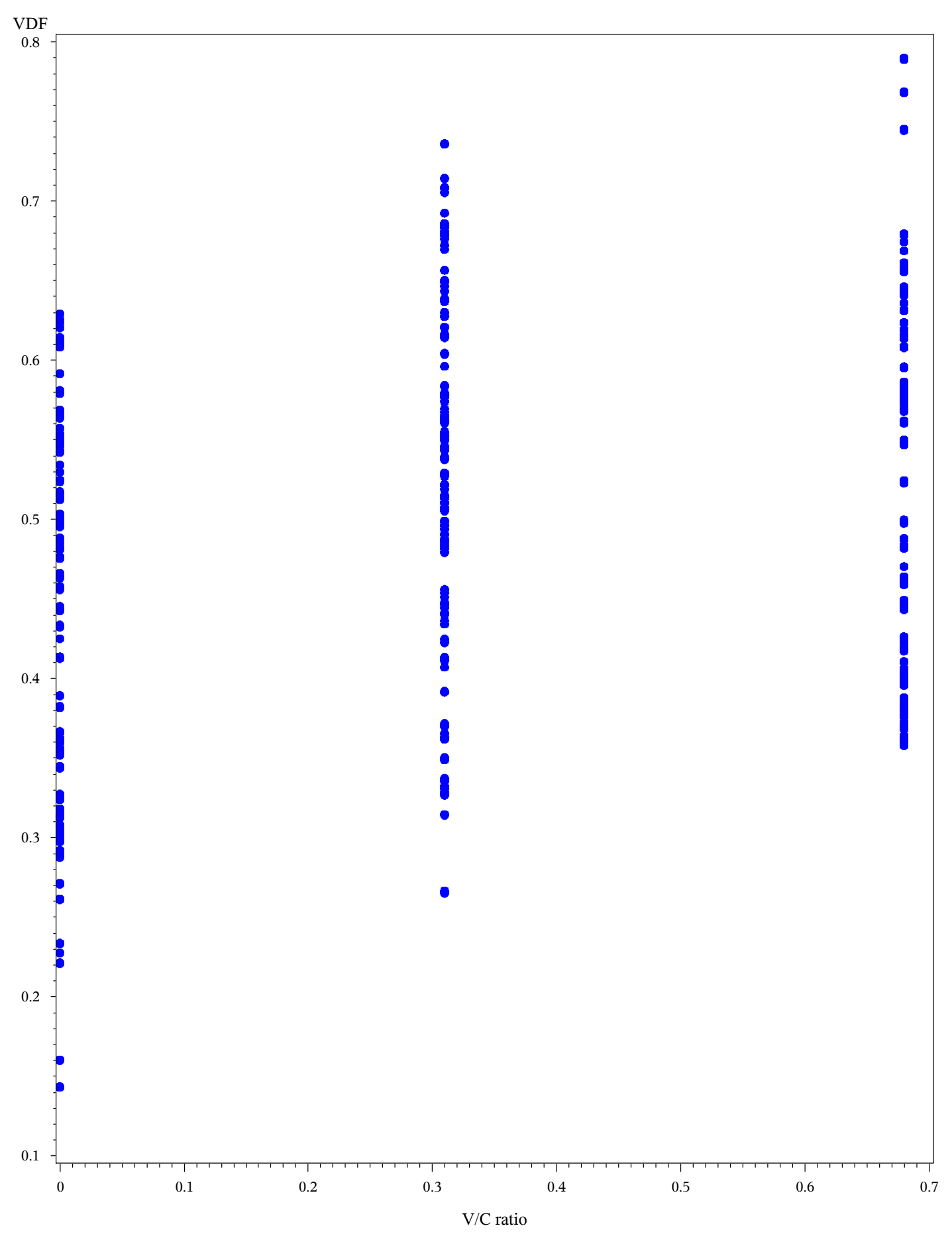




\section{Correlation between tangent VDF and V/C ratio}

\section{The CORR Procedure}

2 Variables: VDF VC_ratio

\begin{tabular}{|l|r|r|r|r|r|r|l|}
\hline \multicolumn{10}{|c|}{ Simple Statistics } \\
\hline Variable & $\mathbf{N}$ & Mean & Std Dev & Sum & Minimum & Maximum & Label \\
\hline VDF & 468 & 0.48242 & 0.13143 & 225.77323 & 0.14332 & 0.78989 & VDF \\
\hline VC_ratio & 468 & 0.33000 & 0.27827 & 154.44000 & 0 & 0.68000 & V/C ratio \\
\hline
\end{tabular}

\begin{tabular}{|l|r|r|}
\hline \multicolumn{3}{|c|}{$\begin{array}{c}\text { Pearson Correlation Coefficients, } \mathbf{N}=\mathbf{4 6 8} \\
\text { Prob }>|\mathbf{r}| \text { under H0: } \mathbf{R h o}=\mathbf{0}\end{array}$} \\
\hline & VDF & VC_ratio \\
\hline VDF & 1.00000 & $\begin{array}{r}0.38335 \\
<.0001\end{array}$ \\
VDF & & 1.00000 \\
\hline VC_ratio & 0.38335 & \\
V/C ratio & $<.0001$ & \\
\hline
\end{tabular}


Correlation between tangent $V D F$ and $V / C$ ratio

The CORR Procedure

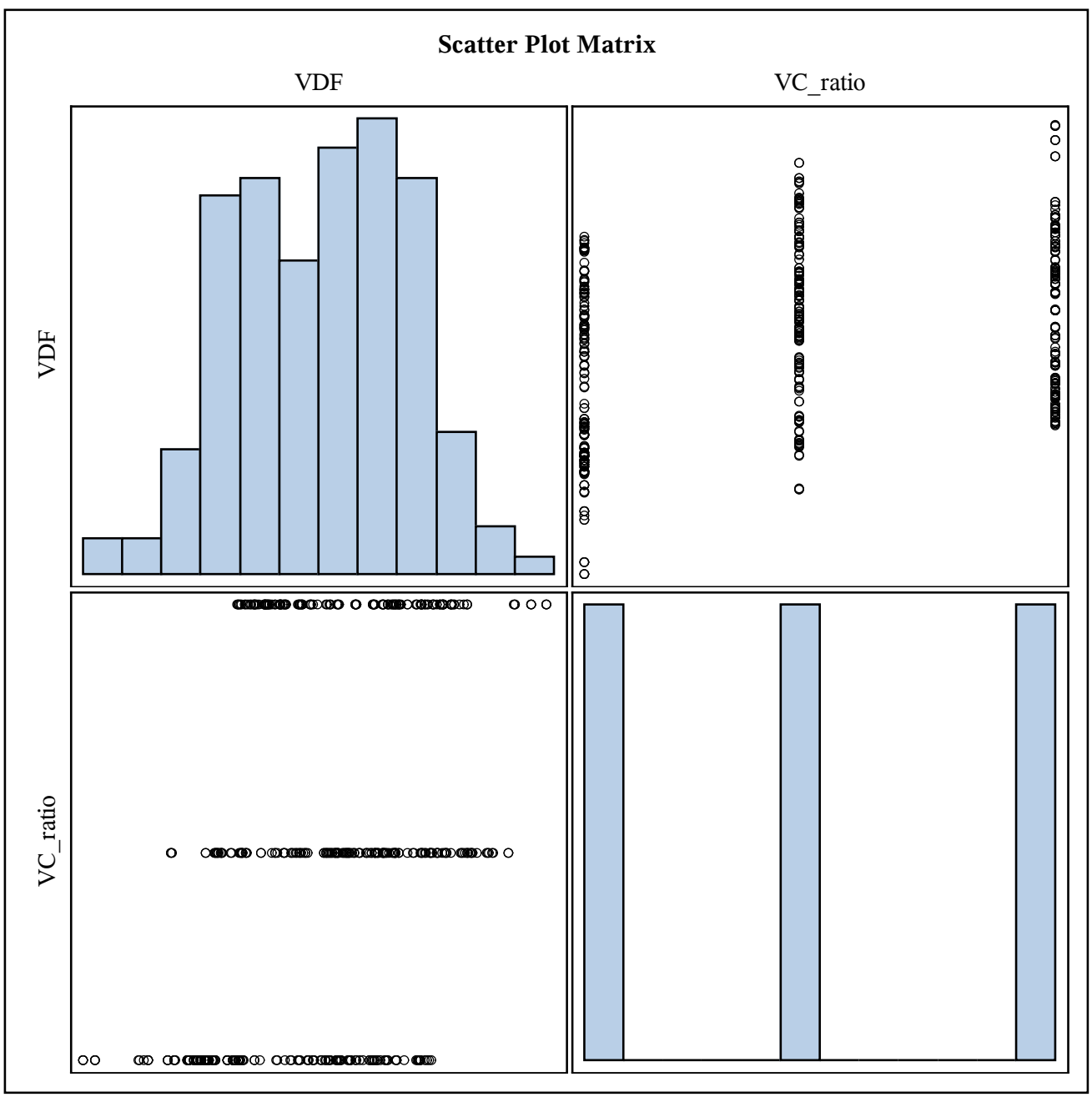


Fitting Model between Tangent VDH all variable without interaction terms

\section{The GENMOD Procedure}

\begin{tabular}{|l|r|r|}
\hline \multicolumn{3}{|c|}{ Model Information } \\
\hline Data Set & ROAD.TANGENT_VDH & \\
\hline Distribution & Normal & \\
\hline Link Function & Log & \\
\hline Dependent Variable & VDH & VDH \\
\hline
\end{tabular}

\begin{tabular}{|l|c|}
\hline Number of Observations Read & 468 \\
\hline Number of Observations Used & 468 \\
\hline
\end{tabular}

\section{Criteria For Assessing Goodness Of Fit}

\begin{tabular}{|l|r|r|r|}
\hline Criterion & DF & Value & Value/DF \\
\hline Deviance & 466 & 9.4992 & 0.0204 \\
\hline Scaled Deviance & 466 & 468.0000 & 1.0043 \\
\hline Pearson Chi-Square & 466 & 9.4992 & 0.0204 \\
\hline Scaled Pearson X2 & 466 & 468.0000 & 1.0043 \\
\hline Log Likelihood & & 247.8965 & \\
\hline Full Log Likelihood & & 247.8965 & \\
\hline AIC (smaller is better) & & -489.7930 & \\
\hline AICC (smaller is better) & & -489.7412 & \\
\hline BIC (smaller is better) & & -477.3475 & \\
\hline
\end{tabular}

Algorithm converged.

\begin{tabular}{|l|r|r|r|r|r|r|r|}
\hline \multicolumn{7}{|c|}{ Analysis Of Maximum Likelihood Parameter Estimates } \\
\hline Parameter & DF & Estimate & $\begin{array}{r}\text { Standard } \\
\text { Error }\end{array}$ & $\begin{array}{c}\text { Wald 95\% } \\
\text { Confidence } \\
\text { Limits }\end{array}$ & $\begin{array}{r}\text { Wald } \\
\text { Chi-Square }\end{array}$ & Pr > ChiSq \\
\hline Intercept & 1 & -0.7662 & 0.0210 & -0.8073 & -0.7251 & 1334.38 & $<.0001$ \\
\hline VC_ratio & 1 & 0.3923 & 0.0435 & 0.3070 & 0.4775 & 81.35 & $<.0001$ \\
\hline Scale & 1 & 0.1425 & 0.0047 & 0.1336 & 0.1519 & & \\
\hline
\end{tabular}

Note: The scale parameter was estimated by maximum likelihood. 
Fitting Model between Tangent VDH all variable with interaction terms

\section{The GENMOD Procedure}

\begin{tabular}{|l|r|r|}
\hline \multicolumn{3}{|c|}{ Model Information } \\
\hline Data Set & ROAD.TANGENT_VDH & \\
\hline Distribution & Normal & \\
\hline Link Function & Log & \\
\hline Dependent Variable & VDH & VDH \\
\hline
\end{tabular}

\begin{tabular}{|l|l|}
\hline Number of Observations Read & 468 \\
\hline Number of Observations Used & 468 \\
\hline
\end{tabular}

\section{Criteria For Assessing Goodness Of Fit}

\begin{tabular}{|l|r|r|r|}
\hline Criterion & DF & Value & Value/DF \\
\hline Deviance & 464 & 9.3800 & 0.0202 \\
\hline Scaled Deviance & 464 & 468.0000 & 1.0086 \\
\hline Pearson Chi-Square & 464 & 9.3800 & 0.0202 \\
\hline Scaled Pearson X2 & 464 & 468.0000 & 1.0086 \\
\hline Log Likelihood & & 250.8508 & \\
\hline Full Log Likelihood & & 250.8508 & \\
\hline AIC (smaller is better) & & -491.7016 & \\
\hline AICC (smaller is better) & & -491.5717 & \\
\hline BIC (smaller is better) & & -470.9592 & \\
\hline
\end{tabular}

Algorithm converged.

\begin{tabular}{|l|r|r|r|r|r|r|r|}
\hline \multicolumn{7}{|c|}{ Analysis Of Maximum Likelihood Parameter Estimates } \\
\hline Parameter & DF & Estimate & $\begin{array}{r}\text { Standard } \\
\text { Error }\end{array}$ & $\begin{array}{c}\text { Wald 95\% } \\
\text { Confidence } \\
\text { Limits }\end{array}$ & $\begin{array}{r}\text { Wald } \\
\text { Chi-Square }\end{array}$ & Pr > ChiSq \\
\hline Intercept & 1 & -0.8436 & 0.0396 & -0.9213 & -0.7660 & 453.55 & $<.0001$ \\
\hline VC_ratio & 1 & 0.6259 & 0.1236 & 0.3838 & 0.8681 & 25.66 & $<.0001$ \\
\hline PEINV*PEDEL & 1 & 1.1404 & 0.4842 & 0.1914 & 2.0894 & 5.55 & 0.0185 \\
\hline VC_ratio*PEDEL & 1 & -0.0047 & 0.0023 & -0.0093 & -0.0001 & 4.07 & 0.0437 \\
\hline Scale & 1 & 0.1416 & 0.0046 & 0.1328 & 0.1509 & & \\
\hline
\end{tabular}

Note: The scale parameter was estimated by maximum likelihood. 
Scatter Plot for tangent VDH and V/C ratio

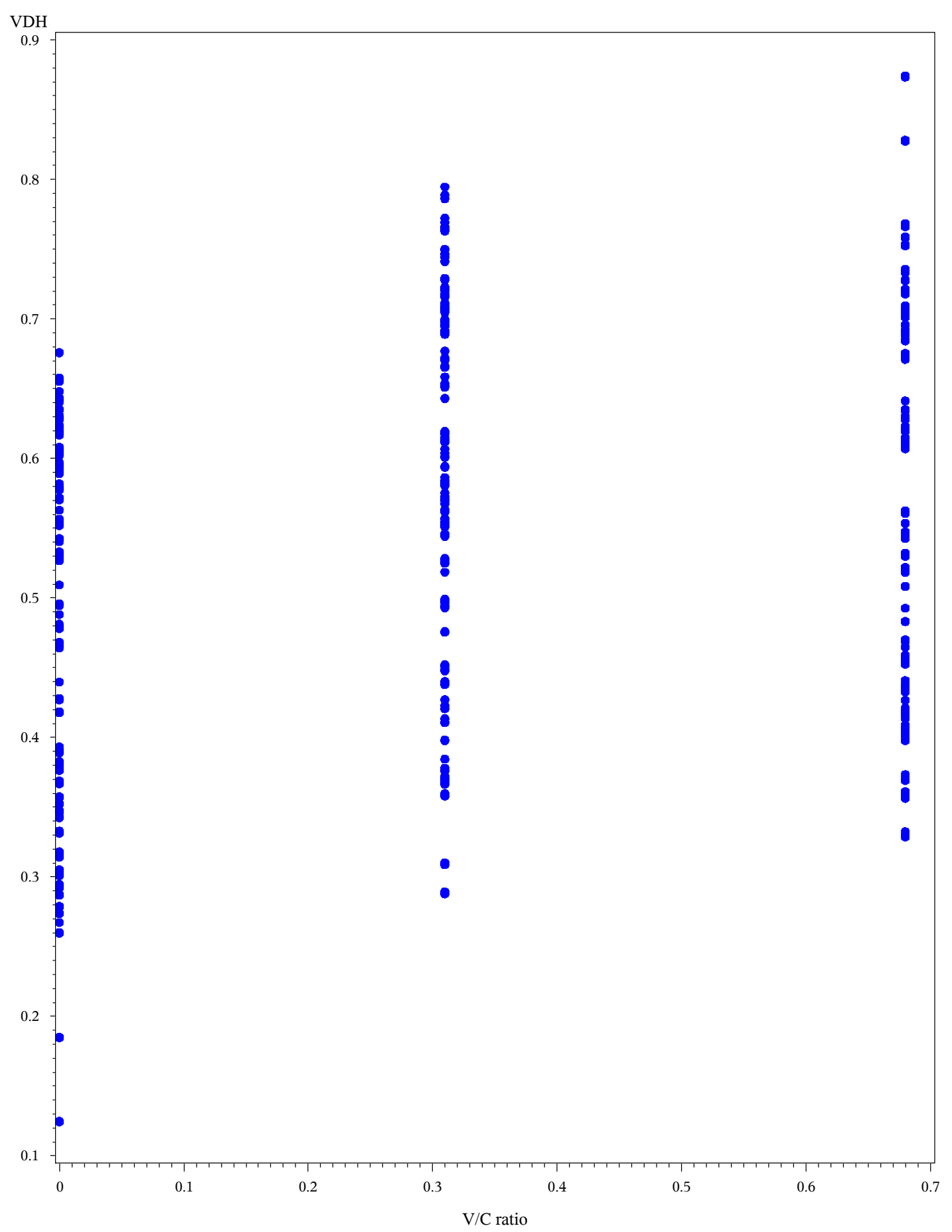




\section{Correlation between tangent $V D H$ and $V / C$ ratio}

\section{The CORR Procedure}

2 Variables: VDH VC_ratio

\begin{tabular}{|l|r|r|r|r|r|r|l|}
\hline \multicolumn{10}{|c|}{ Simple Statistics } \\
\hline Variable & $\mathbf{N}$ & Mean & Std Dev & Sum & Minimum & Maximum & Label \\
\hline VDH & 468 & 0.53204 & 0.15461 & 248.99354 & 0.12460 & 0.87443 & VDH \\
\hline VC_ratio & 468 & 0.33000 & 0.27827 & 154.44000 & 0 & 0.68000 & V/C ratio \\
\hline
\end{tabular}

\begin{tabular}{|l|r|r|}
\hline \multicolumn{3}{|c|}{$\begin{array}{c}\text { Pearson Correlation Coefficients, } \mathbf{N}=\mathbf{4 6 8} \\
\text { Prob }>|\mathbf{r}| \text { under H0: } \text { Rho=0 }\end{array}$} \\
\hline & VDH & VC_ratio \\
\hline VDH & 1.00000 & $\begin{array}{r}0.39522 \\
<.0001\end{array}$ \\
VDH & & 1.00000 \\
\hline VC_ratio & 0.39522 & \\
V/C_ratio & $<.0001$ & \\
\hline
\end{tabular}




\section{Correlation between tangent $\mathrm{VDH}$ and $\mathrm{V} / \mathrm{C}$ ratio}

The CORR Procedure

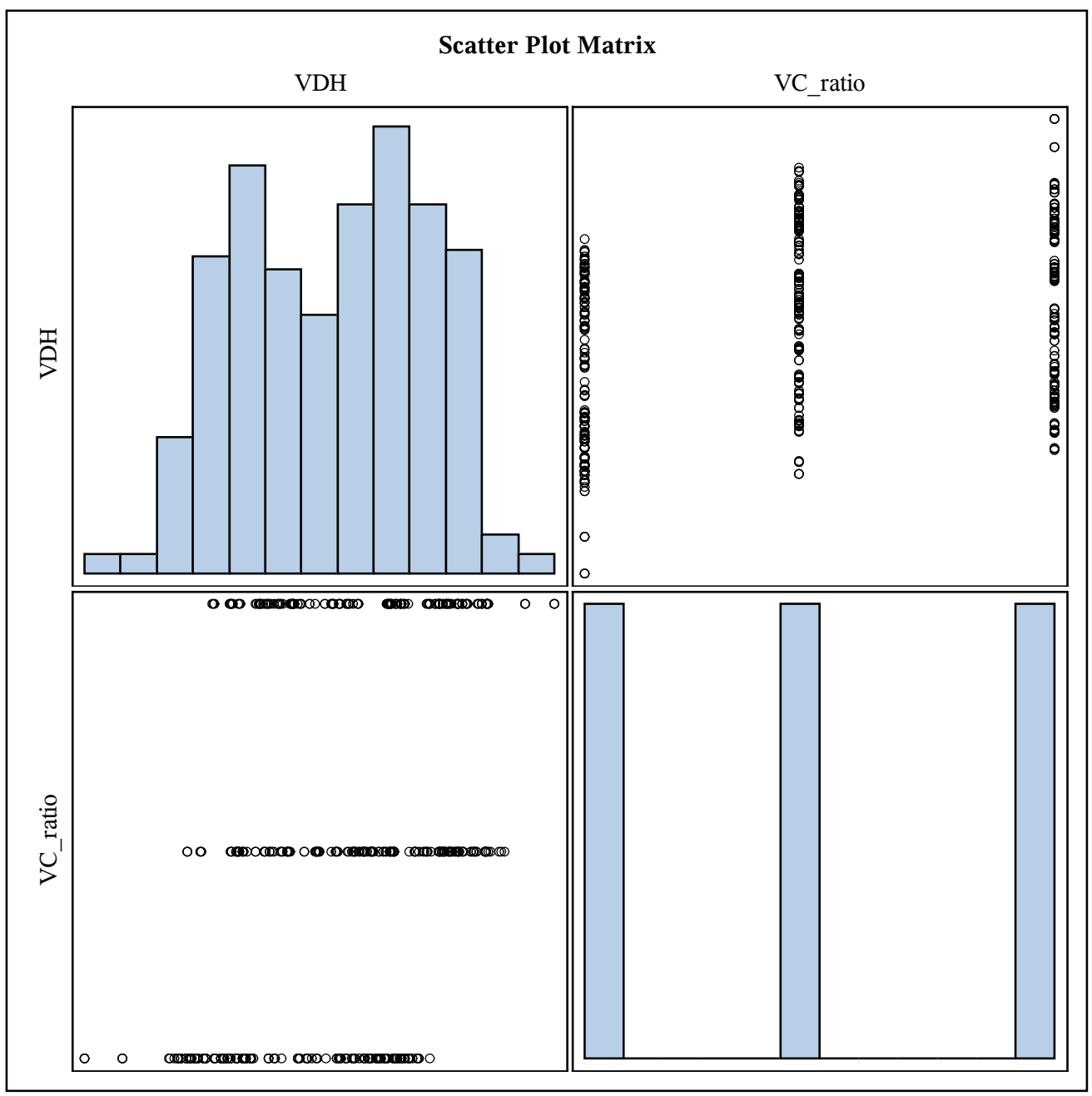




\title{
Appendix 4
}

\section{Glossary of Acronyms}

\author{
TAC Transportation Association of Canada \\ SDL Scenario Definition Language \\ FHWA Federal Highway Administration \\ ISTEA Intermodal Surface Transportation Efficiency Act \\ AASHTO American Association of State Highway and Transportation Officials \\ VD Visual Demand \\ V/Cratio Volume/Capacity Ratio \\ $V D 30 \quad$ Visual demand for the first 30 meters of the element \\ $V D H \quad$ Visual demand for half of the length of the element \\ $V D F \quad$ Visual demand for the entire length of the element \\ PrcCrvRad Preceding curve radius \\ PEINV Preceding curves inverse radius \\ PETD (R) Preceding curve direction (left) \\ PETD (L) Preceding curve direction (right) \\ PEDEL Preceding curves deflection angle
}




$\begin{array}{ll}\text { Def Angl } & \text { Deflection Angle } \\ R & \text { Right turning curve } \\ L & \text { Left turning curve } \\ C C & \text { Compound curve } \\ R C & \text { Reverse curve } \\ T & \text { Tangent } \\ 1 / R & \text { Inverse of radius of curve }\end{array}$




\section{References}

AASHTO, A., 2004. Policy on Geometric Design of Highways and Streets. American Association of State Highway and Transportation Officials, Washington, DC, 1, 990.

Abul-Magd, A., 2007. Modeling highway-traffic headway distributions using superstatistics. Physical Review E, 76 (5), 057101.

Alexander, G. and Lunenfeld, H., 1986. Driver Expectancy in Highway Design and Traffic Operation. Final Report. .

Allen, R.W., et al., 2003. Scenarios produced by procedural methods for driving research, assessment and training applications. In: .

Baldwin, C.L. and Coyne, J.T., 2003. Mental workload as a function of traffic density: Comparison of physiological, behavioral, and subjective indices. In: Proceedings of the Second International Driving Symposium on Human Factors.

Boer, E.R., 2001. Behavioral entropy as a measure of driving performance. .

Cantin, V., et al., 2009. Mental workload when driving in a simulator: Effects of age and driving complexity. Accident Analysis \& Prevention, 41 (4), 763-771.

Chan, H. and Courtney, A.J., 1998. Stimulus size scaling and foveal load as determinants of peripheral target detection. Ergonomics, 41 (10), 1433-1452.

Chen, X., Li, L., and Zhang, Y., 2010. A Markov model for headway/spacing distribution of road traffic. IEEE Transactions on Intelligent Transportation Systems, 11 (4), 773-785.

Council, F.M. and Stewart, J.R., 1999. Safety effects of the conversion of rural two-lane to four-lane roadways based on cross-sectional models. Transportation Research Record: Journal of the Transportation Research Board, 1665 (1), 35-43.

Easa, S. and Ganguly, C., 2005. Modeling driver visual demand on complex horizontal alignments. Journal of Transportation Engineering, 131 (8), 583-590.

Easa, S.M. and He, W., 2006. Modeling driver visual demand on three-dimensional highway alignments. Journal of transportation engineering, 132 (5), 357-365. 
Easa, S., 2002. Geometric design guide update: design consistency assessment methodologiesrevised design consistencychapter of the TAC design guide. Transportation Association of Canada, Ottawa.

Easa, S., 2003. Design consistency. Geometric Design Guide for Canadian Roads.

Ganguly, C., 2004. Evaluation of driver visual demand in complex tw dimensaionl rural highway alignments. .

Gibreel, G., et al., 1999. State of the art of highway geometric design consistency. Journal of Transportation Engineering, 125 (4), 305-313.

Groeger, J.A., 2000. Understanding driving: Applying cognitive psychology to a complex everyday task. Psychology Press.

Hagring, O., 2002. Calibration of headway distributions. .

Haigney, D. and Westerman, S., 2001. Mobile (cellular) phone use and driving: a critical review of research methodology. Ergonomics, 44 (2), 132-143.

Hall, F.L., 1996. Traffic stream characteristics. Traffic Flow Theory. US Federal Highway Administration.

Hancock, P., Lesch, M., and Simmons, L., 2003. The distraction effects of phone use during a crucial driving maneuver. Accident Analysis $\&$ Prevention, 35 (4), 501-514.

He, S., Guan, W., and Ma, J., 2009. Observed time-headway distribution and its implication on traffic phases. 1-6.

He, W.L., 2004a. Evaluation of driver visual demand on three-dimensional rural highway alignments. In: Masters Abstracts International, Vol. 47.

He, W., 2004b. Evaluation of driver visual demand on three-dimensional rural highway alignments.

Highway Capacity Manual, 2010. HCM2010. National Academy of Sciences. Yhdysvallat.

Hoogendoorn, S. and Bovy, P., 1999. Estimation and analysis of multilane multiclass headway distribution model. .

Kerner, B.S., 2009. Introduction to modern traffic flow theory and control. Springer.

Knospe, W., et al., 2002. A realistic two-lane traffic model for highway traffic. Journal of Physics A: Mathematical and General, 35 (15), 3369.

Knowles, W., 1963. Operator loading tasks. Human Factors: The Journal of the Human Factors and Ergonomics Society, 5 (2), 155-161.

Kosonen, I., 2009a. Final Report Part C: The HUTSIM-TPMA elementary models. . 
Kosonen, I., 2009b. Final Report Part D: The Bosch-Tests. .

Kosonen, I., 2009c. Final Report Part D2: The Bosch-Tests. .

Lamble, D., Laakso, M., and Summala, H., 1999. Detection thresholds in car following situations and peripheral vision: Implications for positioning of visually demanding in-car displays. Ergonomics, 42 (6), 807-815.

Lamm, R., Guenther, A.K., and Choueiri, E.M., 1995. Safety module for highway geometric design. Transportation Research Record, (1512), 7-15.

Lamm, R., et al., 1999. Highway Design and Traffic Safety Engineering Handbook. Vol. 2. McGraw-Hill New York.

Mannering, F., Kilareski, W., and Washburn, S., 2007. Principles of highway engineering and traffic analysis. John Wiley \& Sons.

Manual, H.C., 2000. Transportation research board. National Research Council, Washington, $D C, 113$.

Mathew, T.V. and Krishna Rao, K., 2006. Introduction to Transportation engineering. Civil Engineering-Transportation Engineering. IIT Bombay, NPTEL ONLINE, http://www.cdeep. iitb. ac. in/nptel/Civil\% 20Engineering.

Messer, C.J., 1980. Methodology for evaluating geometric design consistency. Transportation Research Record, (757).

Miura, T., 1986. Coping with situational demands: A study of eye movements and peripheral vision performance. Vision in vehicles, 1, 205-216.

Muneeb, A., 2006. Evaluation of driver visual demand at different design speeds on complex two-dimensional rural highway alignments. .

Nakayama, O., et al., 1999. Development of a steering entropy method for evaluating driver workload. .

National Highway Traffic Safety Administration, 2012. Fatality Analysis Reporting System (FARS) Encyclopedia. .

Navin, F., 2005. Driver Attention Demand and Adaptive Information Management. .

Navin, F. and Musa, P., 2004. The effects of speed and driver adaptive strategies on driver workload assessment. In: Proceedings of the 83rd Annual Meeting of the Transportation Research Board, Washington DC, 11-15.

Ng, J.C. and Sayed, T., 2004. Effect of geometric design consistency on road safety. Canadian Journal of Civil Engineering, 31 (2), 218-227.

Nunes, L. and Recarte, M.A., 2002. Cognitive demands of hands-free-phone conversation while driving. Transportation Research Part F: Traffic Psychology and Behaviour, 5 (2), 133-144. 
Olstam, J., 2005. A model for simulation and generation of surrounding vehicles in driving simulators. .

Olstam, J., 2006. Simulation of vehicles in a driving simulator using microscopic traffic simulation. In: International Symposium on Transport Simulation, 2006.

Piechulla, W., et al., 2003. Reducing drivers mental workload by means of an adaptive manmachine interface. Transportation Research Part F: Traffic Psychology and Behaviour, 6 (4), 233-248.

Plainis, S., et al., 1999. Retinal adaptation under night-time driving conditions. Vision in Vehicles, 7, 61-70.

Rantanen, E.M. and Goldberg, J.H., 1999. The effect of mental workload on the visual field size and shape. Ergonomics, 42 (6), 816-834.

Recarte, M.A. and Nunes, L.M., 2003. Mental workload while driving: effects on visual search, discrimination, and decision making.. Journal of experimental psychology, 9 (2), 119.

Senders, J., 1970. The estimation of operator workload in complex systems. Systems psychology, $207-216$.

Shafer, M.A., 1996. Driver mental workload requirements on horizontal curves based on occluded vision test measurements. .

Stine, J.S., et al., 2010. Analyzing the influence of median cross-section design on highway safety using vehicle dynamics simulations. Accident Analysis $\&$ Prevention, 42 (6), 1769-1777.

Strayer, D.L. and Johnston, W.A., 2001. Driven to distraction: Dual-task studies of simulated driving and conversing on a cellular telephone. Psychological science, 12 (6), 462-466.

Summala, H., Nieminen, T., and Punto, M., 1996. Maintaining lane position with peripheral vision during in-vehicle tasks. Human Factors: The Journal of the Human Factors and Ergonomics Society, 38 (3), 442-451.

TAC, 2013. Geometric Design Guide for Canadian Roads. Tranportation Association of Canada.

Tijerina, L., 2000. Issues in the evaluation of driver distraction associated with in-vehicle information and telecommunications systems. Transportation Research Inc.

TransportCanada, 2010. Canadian Motor Vehicle Traffic Collision Statistics. .

TransportCanada., 2012. Federal Highway Administration. .

TransportCanada, 2013. Canadian Motor Vehicle Traffic Collision Statistics. .

Verwey, W.B. and Veltman, H.A., 1996. Detecting short periods of elevated workload: A comparison of nine workload assessment techniques.. Journal of Experimental Psychology: Applied, 2 (3), 270. 
Waard, D.D., et al., 1995. Effect of road layout and road environment on driving performance, drivers' physiology and road appreciation. Ergonomics, 38 (7), 1395-1407.

Wikman, A.S., Nieminen, T., and Summala, H., 1998. Driving experience and time-sharing during in-car tasks on roads of different width. Ergonomics, 41 (3), 358-372.

Wooldridge, M.D., et al., 2000. Effects of horizontal curvature on driver visual demand. Transportation Research Record: Journal of the Transportation Research Board, 1737 (1), 71-77.

Wooldridge, M.D., et al., 1999. Comparison of driver visual demand in test track, simulator, and on-road environments. Ann Arbor, 1001, 48109-2150.

Yin, S., et al., 2009. Headway distribution modeling with regard to traffic status. In: 2009 IEEE Intelligent Vehicles Symposium, 1057-1062.

Zhang, G., et al., 2007. Examining headway distribution models with urban freeway loop event data. Transportation Research Record: Journal of the Transportation Research Board, 1999 (1), 141-149.

Zhang, Y., Owechko, Y., and Zhang, J., 2008. Learning-based driver workload estimation. Computational Intelligence in Automotive Applications. Springer, 1-17. 
REFERENCES 